B O N N E V I L L E

Lake Roosevelt Fisheries Evaluation Program, Part D

Assessment of the Lake Roosevelt Walleye Population

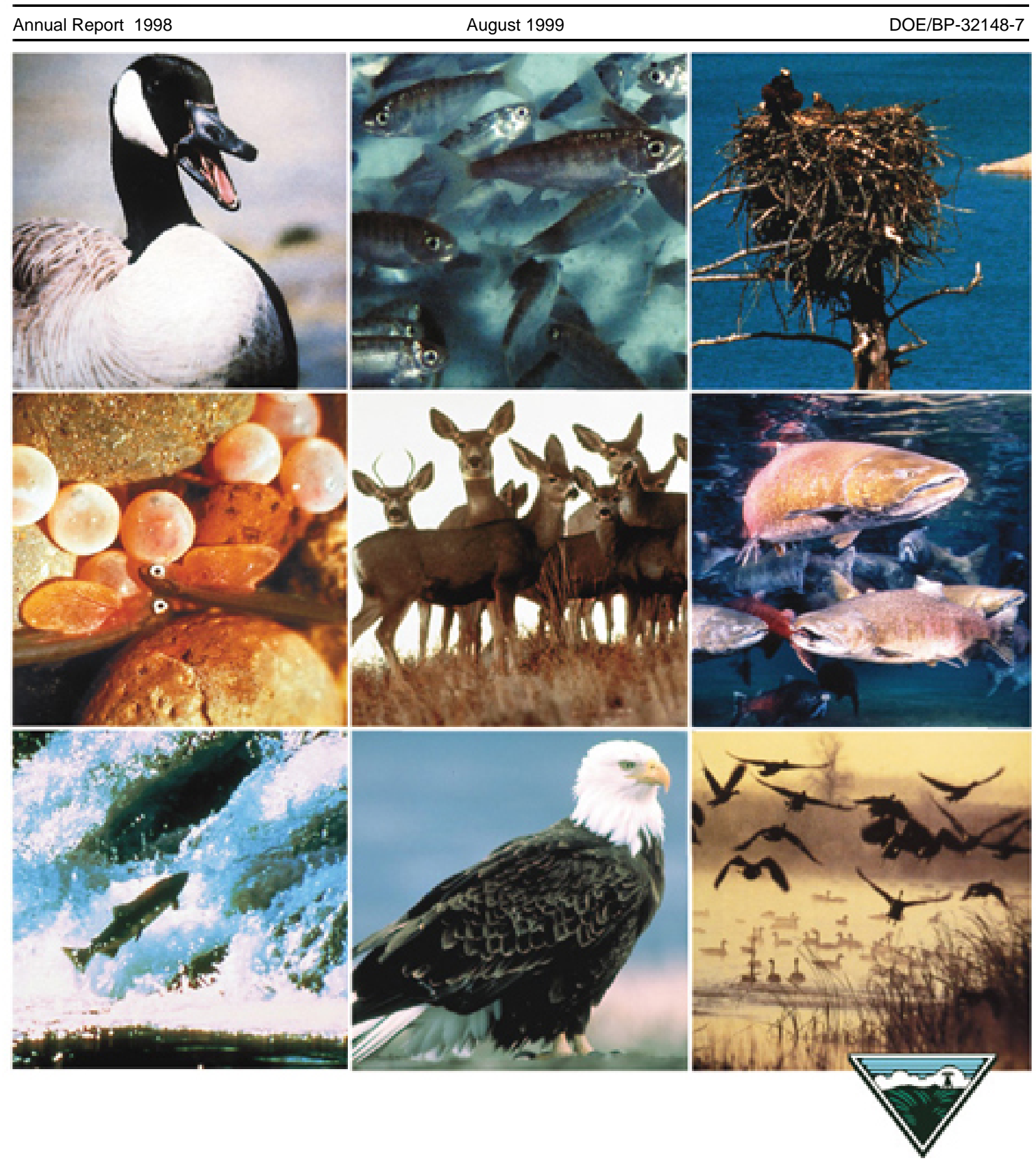


This Document should be cited as follows:

McLellan, Jason, Holly Moffatt, Allan Scholz, "Lake Roosevelt Fisheries Evaluation Program, Part D; Assessment of the Lake Roosevelt Walleye Population", 1998 Annual Report, Project No. 199404300, 67 electronic pages, (BPA Report DOE/BP-32148-7)

\author{
Bonneville Power Administration \\ P.O. Box 3621 \\ Portland, OR 97208
}

This report was funded by the Bonneville Power Administration (BPA), U.S. Department of Energy, as part of BPA's program to protect, mitigate, and enhance fish and wildlife affected by the development and operation of hydroelectric facilities on the Columbia River and its tributaries. The views in this report are the author's and do not necessarily represent the views of BPA. 


\title{
1998 Annual Report, Part D. Lake Roosevelt Fisheries Evaluation Program, Assessment of the Lake Roosevelt Walleye Population.
}

Annual Report 1998

\author{
Prepared by: \\ Jason G. McLellan \\ Holly J. Moffatt \\ and \\ Allan T. Scholz
}

Eastern Washington University

Department of Biology

Cheney, Washington 99004

Current Contract Number 00005756

Current Project Number 1994-043-00

Original 1998 Contract Number 94BI32148

Original 1998 Project Number 94-043

\section{Funded by:}

U.S. Department of Energy

Bonneville Power Administration

Division of Fish and Wildlife

P.O. Box 3621

Portland, Oregon 97283-3621

August 1999 


\section{Table of Contents}

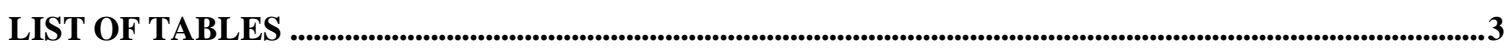

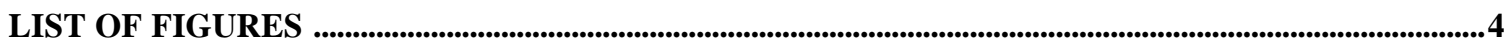

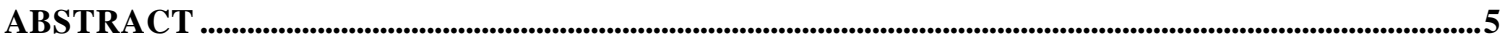

ACKNOWLEDGEMENTS .......................................................................................................................................................6

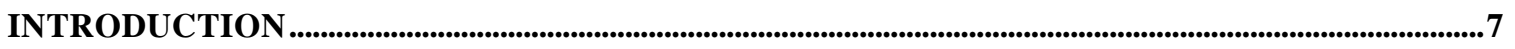

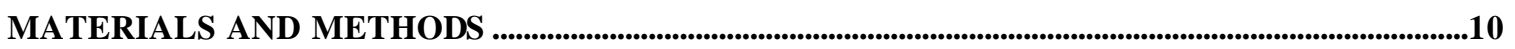

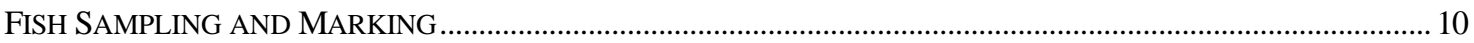

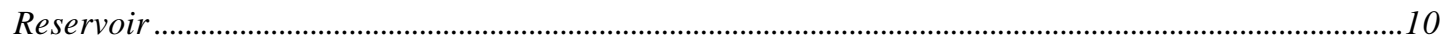

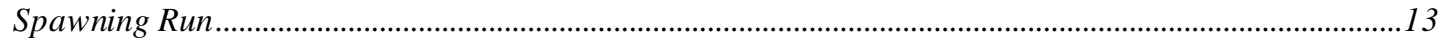

Data Collection and Fish Marking ………………………..............................................................

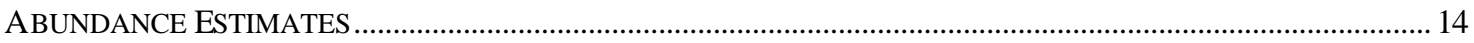

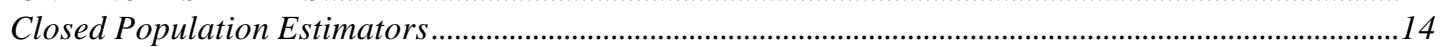

Open Population Estimator............................................................................................................

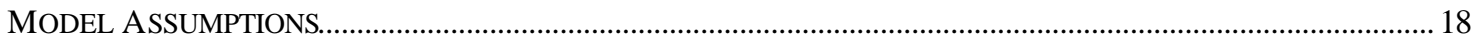

MOVEMENTS

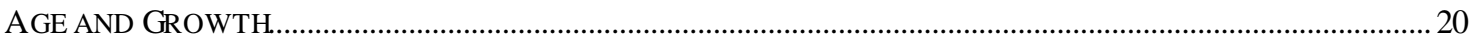

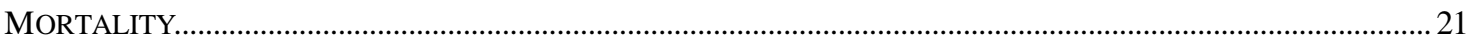

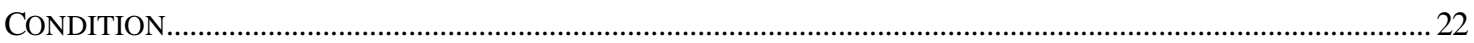

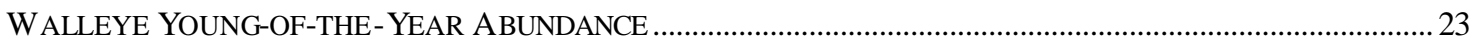

RESULTS ................................................................................................................................................................................................24

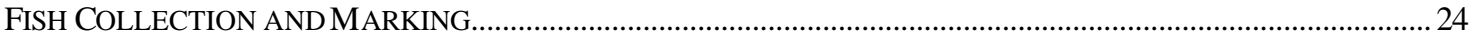

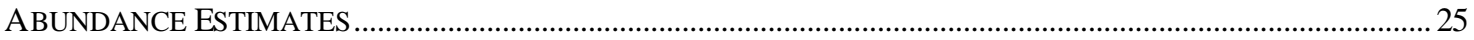

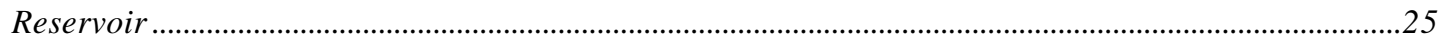

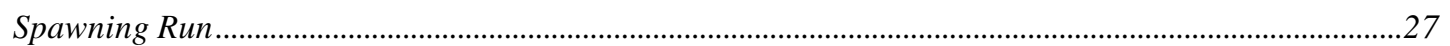

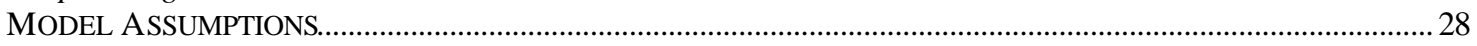

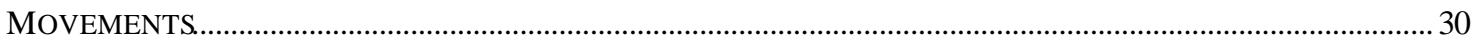

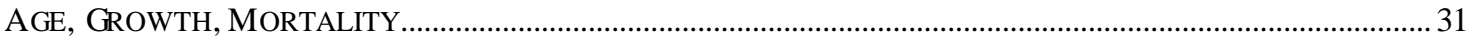

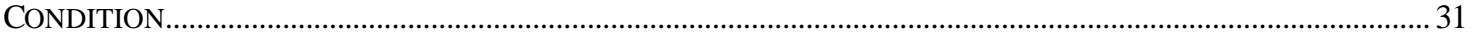

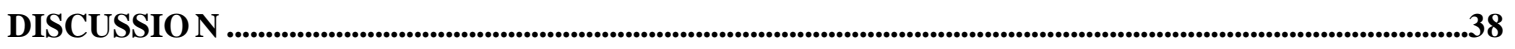

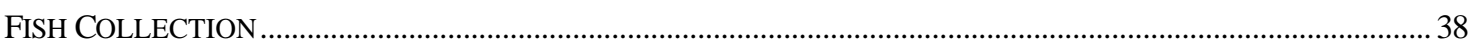

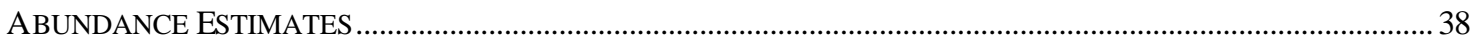

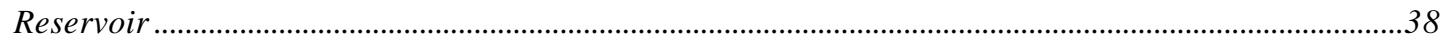

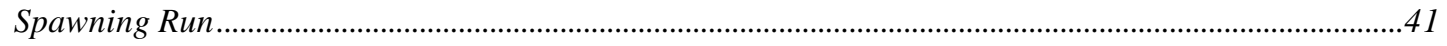

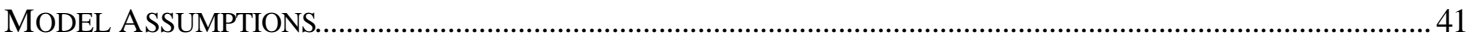

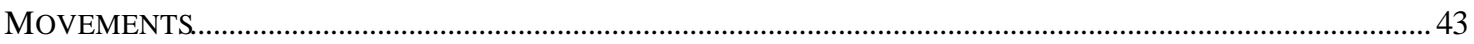

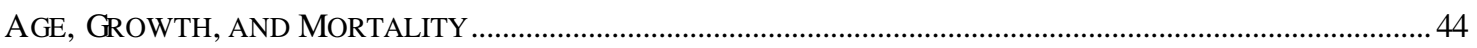

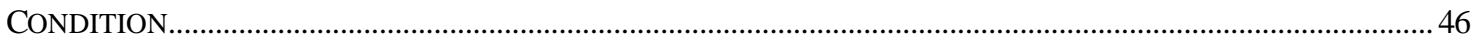

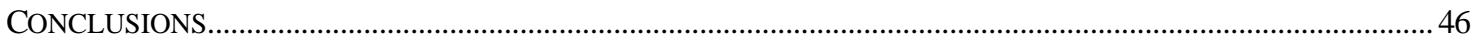

LITERATURE CITED ............................................................................................................................................................49

APPENDICES ..............................................................................................................................................................................53 


\section{List of Tables}

Table 1. Summary of walleye tagged arranged by pass and reservoir section..................................................2

Table 2. Walleye recaptures and tag returns during 1998. ............................................................................. 26

Table 3. Catch-per-unit-effort (CPUE) of walleye collected in Lake Roosevelt (1998) via electrofishing surveys conducted by Eastern Washington University (EWU), .................................................................. 26

Table 4. Estimates of walleye abundance for the entire reservoir, and $95 \%$ confidence intervals, calculated

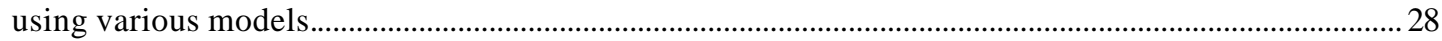

Table 5. Estimates of the size of the walleye spawning run in the Spokane River Arm, and $95 \%$ confidence intervals, calculated using various models. ............................................................................. 28

Table 6. Numbers and ratios of tagged and untagged walleye collected in Lake Roosevelt (1998) via angling and electrofishing...................................................................................................................2 29

Table 7. Back-calculated total lengths at the formation of each annulus of walleye collected in Lake Roosevelt

Table 8. Mean annual mortality rates for each age class of walleye collected in Lake Roosevelt during 1998.

Table 9. Mean condition factors $\left(\mathrm{K}_{\mathrm{TL}}\right)$ of walleye collected in Lake Roosevelt in 1998.................................. 35

Table 10. Comparison of back-calculated total lengths at the formation of each annulus of walleye from

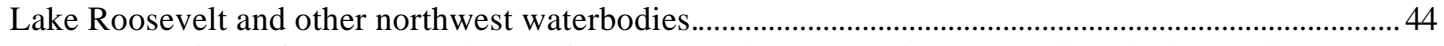

Table 11. Comparison of mean annual mortality rates (\%) between Lake Roosevelt and other walleye producing waters. 


\section{List of Figures}

Figure 1. Map of 1998 Lake Roosevelt sampling sections................................................................................... 11

Figure 2. Age-frequency distribution of walleye collected in Lake Roosevelt during 1998. ...........................32

Figure 3. Body length-scale length regression line for Lake Roosevelt walleye collected and aged during

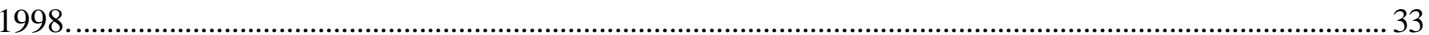

Figure 4. Simple catch-curve for walleye collected in Lake Roosevelt 1998.................................................36

Figure 5. Length-weight regression for walleye collected in Lake Roosevelt, 1998........................................37

Figure 6. Comparison of age frequency distributions for Lake Roosevelt walleye collected in 1980-83,

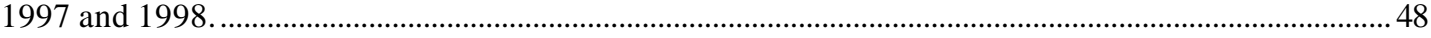




\section{Abstract}

A walleye mark-recapture experiment was initiated on Lake Roosevelt in 1997, with the primary objective of estimating the size of the walleye population. The project was continued in 1998 with a revised sampling regime. The primary goals during 1998 were to estimate the size of the walleye population in Lake Roosevelt, estimate the size of the spawning run in the Spokane River Arm, and describe the age structure of the population for use in managing the population and developing a kokanee bioenergetics model. Secondary objectives included: determining walleye movements, backcalculating growth rates, estimating mortality rates, determining walleye condition, and estimating walleye young-of-the-year (YOY) production in the Spokane River Arm. All walleye, $\geq 150 \mathrm{~mm}$ TL, were marked with individually numbered Floy ${ }^{\circledR}$ tags, during five

passes through the reservoir. The passes occurred between April $1^{\text {st }}$ and September $16^{\text {th }}$, 1998. The most unbiased estimate of walleye abundance in Lake Roosevelt, 186,482 $(40,113 \leq \mathrm{N} \leq 943,213)$, was obtained using the $\mathrm{M}_{\mathrm{tb}}$ model of the CAPTURE program. The most unbiased estimate of the size of the walleye spawning run in the Spokane River Arm, 27,345 (1,535 $\leq \mathrm{N} \leq 57,519)$, was calculated using the Jolly-Seber model. The abundance estimates appeared reasonable, but they had wide $95 \%$ confidence intervals. Wide confidence intervals were attributed to low capture probabilities. Coefficient of variation $(\mathrm{CV})$ values for both estimates indicated that they were not acceptable for general management, not to mention research. Despite the $\mathrm{CV}$ value, we felt that the reservoir estimate was reasonable and that it was the best possible, without a large increase in effort and money. The spawning run estimate could have been improved by a small increase in effort. Ages of walleye in Lake Roosevelt ranged from 0 to 13 years. Growth, mortality, and condition were all average when compared to other walleye producing waters. We recommended that there be no changes in the management of the Lake Roosevelt walleye population and that three separate values of walleye abundance be used in the calculation of the kokanee bioenergetics model. 


\section{Acknowledgements}

We gratefully acknowledge Keith Underwood and Tom Cichosz of the Spokane Tribe Lake Roosevelt Monitoring Program for advise and support in all aspects of this project. We also thank Jennifer Miller and Mary Beth Tilson, Eastern Washington University Fisheries Research Center, for helping with field collection and administrative duties. We thank Mitch Combs [Manager, Sherman Creek Hatchery, Washington Department of Fish and Wildlife (WDFW)] for aiding in fish collection and tagging, and for providing lodging. We thank the Spokane Tribe Lake Roosevelt Monitoring Program crew - Keith Underwood, Tom Cichosz, John Shields, Henry Etue III, Jason Leonhart, Randy Peone, Sam Abrahamson, and Andy Moss - and Spokane Walleye Club (Russ Oberlander, President), Cole Weatherspoon (WDFW), Jim Meskin (WDFW), Curt Vail (WDFW), Richard Le Caire (Colville Tribe), Steven Francis (Colville Tribe), Mike McCartney (Colville Tribe), and Eastern Washington University students - James Hudson, Teresa Nelson, Melissa Buchanan, Leslie Holub, Suzanne Canwell, Chamisa Bird, and Cha Vang - for helping with walleye collection and tagging. We thank Adam Oberlander, a Cheney High School volunteer, for helping with walleye collection and tagging. We also thank the Governor's Cup Walleye Tournament for allowing us to tag walleye caught during the tournament. We thank the Lake Roosevelt Monitoring Program creel clerks - William Matt Sr. (Spokane Tribe), Leroy Williams (Colville Tribe), and Jim Meskin (WDFW) - for collecting walleye tag returns. We thank Eastern Washington University students Nick Kautzman, Teresa Nelson, Leslie Holub, Eric Barnhill, and Fritz Nichols for reading scales. We also thank John Hoskins, Tom Steen, and Buster Hill of Eastern Washington University for equipment, boat, and vehicle repairs. We thank Bruce Haines (U.S. Fish and Wildlife Service, Colorado River Fisheries Project, Vernal, UT) for providing the computer program CAPTURE and for providing instruction for its use.

This project was supported by a contract from the U.S. Department of Energy, Bonneville Power Administration (BPA), Division of Fish and Wildlife, Project No. 8863, Contract No. 94BI32148. The electrofishing boat used in this project was funded by an equipment grant from the National Science Foundation to Allan T. Scholz. The Spokane Walleye Club donated funds for a four-wheel drive vehicle and other equipment used on this project. 


\section{Introduction}

A walleye (Stizostedion vitreum vitreum) mark-recapture study was initiated on Lake Roosevelt, Washington in 1997, with the primary objective of determining the size and age structure of the population (McLellan et al. 1998; McLellan 1998). The study was repeated in 1998 with a more intensive, extensive, and randomized sampling regime due to problems associated with sampling bias in the 1997 study. The 1997 and 1998 results were to be used to determine the status of the walleye population in Lake Roosevelt, as well as be used as the predator component of a kokanee (Oncorhynchus nerka) bioenergetics model that is currently being developed by the Washington Department of Fish and Wildlife (WDFW) and the Lake Roosevelt Monitoring Program (LRMP) (a cooperative investigation of the Lake Roosevelt ecosystem by the Spokane Tribe of Indians (STI), Colville Confederated Tribe of Indians (CCT), and WDFW).

Initial concern about the status of the walleye population in Lake Roosevelt was raised by the U.S. Fish and Wildlife Service (USFWS) in 1985. They concluded that the size and age structure of the population was changing to smaller, younger fish and warned that the population was at risk for collapse (Beckman et al. 1985). Several angling regulations were initiated after 1985, to protect Lake Roosevelt walleye (Washington Department of Fish and Wildlife 1995; McLellan et al. 1998; McLellan 1998). Despite the regulation changes, angler harvest estimates (from LRMP creel surveys) had wide fluctuations from 1988 through 1995, with estimates stabilizing in 1996 and 1997 (Cichosz et al. 1997; Cichosz et al. 1999a). The 1997 walleye assessment was originally designed to determine the status of the Lake Roosevelt population.

Abundance data collected during the 1997 study was generally inconclusive. Estimates of walleye abundance ( \pm 95\% confidence interval) ranged from $51,849( \pm$ $111,620)$ to $64,641( \pm 18,739)$ using Jolly-Seber and Schnabel estimators, respectively (McLellan et al. 1998; McLellan 1998). The estimates were considered underestimates due to a 1997 angler harvest estimate of 115,696 walleye (McLellan et al. 1998; McLellan 1998, Cichosz et al. 1999a). The low values were probably due to sampling bias, as a result of a non-random sampling regime and evidence that the walleye were not moving randomly during the study period (McLellan et al. 1998; McLellan 1998). 
Walleye age data compiled in 1997 was also considered inconclusive. Walleye age analysis in 1997 indicated that the population was comprised mostly of small, young fish, when compared to the USFWS data that had elicited a warning of a potential walleye population collapse. During 1997 there were no walleye collected that were older than 8 years of age, while the USFWS collected 87 walleye between 1980 and 1983 that were between 9 and 13 years of age (Beckman et al. 1985; McLellan et al. 1998; McLellan 1998). However, the comparison of the 1997 and 1980-83 age data was limited, due to the fact that the USFWS data was collected from the walleye spawning run while the EWU data was not (Beckman et al. 1985; McLellan et al. 1998; McLellan 1998). The Lake Roosevelt walleye project was repeated in 1998, in an attempt to remove the sampling related biases of the 1997 analysis.

Determining the abundance and age composition of the Lake Roosevelt walleye population had management implications beyond that of the walleye population itself. In 1991, with the construction of the Spokane Tribal Fish Hatchery and the Sherman Creek Fish Hatchery (WDFW), the LRMP began stocking kokanee into Lake Roosevelt, with the initial objective of developing a kokanee fishery in Lake Roosevelt, as mitigation to the Spokane Indian Tribe for salmon losses due to the construction of Grand Coulee Dam (Northwest Power Planning Council 1986). In order to maximize kokanee production, the LRMP and WDFW are developing a whole reservoir bioenergetics model for Lake Roosevelt (Underwood 1998, STI, personal communication). Predator abundance and kokanee consumption rates are important model inputs. Walleye were the primary predator of kokanee in the reservoir, due to the fact that they were the most abundant piscivore in Lake Roosevelt, based on CPUE (2.60 fish/hour) and relative abundance (19\%), and salmonids were the most relatively important (index of relative importance $(I R I)=28.31)$ food item in walleye stomachs (Cichosz et al. 1997). CPUE's and relative abundances of the other main piscivores in Lake Roosevelt, smallmouth bass (Micropterus dolomieu) (0.78 fish/hour and $6 \%$ ), burbot (Lota lota) (0.58 fish/hour and 4 $\%)$, and northern pikeminnow (Ptychocheilus oregonensis) (0.25 fish/hour and $2 \%)$, were much lower than those of the walleye (Cichosz et al. 1997). Based on the previous diet and relative abundance data, the bioenergetics model needs a walleye abundance estimate. 
During 1998, we conducted a mark-recapture experiment on the Lake Roosevelt walleye population, with the primary objectives of estimating abundance in the entire reservoir, spawning run size in the Spokane River Arm, and describing its age structure, for use in managing the walleye population and developing a kokanee bioenergetics model. Secondary objectives included: 1) determining walleye movements, 2) backcalculating growth rates, 3) estimating mortality rates, 4) determining walleye condition, and 5) estimating walleye young-of-the-year (YOY) abundance in the Spokane River Arm. 


\section{Materials and Methods}

\section{Fish Sampling and Marking}

\section{Reservoir}

The primary means of fish collection was boat electrofishing, which was completed with a Smith-Root ${ }^{\circledR}$ SR-18 boat electrofisher (Smith-Root, Vancouver, WA) with the DC voltage adjusted to produce 3-5 amps, and with a pulse frequency of 120 pulses per second. Sampling was conducted during five passes through the reservoir. A pass consisted of sampling at each of 16 reservoir sections (Figure 1). Pass dates were:

1. April $1^{\text {st }}$ through June $11^{\text {th }}$,

2. June $12^{\text {th }}$ through July $12^{\text {th }}$,

3. July $13^{\text {th }}$ through August $2^{\text {nd }}$,

4. August $3^{\text {rd }}$ through August $24^{\text {th }}$, and

5. August $25^{\text {th }}$ through September $16^{\text {th }}$.

A stratified, random sampling design was used for fish collection. The mainstem reservoir was divided into ten sections, with the first section beginning at the forebay of Grand Coulee Dam and the last section ending at the downstream end of the Little Dalles (just north of China Bend). Each section was 20 kilometers long except the tenth section, which was 27 kilometers long. The Spokane River Arm was divided into two, 20 kilometer sections and one, seven kilometer section. The Sanpoil River Arm was treated as one, 13 kilometer section. The Kettle River Arm was treated as one, ten kilometer section. The Hawk Creek embayment was treated as one seven kilometer section (Figure 1). Within each section both shorelines were divided into one kilometer transects (40 transects per $20 \mathrm{~km}$ reservoir section), which were each assigned a number, with odd numbers on the south and east sides of the reservoir and even numbers on the north and west sides. Each major embayment in the reservoir was numbered consecutively as we moved up the reservoir. Major embayments were considered any deviation from a straight shoreline that had surface water inflow at some point during the year. Decisions as to those embayments that met the criteria were made based on previous observation and/or a nautical chart (U.S. Geologic Survey; scale 1:50,000). 


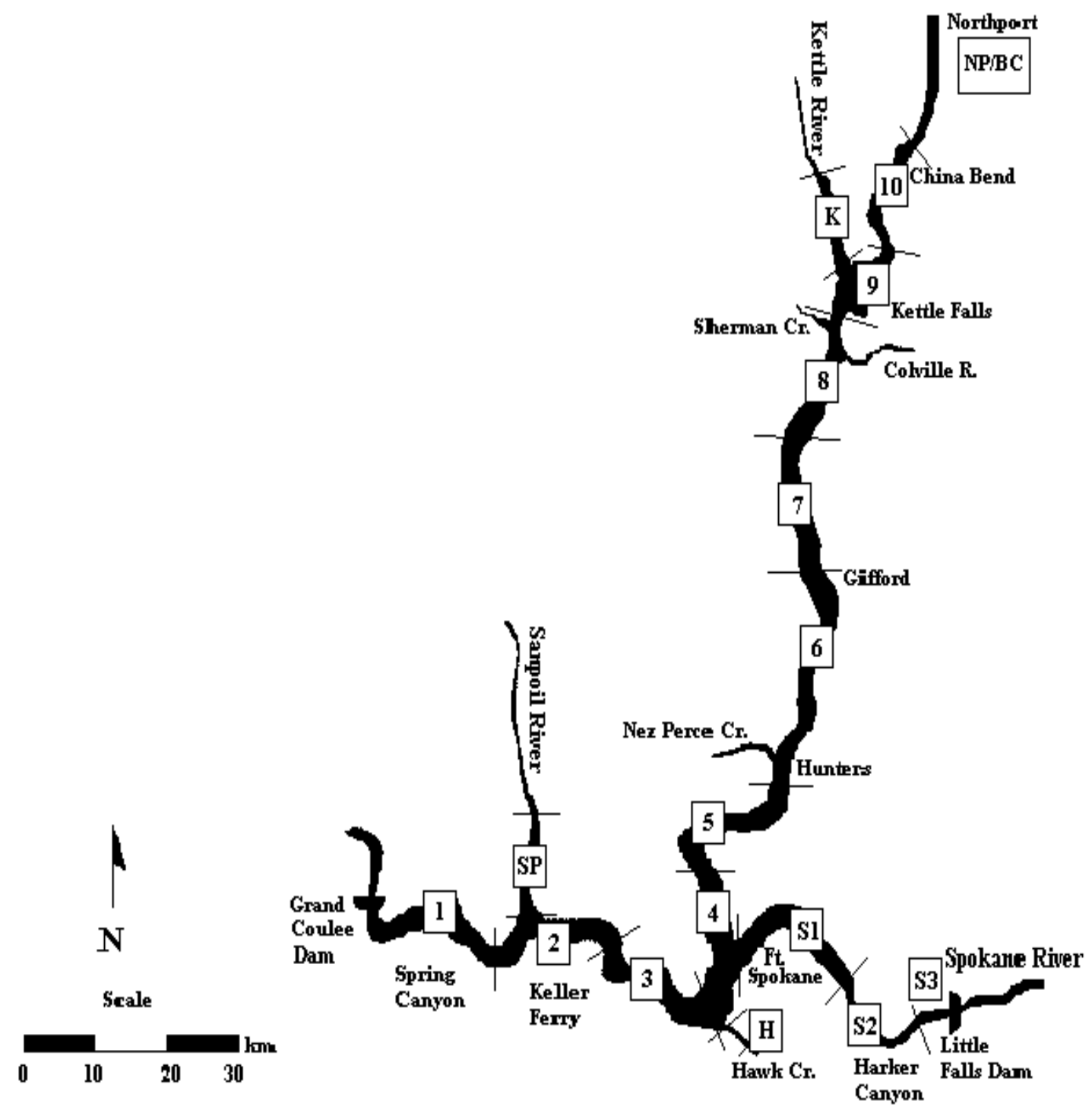

Figure 1. Map of 1998 Lake Roosevelt sampling sections. Section NP/BC includes the Columbia River from the upstream boundary of section 10 to Hugh Keenleyside Dam, British Columbia. 
During the first pass through the reservoir, four randomly selected river transects and four randomly selected embayments were sampled per river section, except at Hawk Creek where we sampled at two randomly selected shorelines and two randomly selected embayments. During the subsequent four passes, we sampled eight randomly selected river transects and all the embayments in each river section, except Hawk Creek and the Kettle River Arm, where we sampled 4 and 6 randomly selected shoreline sites. The division of sampling effort between the shoreline and embayment strata was not proportional, due to the necessity to facilitate marking more fish. White et al. (1982) recommended designing the study to allow for marking as many animals as possible during a mark-recapture project if there was indication that the animals might exhibit behavioral responses to marking. Previous estimates of walleye abundance in Lake Roosevelt resulted in the selection of CAPTURE models that indicated walleye had a behavioral response to collection and marking (McLellan et al. 1998; McLellan 1998). McLellan et al. (1998) reported that the highest densities of walleye occurred in the embayments.

Electrofishing surveys were supplemented with angling on April $4^{\text {th }}$, May $2^{\text {nd }}$ and $30^{\text {th }}$, June $21^{\text {st }}$ and $22^{\text {nd }}$, and August $3^{\text {rd }}, 6^{\text {th }}$, and $12^{\text {th }}$. Angling on April $4^{\text {th }}$ and May $2^{\text {nd }}$ and $30^{\text {th }}$ were conducted in the Spokane Arm, with the assistance of the Spokane Walleye Club. Walleye angling on June $21^{\text {st }}$ and $22^{\text {nd }}$ was in conjunction with the Governor's Cup Walleye Tournament in Kettle Falls, Washington. EWU personnel and Spokane Walleye Club volunteers completed the additional angling in the Keller Ferry, Sanpoil River, Hawk Creek, and Kettle Falls sections, as well as the area between Hawk Creek and Hunters. Personnel from the STI, CCT, and WDFW aided EWU with the walleye tagging during the Spokane River angling days and the Governor's Cup Walleye Tournament.

During the walleye spawning run in the Spokane River Arm, we conducted sampling in addition to the randomly selected Pass 1 sites, in order to mark large numbers of walleye while they were easily accessible. We determined the walleye spawning run in the Spokane Arm occurred between April ${ }^{\text {st }}$ and May $22^{\text {nd }}$, which were the dates when we collected ripe fish in the spawning area below Little Falls Dam. The additional sampling consisted of electrofishing the entire accessible shoreline from Little Falls Dam 
downstream to Harker Canyon. Walleye tagging during the spawning congregation was justified, due to the fact that those fish marked during the spawn randomly disperse following spawning (Beckman et al. 1985).

\section{Spawning Run}

In order to estimate the size of the walleye spawning run above Harker Canyon, we divided the spawning sampling period into six passes and estimates were calculated only using mark-recapture data collected upstream of Harker Canyon, during the spawning run. The passes were as follows:

1. April $4^{\text {th }}$,

2. April $12^{\text {th }}$ through April $18^{\text {th }}$,

3. April $19^{\text {th }}$ through April $25^{\text {th }}$,

4. April $26^{\text {th }}$ through May $2^{\text {nd }}$,

5. May $10^{\text {th }}$ through May $16^{\text {th }}$, and

6. May $17^{\text {th }}$ through May $22^{\text {nd }}$.

\section{Data Collection and Fish Marking}

During electrofishing surveys, all species of fish were collected to standardize catch and effort data to allow for comparisons with previous studies. Total lengths (TL) $(\mathrm{mm})$ were obtained from all fish collected. Weights $(\mathrm{g})$ were measured with an Acculab $^{\circledR}$ (Newton, PA) V-4Kg electric balance. The balance was calibrated, approximately once every three weeks, according to the instructions provided by the manufacturer. Scale samples were also collected and placed in coin envelopes with the length, weight, location, date, tag number, and sex of the fish written on the outside of the envelope. All walleye $\geq 150 \mathrm{~mm}$ TL were affixed with an individually numbered FD 94 3/4 monofilament long 'T'”- anchor Floy ${ }^{\circledR}$ (Floy Tag and Mfg., Inc., Seattle , WA) tag and released. Each tag also possessed the address "EWU CHENEY" so anglers would know where to return them. Tags were inserted into the dorsal musculature of the walleye at the posterior base of the first dorsal fin. Posters informing anglers about fisheries projects on Lake Roosevelt and where to report tag information were placed at major boat launches around the reservoir. Tag return data requested included the tag 
number, length, location and date of capture, and weight (if possible). All anglers who returned walleye tags were sent a letter with information about the when and where their fish was tagged, as well as its length.

Electrofishing catch-per-unit-effort (CPUE) was calculated by dividing the number of fish captured by the amount of electrofishing effort (hours). CPUE was determined for each sampling section, as well as the entire reservoir. would

\section{Abundance Estimates}

Animal populations are generally considered either closed or open. In a closed population there is no change in animal abundance during the course of the study, so there is no death, emigration, birth, and/or immigration occurring in the population. Conversely, an open population experiences some or all of the previous factors, causing its size to change during the course of the study. We determined that the walleye population in Lake Roosevelt was open, due to angler harvest (tag returns) and emigrating fish, in 1997 (McLellan 1998; McLellan et al. 1998).

Using closed and open models, we calculated four estimates of the size of the walleye population in Lake Roosevelt and three estimates of the size of the Spokane River spawning run. The first two models, for estimating the size of closed populations, were the Chapman version of the Schnabel estimate (Seber 1982) and the "most appropriate" model chosen by the IBM computer program CAPTURE (Otis et al. 1978; White et al. 1982). The third model used was the Jolly-Seber model for an open population (Seber 1982). Only recaptures by EWU and STI were used to generate the population estimates. Captured walleye previously tagged by another agency or tagged in 1997 by EWU or STI were treated as first captures, using the original tag. Recaptures of fish tagged during the same pass were ignored.

\section{Closed Population Estimators}

A closed population estimator can be used to estimate the size of an open population, when the assumption of closure are relaxed, which would only affect the timing of the estimate (Pollock et al. 1990). If mortality and emigration had equal effects on the marked and unmarked portions of the population and neither recruitment nor immigration occurred, the estimate would be for the size of the population at the 
beginning of the study (Otis et al. 1978). However, if recruitment (immigration) and mortality (emigration) were both occurring, the size of the population would be overestimated (Otis et al. 1978). Estimates for the open walleye population were calculated using closed estimators, by correcting for recruitment.

Beginning June 1, 1998, we adjusted for recruitment by increasing the minimum TL for tagging by $10 \mathrm{~mm}$ every two weeks, which was the approximate growth of Lake Roosevelt walleye in 1997, based on 98 recaptures with adequate length data provided at each sighting (McLellan et al. 1998; McLellan 1998). By initiating the recruitment adjustment on June $1^{\text {st }}$, we made the assumption that age 1 walleye were $\geq 150 \mathrm{~mm}$ TL prior to the beginning of the study and that YOY walleye would not reach $150 \mathrm{~mm}$ TL by June $1^{\text {st }}$ (Beckman et al. 1985; Peone et al. 1990; Griffith and Scholz 1991; McLellan et al. 1998; McLellan 1998). We assumed no immigration, because previous movement data suggested that walleye would have been migrating out of the study area during the study period rather than into it (Hildebrandt, personal communication, 1998).

The Chapman version of the Schnabel model, corrected for small sample bias, was used to estimate walleye abundance (Seber 1982). For comparison, two estimates of abundance were calculated via the Schnabel model. The first estimate was not adjusted for recruitment and the second was. The Schnabel estimate equation was:

$$
\mathrm{N}=\frac{\sum \mathrm{C}_{\mathrm{t}} \mathrm{M}_{\mathrm{t}}}{\sum \mathrm{R}+1}
$$

where:

$\mathrm{N}=$ estimated population size,

$\mathrm{C}_{\mathrm{t}}=$ total number of fish captured at time $t$,

$\mathrm{M}_{\mathrm{t}}=$ total number of marked fish available for capture at time $t$, and

$\Sigma \mathrm{R}=$ total number of recaptures up to time $t$.

The $95 \%$ confidence intervals were calculated using the Poisson distribution table in Ricker (1975). Both Schnabel estimates were compared statistically $(\alpha=0.05)$ with the test proposed by Chapman and Overton (1966), in order to determine if tagging walleye $\geq$ 150 mm TL in Lake Roosevelt between April 1 and September 16, resulted in negligible recruitment as suggested by McLellan et al. (1998) and McLellan (1998). 
The computer program CAPTURE was used to estimate the size of the reservoir walleye population, with the recruitment adjustment, as well as the estimate of the size of the spawning run. The USFWS developed the computer program, CAPTURE, to calculate closed population estimates using a Petersen-type model, arranged to compensate for heterogeneity in capture probabilities (all animals not having equal probability of capture) (Otis et al. 1978; White et al. 1982). CAPTURE had the ability to select the most "appropriate" of 11 different models, based on the data set. The 11 models were as follows: $\mathbf{M}_{\mathrm{o}}$, the null model, which assumes no differences in capture probability among all animals; $\mathrm{M}_{\mathrm{b}}$, which accounts for differences in capture behavior of the organism; $M_{t}$, which deals with differences in capture methods or environmental conditions (day vs. night); $\mathrm{M}_{\mathrm{h}}$, which accounts for individual differences in capture probability (trap accessibility influenced by sex, territory, age, dominance, etc.); and all the possible combinations of models $\mathrm{M}_{\mathrm{b}}, \mathrm{M}_{\mathrm{t}}$, and $\mathrm{M}_{\mathrm{h}}$ (Otis et al. 1978; White et al. 1982). All the models, excluding $\mathrm{M}_{\mathrm{o}}$, were designed to relax the assumption of equal catchability, because biological populations rarely follow mathematical rules (Otis et al. 1978; White et al. 1982).

\section{Open Population Estimator}

The Jolly-Seber model was the open population estimator used to estimate walleye abundance for the entire reservoir, as well as the spawning run (Seber 1982). The Jolly-Seber model, corrected for small sample bias, was:

$$
\mathrm{N}_{\mathrm{i}}^{*}=\frac{\mathrm{M}_{\mathrm{i}}^{*}\left(\mathrm{n}_{\mathrm{i}}+1\right)}{\mathrm{m}_{\mathrm{i}}+1}
$$

where:

$$
\begin{aligned}
\mathrm{N}_{\mathrm{i}}^{*}= & \text { total number in the population just before sample } i, \\
\mathrm{M}_{\mathrm{i}}^{*}= & \text { the number of marked fish in the population just before } \\
& \text { sample } i, \\
\mathrm{n}_{\mathrm{i}}= & \text { the number of captured at sample } i, \text { and } \\
\mathrm{m}_{\mathrm{i}}= & \text { total number of marked fish caught in sample } i .
\end{aligned}
$$

Before solving for $\mathrm{N}_{\mathrm{i}}{ }^{*}$, we calculated $\mathrm{M}_{\mathrm{i}}{ }^{*}$ using the formula: 
$\mathrm{M}_{\mathrm{i}}^{*}=\left(\frac{\mathrm{R}_{\mathrm{i}}+1}{\mathrm{r}_{\mathrm{i}}+1}\right) \mathrm{Z}_{\mathrm{i}}+\mathrm{m}_{\mathrm{i}}$

where:

$$
\begin{aligned}
\mathrm{M}_{\mathrm{i}}^{*}= & \text { the number of marked fish in the population just before } \\
& \text { sample } i, \\
\mathrm{R}_{\mathrm{i}}= & \text { the number of marked fish released at sample } i, \\
\mathrm{Z}_{\mathrm{i}}= & \text { the sum of all recaptures made later than sample } i \text { and of fish } \\
& \text { marked before sample } i, \\
\mathrm{r}_{\mathrm{i}}= & \text { the total number of recaptures that were first marked at sample } \\
& i \text {, and } \\
\mathrm{m}_{\mathrm{i}}= & \text { total number of marked fish caught in sample } i .
\end{aligned}
$$

The variance and standard error (S.E.) of the population estimate $\left(\mathrm{N}_{\mathrm{i}}{ }^{*}\right)$ were calculated with the following formula (Seber 1982):

$$
\mathrm{V}\left[\mathrm{N}_{\mathrm{i}}^{*} \mid \mathrm{N}_{\mathrm{i}}\right]=\mathrm{N}_{\mathrm{i}}^{*}\left(\mathrm{~N}_{\mathrm{i}}^{*}-\mathrm{n}_{\mathrm{i}}\right)\left\{\frac{\mathrm{M}_{\mathrm{i}}^{*}-\mathrm{m}_{\mathrm{i}}+\mathrm{R}_{\mathrm{i}}}{\mathrm{M}_{\mathrm{i}}^{*}}\left(\frac{1}{\mathrm{r}_{\mathrm{i}}}-\frac{1}{\mathrm{R}_{\mathrm{i}}}\right)+\frac{1-\rho_{\mathrm{i}}}{\mathrm{m}_{\mathrm{i}}}\right\}
$$

where:

$$
\begin{aligned}
\mathrm{V}\left[\mathrm{N}_{\mathrm{i}}^{*} \mid \mathrm{N}_{\mathrm{i}}\right] & =\text { the variance of the population estimate }\left(\mathrm{N}_{\mathrm{i}}{ }^{*}\right), \\
\mathrm{N}_{\mathrm{i}} & =\text { actual size of the population just before sample } i, \text { and } \\
\rho_{\mathrm{i}} & =\mathrm{m}_{\mathrm{i}} / \mathrm{n}_{\mathrm{i}} .
\end{aligned}
$$

S.E. $=\sqrt{\left[\mathrm{N}_{\mathrm{i}}^{*} \mid \mathrm{N}_{\mathrm{i}}\right]}$

The $95 \%$ confidence interval was calculated assuming a normal distribution.

Precision of the estimates was measured by calculating a coefficient of variance (CV), which was defined as the ratio of the standard error of the estimate to the estimate (Hightower and Gilbert 1984).

In order to verify the reservoir walleye abundance estimate, walleye density was extrapolated from the following equation (Beard et al. 1997): angler catch/hour = 0.018(number of walleye/acre). The angler catch rate (0.098 fish/hour) was determined from the LRMP creel surveys (Cichosz et al. 1999b). Walleye abundance was estimated by multiplying the walleye density estimate by the surface area of Lake Roosevelt (82,720 acres; Beckman et al. 1985). 
In order to determine if a walleye population the size of which we estimated could support an angler harvest of approximately 100,000 fish, the potential recruitment to age four was calculated. Age four was selected because that was the age that most female walleye matured in Lake Roosevelt (Beckman et al. 1985). The mean fecundity of the female walleye collected during the spawning run was estimated using the regression equation (Forney 1976): fecundity $=-7,900+70,600$ (weight in grams). Total number of female spawners was estimated by applying the percentage of female spawners collected during electrofishing surveys, to the mean estimated size of the spawning run. Egg production was calculated by multiplying the total number of female spawners by the mean fecundity. The potential recruitment to age four was calculated by applying survival rates to the estimated egg production. Egg to age one survival was assumed to be $0.0026(0.26 \%)$, which was the lowest value we could find in the literature (Carlander 1997). Survival of Lake Roosevelt walleye was previously shown to be $52 \%$ between each age until age four (McLellan et al. 1998; McLellan 1998).

\section{Model Assumptions}

Models designed to estimate animal abundance via mark-recapture have a variety of mathematical and biological assumptions associated with them. Assumptions of the closed models were (Ricker 1975; Otis et al. 1978; White et al. 1982):

1. The population was closed.

2. Animals did not lose their tags during the study.

3. All animals in the population have an equal probability of being captured on each sampling occasion.

The assumptions of the Jolly-Seber model were (Seber 1982):

1. All animals alive and in the population had the same probability of capture at each sampling occasion.

2. All animals have the same probability of surviving or remaining in the population from sample $i$ to sample $i+1$, if it was alive immediately after sample $i$.

3. Animals do not lose their tags.

4. All samples are instantaneous, so sampling time is negligible, and each release is made immediately after the sample. 
In order to assure the validity of the abundance estimates, we had to insure the model assumptions had been met or could be relaxed.

The assumption of closure was relaxed by adjusting for recruitment for calculation of the CAPTURE estimate and one of the Schnabel estimates. An alternative estimate of abundance was calculated using the Schnabel method to determine whether or not tag loss was negligible in 1998. The alternative estimate was made by adding the number of recaptures per pass at the approximate observed rate of tag loss in 1998, similar to the method of Beamesderfer and Rieman (1991). The Schnabel estimate corrected for tag loss was compared statistically with the estimate assuming no tag loss, using the test for differences between Schnabel estimates (Chapman and Overton 1966).

The assumption of equal catchability was tested using the CAPTURE programs model selection procedure (Otis et al. 1978; White et al. 1982) and by comparing recapture rates of marked walleye collected via electrofishing with those collected via angling. The comparison of recapture rates was made using the chi-square Test for Independence $(\alpha=0.05,1$ degree of freedom (d.f.)) (Johnson and Bhattacharyya 1996). Angler catch ratios were determined from the Spokane River Angling Days, Governor's Cup Walleye Tournament, and data provided by anglers with tag returns. Several anglers provided catch data, with their voluntary tag returns, that included the numbers of marked and unmarked walleye captured on their outing.

The validity of the Jolly-Seber model was tested using Goodness of Fit Tests ( $\alpha=$ 0.05) proposed by Pollock et al. (1990).

\section{Movements}

Walleye movement from release location to subsequent recapture location was estimated from biologist and angler reported recaptures. Only returns with specific recapture locations and dates were included in the analysis. Walleye recaptured within 7 days of release were ignored for movement analysis. Minimum distance traveled between release and recapture location was estimated by measuring the shortest distance from the point of release to the location of recapture on a U.S. Geologic Survey Nautical Chart $($ scale $=1: 50,000)$. Distance between the release and recapture location of walleye that were recaptured on more than one occasion was calculated from the most recent 
release to the subsequent recapture. Recaptures of walleye recaptured more than once were treated individually during analysis. Distances between release and subsequent recapture location were calculated for walleye tagged in 1997 and recaptured in 1998, walleye tagged and recaptured in 1998, walleye tagged during the 1998 spawning run in the Spokane Arm and recaptured following the spawning run, and walleye tagged in 1998 after the spawning run.

Mean minimum distance traveled between release and recapture location by walleye tagged on the spawning run were compared statistically with those tagged following the spawning run, to determine if spawning walleye were recaptured farther from their release location, on average, than those marked following the spawning run. The comparison was made using a one-sided t-Test, assuming unequal variances $(\alpha=0.05)$ (Johnson and Bhattacharyya 1996).

\section{Age and Growth}

Scale samples were obtained from 4,614 walleye for scale analysis. For equal representation of all size classes, scales from five walleye per $1 \mathrm{~cm}$ length class were randomly selected for analysis. If fewer than five fish were collected in a length class, all the scale samples from fish in that specific length-class were analyzed. Scales were placed between two microscope slides and magnified (24X) with an Eyecom $3000^{\circledR}$ (Eye Communication Systems, Hartland, WI) microfiche reader. Ages were determined by counting the number of annuli formed on each scale (Devries and Frie 1996). Measurements for back-calculations were obtained by measuring the distance, to the nearest $\mathrm{mm}$, from the focus of the scale to outermost edge of each annulus and to the edge of the scale. Measurements were made along the longest axis, from the focus to the scale edge, using a transparent ruler. Two individuals read all scales. If there was a disagreement about the age of a fish, the researchers discussed the scale until a consensus was reached.

The Fraser-Lee method was used to back-calculate the total length at each annulus formation. The equation for Fraser-Lee Method was (Devries and Frie 1996): 


$$
\mathrm{L}_{\mathrm{i}}=\left(\frac{\mathrm{L}_{\mathrm{c}}-\mathrm{a}}{\mathrm{S}_{\mathrm{c}}}\right) \mathrm{S}_{\mathrm{i}}+\mathrm{a}
$$

where:

$\mathrm{L}_{\mathrm{i}}=$ back-calculated TL of the fish at the formation of the $\mathrm{i}^{\text {th }}$ annulus,

$\mathrm{L}_{\mathrm{c}}=\mathrm{TL}$ of the fish at capture,

$\mathrm{S}_{\mathrm{c}}=$ length from the focus to the outermost edge of the scale at capture,

$S_{i}=$ length from focus of the scale to the outer edge of the $i^{\text {th }}$ annulus, and

$\mathrm{a}=$ the Y-intercept of the body length vs. scale length regression line.

An age-length key was created to assign ages to fish from which scales were not obtained or analyzed (Anderson and Neuman 1996). The key was constructed by determining the total number of fish collected in each length-group. Length-groups were created by rounding the TL $(\mathrm{mm})$ to the nearest centimeter $(\mathrm{cm})$. Ages were determined for a subsample of fish in each length-group via scale analysis. Using the proportions of fish of each age in the subsample of a length-group, the total numbers of fish of each age in the length-group were estimated.

\section{Mortality}

Age frequency information derived from the age-length key was used to develop a simple catch-curve, according to the method in Ricker (1975). Instantaneous mortality (Z) was calculated via the Baranov method (Ricker 1975), where the absolute value of the slope of the regression line that described the descending limb of the catch-curve was multiplied by 2.3026 . The age class at the peak of the curve and age classes represented by fewer than 10 individuals were ignored for the calculation of the regression equation. Mean annual survival was calculated with the following formula (Ricker 1975):

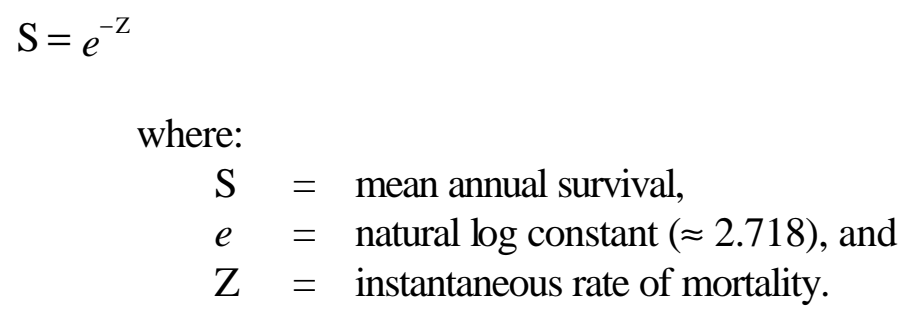


Mean annual mortality (A) was calculated with the formula $\mathrm{A}=1-\mathrm{S}$, where $\mathrm{A}$ and $\mathrm{S}$ were previously defined (Ricker 1975).

Assuming equal numbers at birth and equal mortality between each age class, for all cohorts, mean annual mortality between age classes was estimated with the formula $\mathrm{A}$ $=1-\mathrm{S}$ (Ricker 1975). Before calculating the annual mortality (A) between age classes, annual survival (S) between age classes was estimated using the formula:

$\mathrm{S}=\frac{\mathrm{N}_{\mathrm{t}+1}}{\mathrm{~N}_{\mathrm{t}}}$

where:

$\mathrm{S}=$ annual survival,

$\mathrm{N}_{\mathrm{t}}=$ number of age $t$ fish collected, and

$\mathrm{N}_{\mathrm{t}+1}=$ number of age $t+1$ fish collected.

\section{Condition}

The length to weight relationship of walleye was determined by calculating a regression equation. Both variables were log-transformed in order to obtain the best-fit regression equation (Anderson and Neuman 1996).

Condition factors $\left(\mathrm{K}_{\mathrm{TL}}\right)$ were calculated as an index of how Lake Roosevelt walleye add weight in relation to increasing length (Anderson and Neuman 1996). Mean condition factor was calculated for the entire walleye population and for each age class using the following formula:

$$
\mathrm{K}_{\mathrm{TL}}=\left(\frac{\mathrm{WT}}{\mathrm{TL}^{3}}\right) \times 10^{5}
$$

where:

$\mathrm{K}_{\mathrm{TL}}=$ condition factor based on total length,

$\mathrm{WT}=$ weight, and

$\mathrm{TL}=$ total length. 


\section{Walleye Young-of-the-Year Abundance}

We attempted to estimate the abundance of YOY walleye in the Spokane River Arm, via a mark-recapture experiment. YOY walleye were collected via electrofishing on August $3^{\text {rd }}, 4^{\text {th }}$, and $6^{\text {th }}, 1998$. Transects in the Spokane River Arm were randomly selected using the protocol scheme described for the adult estimates. All walleye $<150$ mm TL were assumed to be YOY, based on scale analysis (McLellan et al. 1998; McLellan 1998) and were marked with yellow and green elastomere on August $3^{\text {rd }}$ and $4^{\text {th }}$, and August $6^{\text {th }}$, respectively. Due to low numbers of YOY walleye captured and no recaptures, the estimate was determined to be unfeasible and was abandoned after August $6^{\text {th }}, 1998$. 


\section{Results}

\section{Fish Collection and Marking}

Between April $1^{\text {st }}, 1998$ and September $16^{\text {th }}, 1998$, EWU biologists, with the aid of anglers, collected 5,025 walleye. Of those fish collected, 4,747 were marked with "Floy" tags (Table 1). In an attempt to increase the precision of the entire reservoir walleye abundance estimate, STI walleye marking data was combined with the EWU data (Table 1) (Cichosz et al. 1999b). There were 453 recapture events during 1998 (Table 2; Appendix A).

Twenty-four walleye recaptured in 1998 had been recaptured on at least one other occasion in either 1997 or 1998 . Twenty-two of the multiple recaptures were fish recaptured on two occasions and 2 were fish recaptured on three occasions. Of the multiple recaptures, 17 occurred in the Spokane Arm, 3 occurred in the Kettle Falls area, and 1 occurred at Hunters. A walleye tagged near Sherman Creek in 1997 was subsequently recaptured on three occasions in the Spokane Arm in 1998. A walleye tagged at Hawk Creek in 1997 was later recaptured at Hawk Creek in 1998. The same fish was recaptured a second time in 1998, but an angler left the tag in a tag return box at the Fort Spokane Boat Launch with no other information. A walleye tagged at the Colville River in 1997 was recaptured on two occasions in 1998, both times at Flat Creek, near China Bend. One hundred-sixty seven of the recapture events were of walleye marked during the 1997 project and 286 of the recaptures were of fish marked during 1998. The recapture rate of walleye marked and recaptured in 1998 was $5.6 \%$.

Mean number of days between release and recapture for fish marked in 1998 was 43 days (standard deviation $=30$ ), with a range of 8 to 186 days $(n=197)$. The mean number of days between previous release and subsequent recapture of walleye tagged in 1997 and recaptured in 1998 was 293 days ( $\mathrm{SD}=78)$, and ranged from 24 to 419 days (n $=146)$.

EWU biologists collected 4,071 walleye via electrofishing surveys during the study. Total electrofishing effort was 242.88 hours and total CPUE was 16.76 fish per hour. Sections H (Hawk Creek) and section 10 (China Bend) had the highest and lowest CPUE's at 59.55 and 0.19 fish per hour (Table 4). 
Table 1. Summary of walleye tagged by Eastern Washington University (EWU), with the aid of anglers and Lake Roosevelt Monitoring Program (STI), arranged by pass and reservoir section. Section NP (Northport) was not a regular sampling section, but anglers tagged walleye for $\mathrm{EWU}$ in that area on one day.

\begin{tabular}{ccccccc} 
& \multicolumn{7}{c}{ Pass } & Total \\
\cline { 2 - 5 } Section & $\mathbf{1}$ & $\mathbf{2}$ & $\mathbf{3}$ & $\mathbf{4}$ & $\mathbf{5}$ & 31 \\
\hline $\mathbf{1}$ & 1 & 11 & 15 & 1 & 3 & 98 \\
$\mathbf{2}$ & 2 & 27 & 66 & 2 & 1 & 319 \\
$\mathbf{S P}$ & 46 & 101 & 155 & 5 & 12 & 21 \\
$\mathbf{3}$ & 0 & 5 & 15 & 1 & 0 & 528 \\
$\mathbf{H}$ & 50 & 295 & 133 & 24 & 26 & 302 \\
$\mathbf{4}$ & 29 & 90 & 144 & 25 & 14 & 256 \\
$\mathbf{S} \mathbf{1}$ & 126 & 78 & 25 & 24 & 3 & 477 \\
$\mathbf{S ~ 2}$ & 157 & 133 & 102 & 85 & 0 & 1,587 \\
$\mathbf{S ~ 3}$ & 1,441 & 45 & 78 & 23 & 0 & 148 \\
$\mathbf{5}$ & 25 & 72 & 42 & 81 & 1 & 261 \\
$\mathbf{6}$ & 44 & 113 & 95 & 2 & 7 & 111 \\
$\mathbf{7}$ & 18 & 61 & 32 & 0 & 0 & 513 \\
$\mathbf{8}$ & 62 & 386 & 48 & 8 & 9 & 357 \\
$\mathbf{9}$ & 24 & 321 & 7 & 5 & 0 & 18 \\
$\mathbf{K}$ & 0 & 8 & 0 & 10 & 0 & 49 \\
$\mathbf{1 0}$ & 1 & 47 & 0 & 0 & 1 & 5 \\
NP & 0 & 0 & 0 & 5 & 0 & 5,081 \\
\hline Total & 2,026 & 1,793 & 957 & 228 & 77 & \\
\hline
\end{tabular}

\section{Abundance Estimates}

Reservoir

The number of walleye $\geq 150 \mathrm{~mm}$ TL (95\% confidence interval (C.I.)), in Lake Roosevelt in 1998, was estimated to be $198,137(151,400 \leq \mathrm{N} \leq 277,875)$ via the Schnabel model without the correction for recruitment, and 191,433 (146,278 $\leq \mathrm{N} \leq$ 268,473) via the Schnabel model adjusted for recruitment (Table 4). Using the data set that was corrected for recruitment, CAPTURE selected the $\mathrm{M}_{\mathrm{tb}}$ model as most appropriate and calculated an estimate of 186,482 (40,113 $\leq \mathrm{N} \leq 943,213)$ (Table 4). Selection of model $\mathrm{M}_{\mathrm{tb}}$, by CAPTURE, indicated time and behavioral effects which resulted in unequal capture probabilities between marked and unmarked fish that varied 
Table 2. Walleye recaptures and tag returns during 1998. Tagged walleye were recaptured by anglers, Eastern Washington University (EWU), the Spokane Tribe (STI), the Colville Tribe (CCT), the Washington Department of Fish and Wildlife (WDFW), at the Governor's Cup Walleye Tournament (GCWT), and at the three Spokane River Arm Angling Days (SRAD).

\begin{tabular}{lccccc} 
& \multicolumn{2}{c}{ Walleye Tagged in ... } & & \\
\cline { 2 - 3 } Agency/Group & $\mathbf{1 9 9 7}$ & $\mathbf{1 9 9 8}$ & Total & Percent $(\%)$ \\
\hline Anglers & 89 & 140 & & 229 & 50.6 \\
EWU & 41 & 121 & & 162 & 35.8 \\
STI & 14 & 10 & 24 & 5.3 \\
WDFW & 0 & 1 & 1 & 0.2 \\
CCT & 0 & 1 & 1 & 0.2 \\
GCWT & 20 & 8 & 28 & 6.2 \\
SRAD & 3 & 5 & 8 & 1.8 \\
\hline Total & $\mathbf{1 6 7}$ & $\mathbf{2 8 6}$ & $\mathbf{4 5 3}$ & \\
\hline
\end{tabular}

Table 3. Catch-per-unit-effort (CPUE) of walleye collected in Lake Roosevelt (1998) via electrofishing surveys conducted by Eastern Washington University (EWU).

\begin{tabular}{cccc} 
Section & n & Effort (hours) & CPUE (fish/hour) \\
\hline 1 & 33 & 16.88 & 1.95 \\
2 & 99 & 15.78 & 6.27 \\
SP & 273 & 14.78 & 18.47 \\
3 & 21 & 13.38 & 1.57 \\
H & 530 & 8.90 & 59.55 \\
4 & 313 & 18.78 & 16.67 \\
S 1 & 183 & 17.93 & 10.21 \\
S 2 & 338 & 20.83 & 16.23 \\
S 3 & 1,578 & 28.22 & 55.92 \\
5 & 135 & 14.35 & 9.41 \\
6 & 240 & 13.82 & 17.37 \\
7 & 75 & 14.40 & 5.21 \\
8 & 160 & 16.26 & 9.84 \\
9 & 73 & 12.42 & 5.88 \\
K & 18 & 5.71 & 3.15 \\
10 & 2 & 10.44 & 0.19 \\
\hline Total & $\mathbf{4 , 0 7 1}$ & $\mathbf{2 4 2 . 8 8}$ & $\mathbf{1 6 . 7 6}$ \\
\hline
\end{tabular}


with time. The size of the walleye population $\geq 150 \mathrm{~mm}$ TL (95\% C.I.) was estimated via the Jolly-Seber model was $213,213(5,081 \leq \mathrm{N} \leq 464,215)$ (Table 4). The CV provided by CAPTURE for the $\mathrm{M}_{\mathrm{tb}}$ estimate was $98 \%$. The probabilities of capture, calculated by CAPTURE, for passes one through five were as follows: 0.011, 0.010, 0.005, 0.001, 0.000. Walleye density in Lake Roosevelt was 5.44 fish/acre and the estimated size of the walleye population, extrapolated from Beard et al.'s (1997) equation and the surface area, was 450,364.

When the Schnabel estimate without the recruitment adjustment was compared to the corrected Schnabel estimate, the null hypothesis that the two estimates were not significantly different was not rejected $(\alpha=0.05, \mathrm{z}=-0.01, \mathrm{p} \geq 0.50)$.

\section{Spawning Run}

The size of the walleye spawning run (95\% C.I.) in the Spokane River Arm was estimated to be $15,222(12,018 \leq \mathrm{N} \leq 19,855)$ via the Schnabel model, 15,178 $(12,093 \leq$ $\mathrm{N} \leq 19,164)$ using the $\mathrm{M}_{\mathrm{t}}$ model of the CAPTURE program, and 27,345 $(1,535 \leq \mathrm{N} \leq$ 57,519) via the Jolly-Seber model (Table 5). The model selected as the most appropriate by the CAPTURE program was $\mathrm{M}_{\mathrm{t}}$, indicating time effects, or changing capture probabilities over time. The CV for the Jolly-Seber estimate was 57\%. Raw data used to generate all of the estimates was provided in Appendix B.

During the walleye spawning run there were 96 females (6.3\%), 1,118 males $(73.7 \%)$, and $304(20.0 \%)$ fish of undetermined sex collected. The mean fecundity of the female spawners was 186,134 eggs/female $(\mathrm{SD}=112,078)$. There were an estimated 1,723 female walleye that spawned in the Spokane Arm, when we applied the $6.3 \%$ to the Jolly-Seber estimate for the size of the run. The estimated egg production was $3.21 \mathrm{x}$ $10^{8}$ eggs. After applying the survival rates, the Spokane Arm walleye spawning run had the potential to produce 117,245 recruits to age four, sexual maturity. 
Table 4. Estimates of walleye abundance for the entire reservoir, and $95 \%$ confidence intervals (95 \% C.I.), calculated using various models.

\begin{tabular}{lccc} 
Model & N & Lower 95 \% C.I. & Upper 95 \% C.I. \\
\hline Schnabel $^{\mathrm{a}}$ & 198,137 & 151,400 & 277,875 \\
Schnabel $^{\mathrm{b}}$ & 191,433 & 146,278 & 268,473 \\
Schnabel $^{\mathrm{c}}$ & 183,364 & 146,204 & 268,338 \\
CAPTURE $\left(\mathrm{M}_{\mathrm{tb}}\right)^{\mathrm{b}}$ & 186,482 & 40,113 & 943,213 \\
Jolly-Seber & 213,213 & 5,081 & 464,215 \\
\hline
\end{tabular}

${ }^{\mathrm{a}}$ Not adjusted for recruitment.

${ }^{\mathrm{b}}$ Adjusted for recruitment.

${ }^{\mathrm{c}}$ Adjusted for 5\% tag loss and recruitment.

Table 5. Estimates of the size of the walleye spawning run in the Spokane River Arm, and $95 \%$ confidence intervals (95\% C.I.), calculated using various models.

\begin{tabular}{lccc} 
Model & $\mathbf{N}$ & Lower 95 \% C.I. & Upper 95 \% C.I. \\
\hline Schnabel & 15,222 & 12,018 & 19,855 \\
CAPTURE $\left(\mathrm{M}_{\mathrm{t}}\right)$ & 15,178 & 12,093 & 19,164 \\
Jolly-Seber & 27,345 & 1,535 & 57,519 \\
\hline
\end{tabular}

\section{Model Assumptions}

The Lake Roosevelt walleye population was determined to be "open" during the 1998 study, due to evidence of moralities (angler tag returns) and emigration (angler tag returns from British Columbia, Canada). The spawning run was determined to be open because fish were immigrating into and emigrating from the spawning area during the study period, according to recapture data.

EWU and STI biologists examined 193 recaptures in 1998, of which 7 had obvious tag scars, indicating a tag loss rate of $3.6 \%$. Because we could only see obvious tag scars, we estimated total tag loss at $5 \%$. Estimated abundance of walleye $( \pm 95 \%$ C.I.) calculated with the assumption of $5 \%$ tag loss was 183,364 (146,204 $\leq \mathrm{N} \leq$ 268,338) (Table 5). The walleye abundance estimate that was calculated with the data corrected for $5 \%$ tag loss was not significantly different than the estimate without the tag loss correction $(\alpha=0.05, \mathrm{z}=-0.13, \mathrm{p}>0.50)$. There was no evidence of tag loss during the spawning run. 
The CAPTURE program indicated that there were time and behavioral effects in the reservoir population, which caused differences in capture probabilities between the marked and unmarked groups of fish that varied with time. CAPTURE did not indicate differences in capture probability between individual fish. Approximately 1 out of 25 walleye captured by anglers had a tag compared to 1 out of 20 captured via electrofishing (Table 7). The recapture ratios of walleye marked and recaptured in 1998 did not differ significantly between electrofishing and angling $\left(\mathrm{X}^{2}=1.99,1\right.$ d.f, $\left.\mathrm{p}>0.10\right)$.

Pollock et al.'s (1990) Jolly-Seber Goodness of Fit Tests indicated that the Jolly-Seber estimate was valid $\left(X^{2}=0.90,1\right.$ d.f., $\left.p>0.10\right)$. However, due to low expected values, only the Goodness of Fit Test \#2 was calculated for the third sampling period.

Capture probabilities varied only with time during the spawning run estimate, according to the CAPTURE model selection procedure. The Jolly-Seber Goodness-of-Fit Tests (Pollock et al. 1990) suggested that the Jolly-Seber estimate for the size of the spawning run was valid $\left(\mathrm{X}^{2}=0.13,1\right.$ d.f., $\left.\mathrm{p} \geq 0.50\right)$. The only test calculated was the Goodness-of-Fit Test \#2 for the fourth sampling period, as a result of low expected values.

Table 6. Numbers and ratios of tagged and untagged walleye collected in Lake Roosevelt (1998) via angling and electrofishing.

\begin{tabular}{lccc}
\multicolumn{1}{c}{ Angler } & Number Tagged & Number Not Tagged & Ratio \\
\hline Kern & 1 & 14 & $1: 14$ \\
Hullett & 20 & 110 & $1: 5.5$ \\
Marshall & 2 & 29 & $1: 14.5$ \\
Resen & 1 & 25 & $1: 25$ \\
Mannick & 1 & 13 & $1: 13$ \\
Bough & 1 & 54 & $1: 54$ \\
GCWT & 28 & 699 & $1: 25$ \\
EWU Angling & 9 & 313 & $1: 35$ \\
\hline Total Angling & $\mathbf{6 3}$ & $\mathbf{1 , 2 5 7}$ \\
\hline EWU Electrofishing & $\mathbf{1 6 2}$ & $\mathbf{4 , 0 0 5}$ & $\mathbf{1 : 2 5}$ \\
\hline${ }^{\mathrm{a}}$ Governor's Cup Walleye Tournament, Kettle Falls, WA, June $20^{\text {th }}-21^{\text {st }}, 1998$. & \\
${ }^{b}$ Includes angling by EWU personnel and volunteers on August $3^{\text {rd }}, 6^{\text {th }}, 7^{\text {th }}, 12^{\text {th }}$ and $24^{\text {th }}, 1998$ \\
and the Spokane Arm Angling Days on April $1^{\text {st }}$, May $2^{\text {nd }}$, and May $30^{\text {th }}, 1998$.
\end{tabular}




\section{Movements}

During 1998, 382 walleye recapture events were reported with sufficient information to determine distances between previous release point and subsequent recapture location. Fifty-four recapture events were excluded from analysis, because they occurred within 7 days of the previous release (51 and 3 that were initially tagged in 1998 and 1997, respectively).

The walleye tagged in 1997 and recaptured in $1998(n=145)$ traveled a mean distance of $24.59 \mathrm{~km}(\mathrm{SD}=43.53)$ from their previous release location to their subsequent recapture location. The range of distances between previous release location and subsequent recapture location was 0 to $207.5 \mathrm{~km}$. Of those 145 recaptures, $26(17.93 \%)$ were more than $40 \mathrm{~km}, 10(6.90 \%)$ were between 26 and $40 \mathrm{~km}$, and $109(75.17 \%)$ were less than $25 \mathrm{~km}$, from their respective release points. The walleye that was recaptured $207.5 \mathrm{~km}$ from its release location, moved upstream from the mouth of the Sanpoil River to the Washington/Canada border between August 22, 1997 and August 26, 1998. Walleye tagged and recaptured in $1998(\mathrm{n}=182)$ moved a minimum of $22.75 \mathrm{~km}(\mathrm{SD}=$ 43.57) between their release and recapture locations. Distances between release and recapture locations ranged from $0 \mathrm{~km}$ to $252 \mathrm{~km}$. Of those 182 recaptures, $31(17.03 \%)$ were more than $40 \mathrm{~km}, 12(6.60 \%)$ were between 26 and $40 \mathrm{~km}$, and $139(76.37 \%)$ were less than $25 \mathrm{~km}$, from their respective release points. The walleye that was recaptured $252 \mathrm{~km}$ from its release location, moved from the spawning ground at Little Falls (upper Spokane River Arm) to Hugh Keenleyside Dam, British Columbia between April $29^{\text {th }}$, 1998 and September $14^{\text {th }}, 1998$.

There were 73 walleye tagged during the 1998 spawning run in the Spokane Arm that were recaptured following the run. The spawners were recaptured a mean distance of $34.52 \mathrm{~km}(\mathrm{SD}=55.20)$ from their release location, with a range of 0 to $252 \mathrm{~km}$. Walleye marked and recaptured following the spawning, were recaptured a mean distance of $20.46 \mathrm{~km}(\mathrm{SD}=37.35)$ from their release location. There were no walleye that had two recapture events included in the spawn versus post-spawn movement analysis.

When compared statistically, the minimum distances moved between release location and recapture location by spawning and post-spawning walleye were significantly different $(\alpha=0.05, \mathrm{t}=1.76, \mathrm{p} \leq 0.04)$. Walleye marked on the spawning run 
were recaptured significantly farther from their release location than those marked following the spawning run.

\section{Age, Growth, Mortality}

Walleye collected from Lake Roosevelt in 1998 ranged in age from 0 to 13

(Figure 2). The intercept of the body-scale regression line (a) was 25.03 (Figure 3). Back-calculated TL's (mm) at the formation of each annulus were estimated (Table 7). Mortality between year classes were calculated (Table 8). Mean instantaneous and mean annual mortality was estimated at $0.76 \%$ and $46 \%$, respectively, using a simple catchcurve (Figure 4).

\section{Condition}

The length-weight regression equation for Lake Roosevelt walleye was $\log _{10} \mathrm{WT}$ $=\log _{10} \mathrm{TL}-5.15\left(\mathrm{r}^{2}=0.98\right)($ Figure 5$)$. Mean $\mathrm{K}_{\mathrm{TL}}$ of 4,071 walleye measured and weighed was $0.82(\mathrm{SD}=0.17)($ Table 9$)$. 


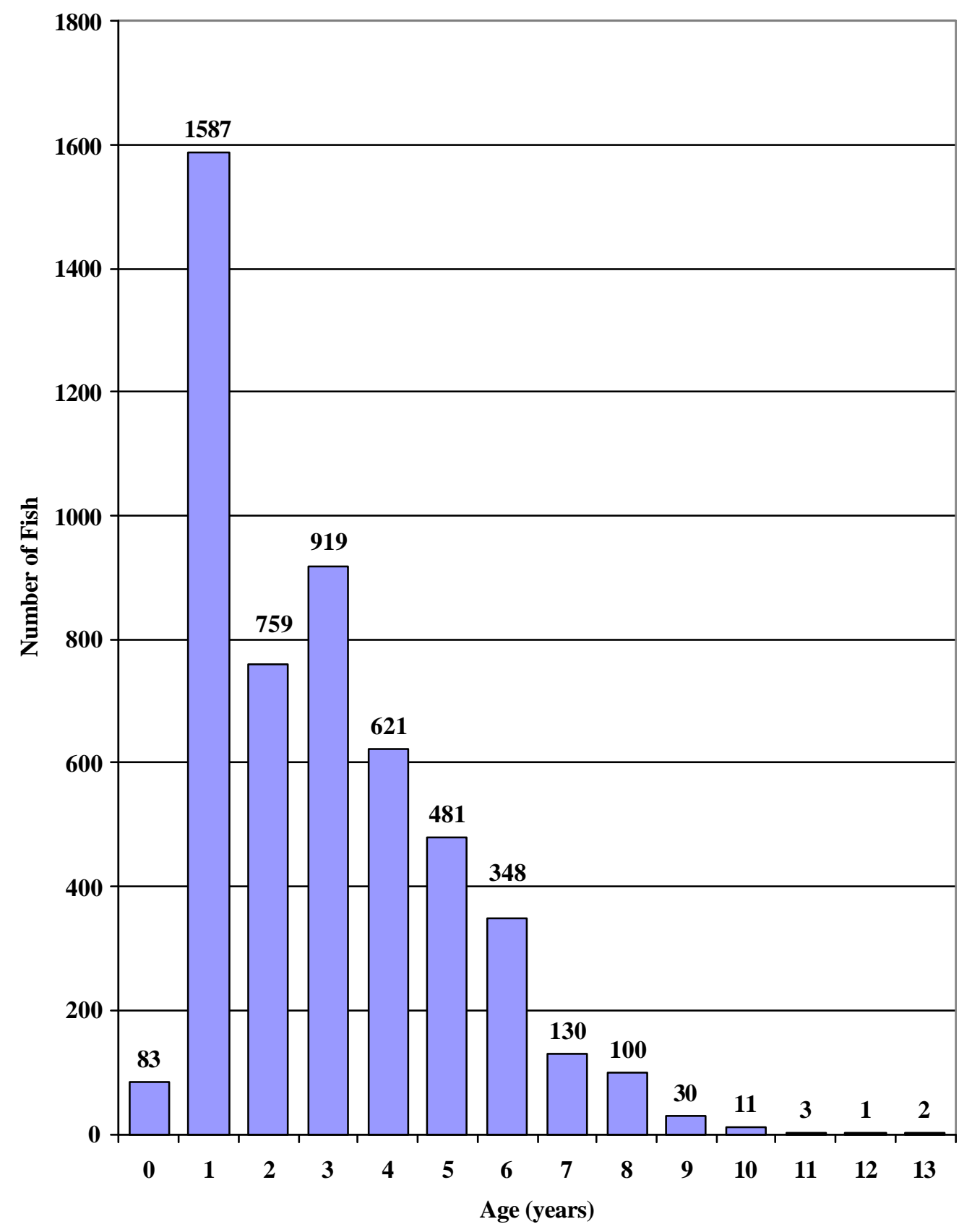

Figure 2. Age-frequency distribution of walleye collected in Lake Roosevelt during 1998. Ages of fish that did not have scales analyzed were estimated via an age-length key. 


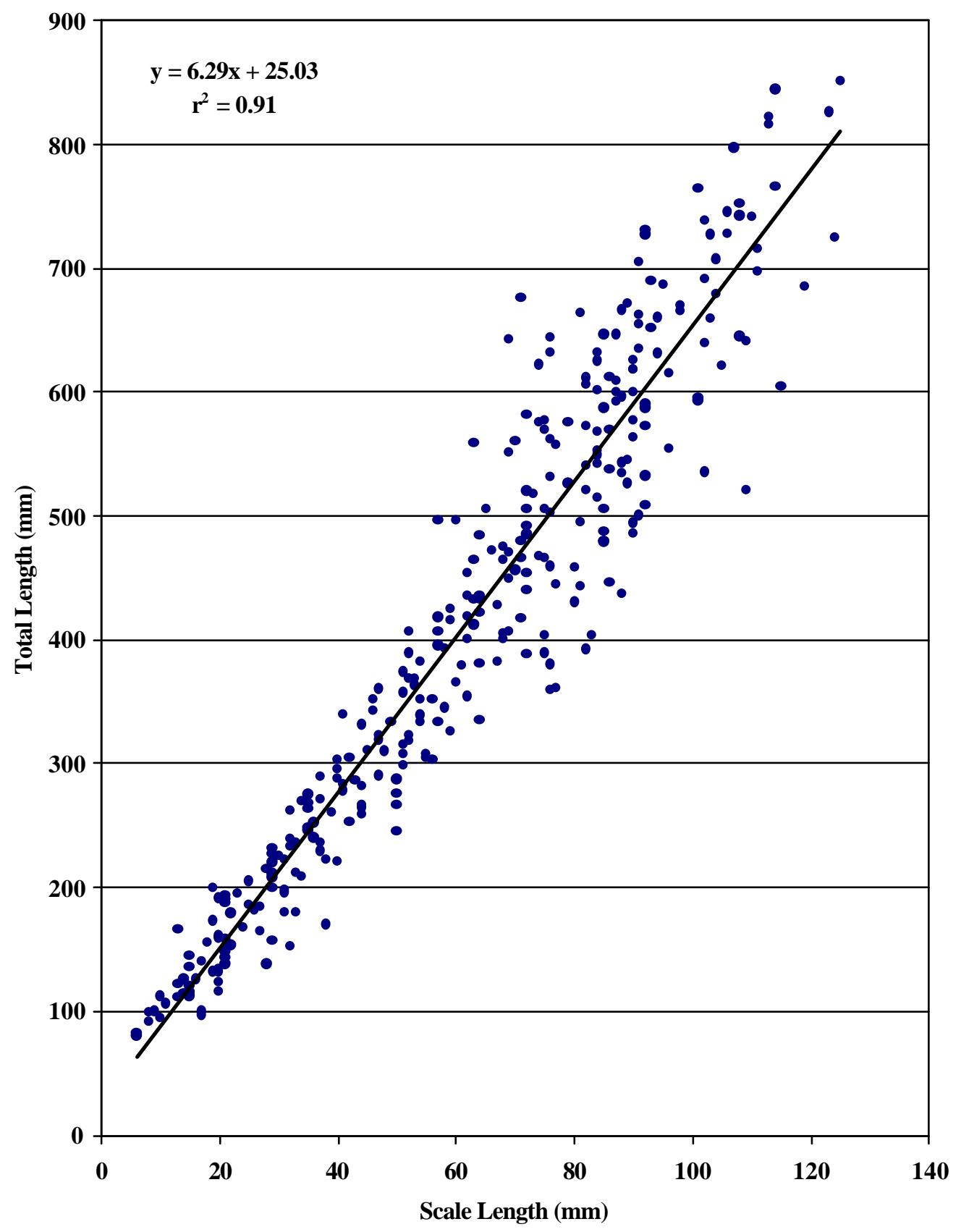

Figure 3. Body length-scale length regression line for Lake Roosevelt walleye collected and aged during 1998. 
Table 7. Mean back-calculated total lengths ( \pm standard deviation) at the formation of each annulus for walleye collected in Lake Roosevelt during 1998.

Mean Total Length (mm) at the Formation of Each Annulus

\begin{tabular}{|c|c|c|c|c|c|c|c|c|c|c|c|c|c|c|}
\hline Cohort & $\mathbf{n}$ & 1 & 2 & 3 & 4 & 5 & 6 & 7 & 8 & 9 & 10 & 11 & 12 & 13 \\
\hline 1997 & 71 & $155 ! 38$ & & & & & & & & & & & & \\
\hline 1996 & 31 & $157 ! 28$ & $274 ! 40$ & & & & & & & & & & & \\
\hline 1995 & 35 & $146 ! 19$ & $261 ! 32$ & $337 ! 30$ & & & & & & & & & & \\
\hline 1994 & 25 & $144 ! 20$ & $268 ! 35$ & $344 ! 39$ & $400 ! 37$ & & & & & & & & & \\
\hline 1993 & 24 & $171 ! 41$ & $279 ! 50$ & $353 ! 49$ & $411 ! 50$ & $454 ! 54$ & & & & & & & & \\
\hline 1992 & 33 & $166 ! 22$ & $287 ! 38$ & $368 ! 42$ & $428 ! 45$ & $476 ! 47$ & $516 ! 52$ & & & & & & & \\
\hline 1991 & 26 & $174 ! 27$ & $283 ! 39$ & $363 ! 51$ & $427 ! 54$ & $484 ! 48$ & $529 ! 49$ & $570 ! 47$ & & & & & & \\
\hline 1990 & 26 & $174 ! 21$ & $286 ! 38$ & $360 ! 45$ & $421 ! 48$ & $472 ! 53$ & $520 ! 54$ & $560 ! 55$ & $598 ! 51$ & & & & & \\
\hline 1989 & 10 & $174 ! 25$ & $291 ! 37$ & $360 ! 55$ & $424 ! 50$ & $481 ! 48$ & $525 ! 50$ & $567 ! 56$ & $600 ! 59$ & $632 ! 68$ & & & & \\
\hline 1988 & 13 & $181 ! 25$ & $273 ! 38$ & $353 ! 44$ & $433 ! 46$ & $489 ! 46$ & $547 ! 40$ & $596 ! 40$ & $640 ! 45$ & $681 ! 45$ & $715 ! 42$ & & & \\
\hline 1987 & 5 & $179 ! 21$ & $291 ! 23$ & $370 ! 40$ & $431 ! 47$ & $489 ! 61$ & $534 ! 62$ & $575 ! 62$ & $620 ! 73$ & $664 ! 72$ & $702 ! 73$ & $731 ! 67$ & & \\
\hline 1986 & 1 & 201 ! N/A & 307 ! N/A & 378 ! N/A & 434 ! N/A & 498 ! N/A & $540 !$ N/A & 589 ! N/A & $660 !$ N/A & 709 ! N/A & 751 ! N/A & $780 !$ N/A & 808 ! N/A & \\
\hline 1985 & 2 & $176 ! 2$ & $288 ! 21$ & $356 ! 17$ & $406 ! 22$ & $468 ! 28$ & $543 ! 15$ & $616 ! 25$ & $668 ! 25$ & $704 ! 12$ & $740 ! 26$ & $770 ! 31$ & $796 ! 31$ & $829 ! 22$ \\
\hline $\begin{array}{l}\text { Grand } \\
\text { Mean } \\
\end{array}$ & 320 & $162 ! 31$ & $277 ! 39$ & $355 ! 39$ & $420 ! 47$ & $475 ! 50$ & $526 ! 50$ & $572 ! 51$ & $613 ! 55$ & $665 ! 59$ & $716 ! 48$ & $746 ! 56$ & $800 ! 23$ & $829 ! 22$ \\
\hline \multicolumn{2}{|c|}{ Mean Annual } & 162 & 114 & 77 & 62 & 51 & 46 & 43 & 40 & 39 & 35 & 29 & 27 & 33 \\
\hline Growth & & & & & & & & & & & & & & \\
\hline
\end{tabular}


Table 8. Mean annual mortality rates for each age class of walleye collected in Lake Roosevelt during 1998. Number of fish per age class was estimated using and age-length key, developed via scale analysis.

\begin{tabular}{ccc} 
& \multicolumn{2}{c}{ Mortality Rate $(\boldsymbol{\%})$ in ... } \\
\cline { 2 - 3 } Age & $\mathbf{1 9 9 7}$ & $\mathbf{1 9 9 8}$ \\
\hline 1 to 2 & 30 & 52 \\
2 to 3 & 35 & -21 \\
3 to 4 & 54 & 32 \\
4 to 5 & 47 & 23 \\
5 to 6 & 66 & 28 \\
6 to 7 & 87 & 63 \\
7 to 8 & 67 & 23 \\
8 to 9 & & 70 \\
9 to 10 & & 63 \\
10 to 11 & & 73 \\
11 to 12 & & 67 \\
12 to 13 & & -100 \\
\hline
\end{tabular}

Table 9. Mean condition factors $\left(K_{T L}\right)$ of walleye collected in Lake Roosevelt in 1998. Mean $K_{T L}$ 's for each age class were calculated only from those fish that were measured and weighed.

\begin{tabular}{cccccc} 
Age & $\mathbf{n}$ & Mean $\mathbf{K}_{\mathbf{T L}}$ & $\begin{array}{c}\text { Standard } \\
\text { Deviation }\end{array}$ & Minimum & Maximum \\
\hline 0 & 17 & 0.91 & 0.29 & 0.59 & 1.87 \\
1 & 71 & 0.81 & 0.17 & 0.42 & 1.43 \\
2 & 30 & 0.77 & 0.08 & 0.65 & 0.98 \\
3 & 22 & 0.77 & 0.08 & 0.55 & 0.90 \\
4 & 18 & 0.78 & 0.09 & 0.69 & 1.08 \\
5 & 17 & 0.78 & 0.15 & 0.29 & 0.92 \\
6 & 31 & 0.85 & 0.11 & 0.67 & 1.11 \\
7 & 26 & 0.91 & 0.13 & 0.71 & 1.16 \\
8 & 26 & 0.96 & 0.14 & 0.72 & 1.25 \\
9 & 10 & 1.03 & 0.14 & 0.86 & 1.26 \\
10 & 13 & 1.15 & 0.22 & 0.73 & 1.56 \\
11 & 5 & 1.17 & 0.08 & 1.07 & 1.26 \\
12 & 1 & 1.28 & - & - & - \\
13 & 2 & 1.12 & 0.10 & 1.05 & 1.18 \\
\hline Total & $\mathbf{4 , 0 7 1}$ & $\mathbf{0 . 8 2}$ & $\mathbf{0 . 1 7}$ & $\mathbf{0 . 2 6}$ & $\mathbf{3 . 7 3}$ \\
\hline
\end{tabular}




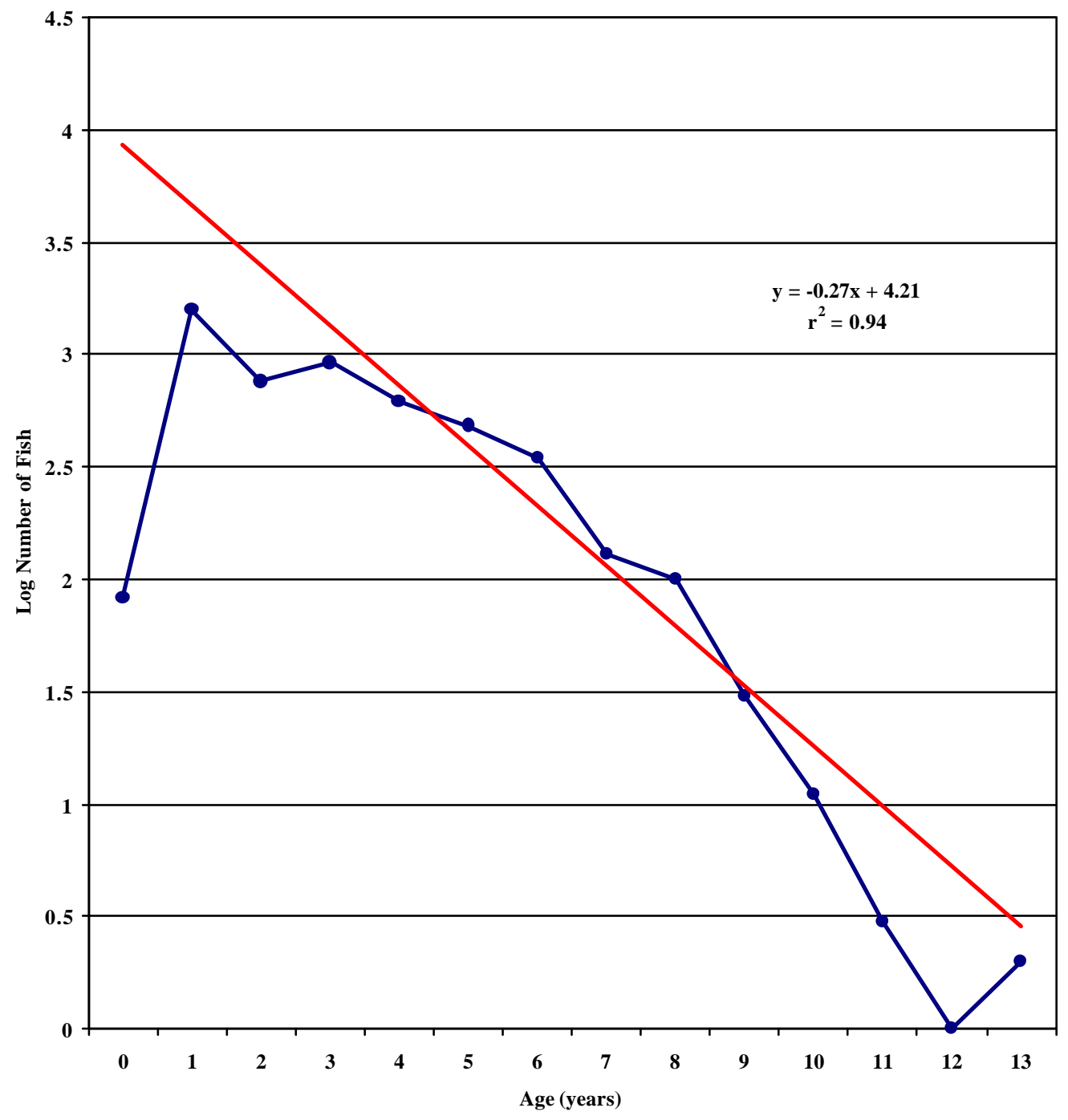

Figure 4. Simple catch-curve for walleye collected in Lake Roosevelt 1998. Ages were estimated via an age-length key. The regression line was calculated for the descending limb of the curve, excluding the peak age class and the age classes with fewer than 10 individuals. 


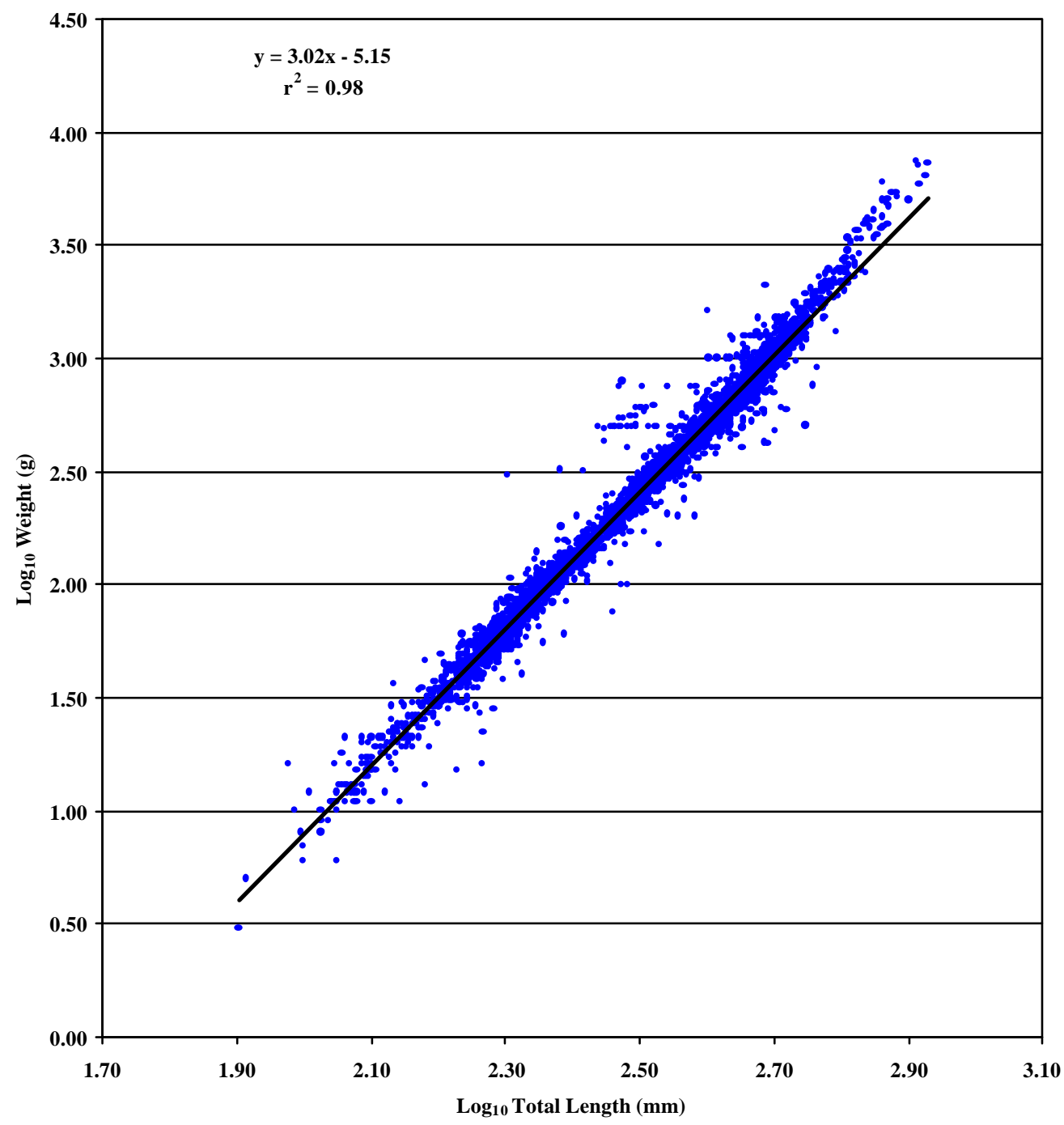

Figure 5. Length-weight regression for walleye collected in Lake Roosevelt, 1998. 


\section{Discussion}

\section{Fish Collection}

The 5.6\% recapture rate of walleye tagged and recaptured during the 1998 study was slightly higher than the 1.0, 3.7, 3.0 and $3.8 \%$ reported in $1988,1989,1990$, and 1997, respectively (Peone et al. 1990; Griffith and Scholz 1991; McLellan et al. 1998; McLellan 1998). The increased return rate may have been the result of increased angler awareness. However, the increase was most likely due to repeated sampling in the Spokane Arm during the spawning run. Return rates reported prior to 1997 were only from voluntary angler returns, unlike the 1997 and 1998 rates which included biologist recaptures. Anglers returned tags from 140 walleye marked in 1998, a return rate of 2.8 $\%$, which was within the range reported in the previous studies. EWU biologists marked and recaptured 82 walleye within the 48 day spawning run, which resulted in a higher total recapture rate.

The mean number of days between release and recapture of walleye tagged in 1998 (43 days) was similar to those reported in 1981 and 1982 (42 and 47 days, respectively), but higher than the mean reported in 1997 (28 days) (Beckman et al 1985; McLellan et al. 1998; McLellan 1998). The sampling protocol used in 1998 did not allow for repeated sampling of the same sites within short periods of time, as in the 1997 study, probably resulting in a longer mean time between recaptures.

\section{Abundance Estimates}

\section{Reservoir}

Of the four estimates of walleye abundance for the entire reservoir, the one calculated using the CAPTURE program's $\mathrm{M}_{\mathrm{tb}}$ model and the data corrected for recruitment was probably the most unbiased. The estimate provided by CAPTURE was the most accurate and unbiased, because the model accounts for unequal capture probabilities due to behavioral effects, which would have biased the other estimators (Otis et al. 1978; White et al. 1982). Both the Schnabel and Jolly-Seber models allow for 
time variation in capture probabilities, however, unequal capture probabilities due behavior would have biased their estimates either positively or negatively (Otis et al. 1978; Begon 1979; White et al. 1982; Pollock et al. 1990). Bias due to behavior during the current study was probably positive due to the low numbers of fish recaptured on more than one occasion, which indicated a possible avoidance to the collection methods. The estimate calculated with the Schnabel model $(191,433)$ was greater than the one generated using the CAPTURE $\mathrm{M}_{\mathrm{tb}}$ model $(186,482)$, suggesting overestimation due to unequal capture probabilities, which were probably the result of capture avoidance. Since the estimates generated by the closed models (beginning) and the Jolly-Seber model (end) were for different sampling periods, the differences between the estimates could not be attributed to bias from unequal capture probabilities due to behavior. However, the fact that there were unequal probabilities of capture due to behavior, it was concluded that the Jolly-Seber estimate was biased. Pollock et al. (1990) reported that the model selection procedure of CAPTURE was subject to error, especially when capture probabilities were low. Despite the suggested problems with the model selection procedure, there were no good alternatives to the procedure and no intuitive reasons to dispute the recommended model.

The primary shortcoming of the 1998 abundance estimate was low precision, indicated by the wide confidence interval. White et al. (1982) suggested that a coefficient of variation of $\mathrm{N}$ should not exceed $20 \%$ for reliable scientific studies and should be within the range of 20 to $50 \%$ for less exacting management studies, including long term monitoring. Studies producing coefficient of variation values above $50 \%$ can indicate only order-of-magnitude changes in population size (White et al. 1982). The walleye abundance estimate should have had a coefficient of variation (CV) of less than $20 \%$ for use in the kokanee bioenergetics model and a CV between 20 and $50 \%$ for the general management assessment of the population. However, the actual coefficient of variation was $98 \%$, indicating the estimate was not precise enough to meet any of the study objectives. The low precision of the estimate was probably the result of low capture probabilities $(0.011,0.010,0.005,0.001$, and 0.000). According to Hightower and Gilbert (1984), capture probabilities should be 0.04 to provide acceptable estimates for general management surveys, when survival was high. Greater sampling effort, or higher 
capture probabilities, would have been necessary if more precise estimates were needed or in the case of low mortality (Hightower and Gilbert 1984). Capture probabilities and precision could have been increased, by marking more fish during the study. However, EWU biologists conducted 1,090 electrofishing runs during the study period, so we believe increasing effort would be unrealistic due to time and monetary constraints. Considering the inability to realistically increase effort, we believe our estimate was the best estimate that could be calculated for the size of the Lake Roosevelt walleye population based on logistic constraints.

Further evidence that the estimated mean size of the Lake Roosevelt walleye population was accurate was the creel survey data collected by the LRMP. The creel survey data for 1997 and 1998 indicated an annual walleye harvest in the range of 87,515 to 119,346 fish (Cichosz et al. 1999; Cichosz et al. 1999b). Also, annual walleye harvest may have actually been lower than reported, because the LRMP uses total fishing pressure to estimate harvest, which could lead to an overestimation of harvest for individual species (Cichosz et al. 1997). It would be reasonable to assume that a walleye population of 186,482 fish ( $\geq 150 \mathrm{~mm}$ TL), with a spawning run of 27,345 fish, could support a sport fishery that harvests 100,000 fish a year. Spawning surveys indicated that approximately 321 million eggs were produced in the Spokane Arm and, using the most conservative survival estimates from the literature, 117,245 of those could reach sexual maturity. Our estimates of walleye abundance in the reservoir indicated the actual number of sexually mature walleye was approximately 117,245 , indicating the survival of YOY walleye in Lake Roosevelt was similar to the most conservative rates reported in the literature.

Walleye density in Lake Roosevelt (5.44 fish/acre) was higher than that in John Day Reservoir, Columbia River (1.98 fish/acre; Beamesderfer and Rieman 1991). The estimated size of the population based on the Beard et al. (1997) equation fell within the $95 \%$ C.I. for the reservoir estimate, but it was more than double the mean estimate. The differences in the estimates may have been due to the applicability of the equation for Lake Roosevelt. Beard et al.'s (1997) equation was developed on small Wisconsin lakes (all $\leq 5,100$ acres, except one 15,300 acre lake), so it may not be applicable to Lake Roosevelt, a large reservoir (82,720 acres). 
Despite the high CV values for the reservoir walleye abundance estimate, we suggest that it be used in the kokanee bioenergetics model. However, due to its shortcomings recommend the bioenergetics model be calculated using three different values for the walleye abundance; 186,482 (CAPTURE mean value), 450,364 (Beard et al.'s (1997) equation), and 943,213 (CAPTURE upper 95 \% C.I.). The lower $95 \%$ C.I. should be excluded, because it was unrealistically low according to the harvest estimates.

A statistical comparison of the Schnabel estimates calculated for data not corrected for recruitment and data corrected for recruitment indicated no significant difference. The data supported the 1997 study results that suggested that recruitment of walleye to a taggable size $(150 \mathrm{~mm})$ was negligible prior to September 1 in Lake Roosevelt (McLellan et al. 1998; McLellan 1998).

\section{Spawning Run}

The most unbiased estimate of the size of the walleye spawning run was most likely the one generated with the Jolly-Seber model. We believe the Jolly-Seber estimate was the most accurate, because the spawning run was open and neither immigration nor emigration could be accounted for. The CAPTURE model selection procedure suggested that the sole cause of variable capture probabilities was due to time effects, which does not bias the Jolly-Seber estimator (White et al. 1982). The CV of the spawning run estimate indicated that it was not adequate for general management studies. However, the $\mathrm{CV}$ was close to an acceptable value, indicating a slight increase in effort could provide a reasonably precise estimate for the size of the spawning run.

\section{Model Assumptions}

The assumptions of the models were tested or relaxed, in order to provide the most unbiased estimates possible. The closure assumption was relaxed for the estimates of walleye abundance for the entire reservoir by correcting the data to account for recruitment to a taggable size, in some cases, and assuming no immigration based on past data. In the case of no additions to the population, assuming mortality and emigration rates were equal for both the marked and unmarked aspects of the population, only the 
timing of the estimate was affected (White et al. 1982). The estimate was for the size of the population at the beginning of the study.

Tag loss was assumed to be negligible in all estimates. The $3.6 \%$ tag loss rate observed during the 1998 study, was most likely the result of long-term tag loss by fish tagged in 1997, due to no evidence of short-term tag loss during the 1997 study (McLellan et al. 1998; McLellan 1998). When estimates of abundance, calculated with the Schnabel model, assuming 0 and $5 \%$ tag loss were compared, there was no significant difference. The occurrence of tag loss would have resulted in an overestimation of walleye abundance when using the closed estimators, such as a CAPTURE model or the Schnabel model (Begon 1979); however, tag loss was not significant during this project. Arnason and Mills (1981) demonstrated that low levels of tag loss $(\leq 20 \%)$ had no effect on estimates of fish abundance calculated with the full Jolly-Seber model, except that precision may have been reduced.

CAPTURE's model selection procedure indicated unequal probabilities of capture due to time effects and behavioral effects for the whole reservoir population size estimate, which indicates the violation of the assumption equal catchability of all animals. However, CAPTURE provided the estimator $\mathrm{M}_{\mathrm{tb}}$ that accounted for the differences in capture probabilities (Otis et al. 1978; White et al. 1982). The result of the comparison of angling and electrofishing recapture ratios was that there was no significant difference, indicating that both the pelagic and littoral aspects of the walleye population in Lake Roosevelt were sampled during the project. Since the recapture ratios for pelagic versus littoral sampling were not significantly different, we can conclude that the reservoir abundance estimate was truly for the entire walleye population. According to the CAPTURE tests there was no unequal probability of capture for spawning walleye, except due to time, which indicated the Jolly-Seber model (robust to changes in capture probability over time) was not biased due to heterogeneous capture probabilities.

Pollock et al.'s (1990) Jolly-Seber Goodness of Fit Test indicated that the data for the whole reservoir abundance estimate met all the assumptions of the model and that our estimate was valid. However, due to low expected values and low capture probabilities the test was not considered reliable. The Goodness-of-Fit Tests indicated the Jolly-Seber 
model was valid, but little value was placed on the test results due to the low expected values.

\section{Movements}

Walleye marked and recaptured in 1998 appeared to move farther between previous release and subsequent recapture locations than walleye tagged and recaptured in 1997. The mean distance between previous release and subsequent recapture locations was $22.75 \mathrm{~km}$ in 1998 compared to $4.7 \mathrm{~km}$ in 1997 . The increase in distances traveled in 1998 was probably due to marking of large numbers of walleye on the spawning run, many of which migrated long distances from the spawning area. During the 1997 study, when only 13 walleye were tagged on the spawning run, $116(90 \%)$ of recaptures were within $9.5 \mathrm{~km}$ of release, while 43 (23.09\%) fish tagged in 1998 had moved more than $25 \mathrm{~km}$. Only two walleye were recaptured more than $35 \mathrm{~km}$ from their previous release location in 1997, and the maximum distance was $121 \mathrm{~km}$. During the 1998 project, 31 walleye were recaptured more than $40 \mathrm{~km}$ from their previous release location, including 10 that were more than $121 \mathrm{~km}$ from their previous release location, with a maximum of $252 \mathrm{~km}$.

Previous walleye tagging studies on Lake Roosevelt collectively indicated that walleye migrated long distances in the early spring to the only known walleye spawning area, in the upper reaches of the Spokane River Arm. Following spawning, which peaked in late April and early May, walleye rapidly dispersed throughout the reservoir, with the majority moving north, and established summer home ranges (SHR) (Nigro et al. 1982; Beckman et al. 1985; Hall et al. 1985; Peone et al. 1990; Griffith and Scholz 1991; Hildebrand et al. 1991; Hildebrand, R.L.\&L. Environmental Services, personal communication, 1998; McLellan et al. 1998; McLellan 1998).

Walleye tagged on the spawning run, in 1998, traveled significantly farther than walleye tagged following the spawning run, which supported the idea that the majority of walleye movement was associated with the spawning run and that following dispersal from the spawning they establish SHR's and move little. The mean distance moved between release and recapture by walleye marked following the spawning run $(20.46 \mathrm{~km})$ was within the 0 to $25 \mathrm{~km}$ range of a SHR (Hall et al. 1985). The high proportion of 
walleye recaptured within $25 \mathrm{~km}$ of release in 1998 (75.17\%), also supported the idea that walleye establish SHR's. Beamesderfer and Rieman (1988) indicated that walleye movements declined after June in John Day Reservoir, Columbia River.

\section{Age, Growth, and Mortality}

McLellan et al. (1998) and McLellan (1998) reported that there were fewer age classes and old walleye were less abundant in Lake Roosevelt in 1997, when compared to USFWS data from 1980 to 1983, and warned that the age structure may be an indication of an impending population collapse. However, when the 1998 age data was compared to the 1980-83 USFWS study, the same age classes were represented and there were relatively similar numbers of old walleye (Figure 6). The main reason for the absence of the older year classes and low numbers of old walleye in 1997 was probably due to the inability to effectively sample the spawning run, as suggested by McLellan et al. (1998) and McLellan (1998). The spawning run was effectively sampled in the 1998 and 198083 projects and they both had similar age distributions. The data collected in 1998 indicated the walleye population was stable and the concerns about the age structure that were addressed in 1997 were not warranted.

The $25.03 \mathrm{~mm}$ intercept of the body scale regression line was lower than the 56.7 mm intercept reported for Lake Roosevelt walleye in 1997 (McLellan et al. 1998; McLellan 1998) and the standard intercept of $55.0 \mathrm{~mm}$, recommended by Carlander (1997). However, the intercept fell within the range of intercepts $(6.0$ to $83.0 \mathrm{~mm})$ reported by Carlander (1997). The differences in the intercepts calculated for Lake Roosevelt walleye was likely due to the methods by which they were calculated. In 1997, scales were analyzed from 2,614 walleye of which the majority were young and small, possibly biasing the intercept toward values for small fish (McLellan et al. 1998; McLellan 1998). The intercept was calculated in 1998, using relatively equal numbers of samples from every length class, by using scale lengths from no more than five individuals per $1 \mathrm{~cm}$ length class. The 1998 intercept value was the probably the most accurate due to equal weighting of the scale length and body length relationship for all sizes of fish. 


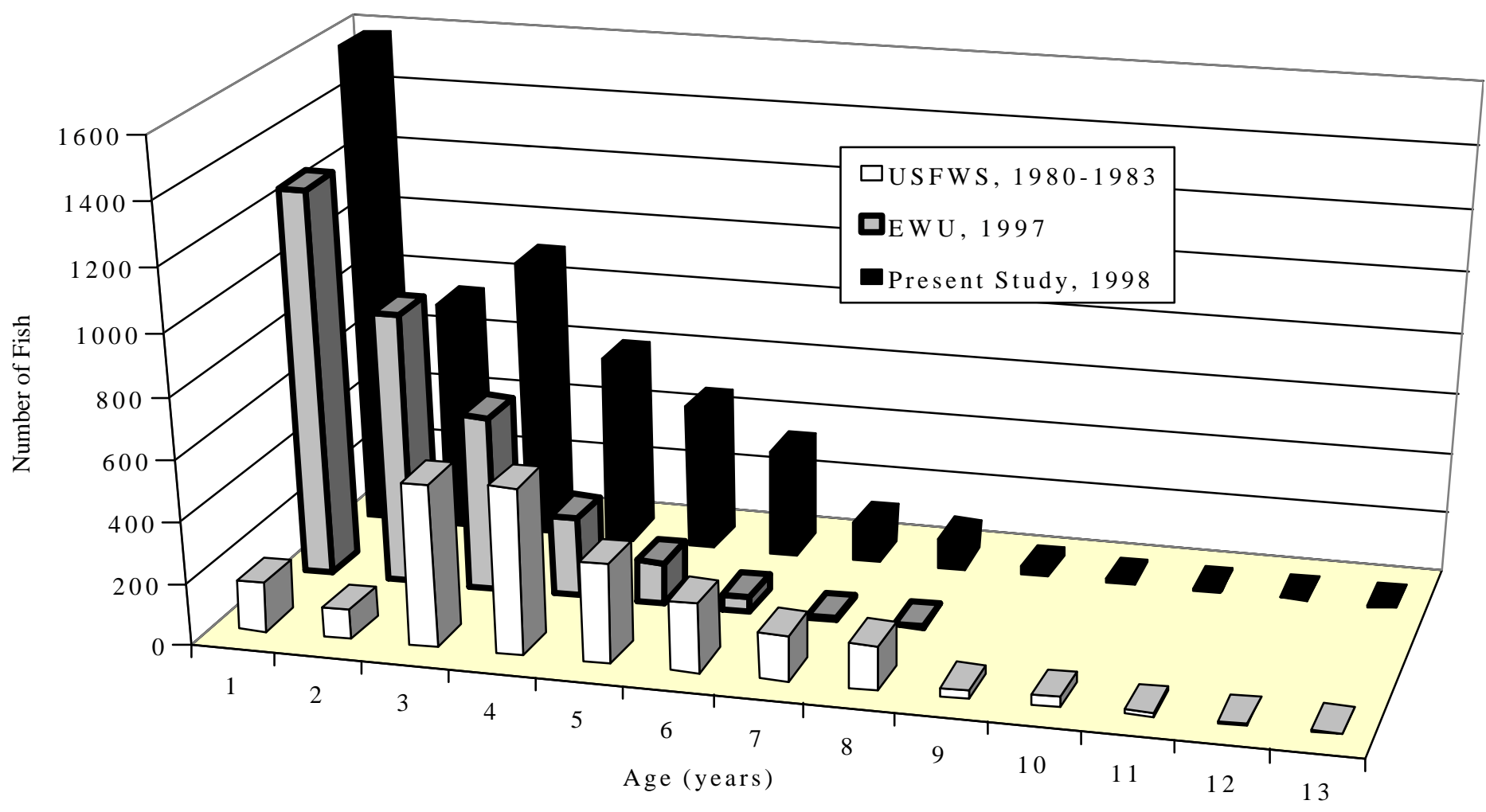

Figure 6. Comparison of age-frequency distributions of walleye collected on Lake Roosevelt in 1980-83, 1997, and 1998, by USFWS and EWU, respectively. 
Growth of Lake Roosevelt walleye, estimated by back-calculation, was average when compared to the mean total lengths at the formation of each annulus of walleye from 16 lakes and rivers in the United States and Canada (Peone et al. 1990) (Table 10). Back-calculated total lengths at the formation of each annulus for walleye with scales analyzed in 1998 were roughly the same as those reported for 1997, except that first year growth had decreased by $10 \mathrm{~mm}$ and growth had decreased after age 6, in 1998 (Table 7).

The mean annual mortality rate of Lake Roosevelt walleye calculated in 1998 was similar to the estimated mean annual mortality in 1997 and was average when compared to other walleye producing waters (Table 11). Mean annual mortality rates between age classes of walleye collected in Lake Roosevelt in 1998 were different than those in 1997 (Table 8). There were some negative values for mortality rates in 1998 (Table 8), indicating we did not meet the assumptions of equal selectivity to sampling, equal numbers born in each cohort, or equal mortality between each age class for each cohort.

\section{Condition}

Mean $\mathrm{K}_{\mathrm{TL}}$ (0.82) in 1998 was similar to the mean for Lake Roosevelt walleye reported in 1997 (0.81) (McLellan et al. 1998, McLellan 1998), indicating stable growth.

The length-weight regression equation, calculated in 1998, was similar to the equations calculated for Lake Roosevelt walleye in 1997 and 1980-83.

\section{Conclusions}

We believe that the Lake Roosevelt walleye population consisted of approximately 186,000 individuals, as of the spring of 1998 and that approximately 27,000 members of the population spawned in the Spokane River Arm. The estimates provided had low precision due to low capture probabilities, however they appeared to be reasonable when compared to creel harvest estimates. We believe we have provided the most accurate and reasonable estimates that could be provided without a large increase in effort and money or developing new sampling techniques that are more effective. 
Table 10. Comparison of mean back-calculated total lengths $(\mathrm{mm})$ at annulus formation between an average from 16 lakes and rivers in the United States and British Columbia and Lake Roosevelt, Washington.

\begin{tabular}{|c|c|c|c|c|c|c|c|c|c|c|c|c|c|c|c|}
\hline \multirow[b]{2}{*}{ Location } & \multirow[b]{2}{*}{$\mathbf{n}$} & \multicolumn{13}{|c|}{ Mean Total Length (mm) at Annulus Formation } & \multirow[b]{2}{*}{ Reference } \\
\hline & & 1 & 2 & 3 & 4 & 5 & 6 & 7 & 8 & 9 & 10 & 11 & 12 & 13 & \\
\hline Average & & 177 & 280 & 368 & 431 & 483 & 530 & 554 & 548 & 675 & 675 & 728 & & & Peone et al. (1990) \\
\hline L. Roosevelt, 1980-83 & 3248 & 189 & 307 & 385 & 450 & 515 & 569 & 629 & 668 & 702 & 742 & 740 & 761 & 780 & Beckman et al. (1985) \\
\hline L. Roosevelt, 1988 & 369 & 204 & 273 & 348 & 410 & 470 & 532 & 590 & 635 & 688 & 689 & & & & Peone et al. (1990) \\
\hline L. Roosevelt, 1989 & 467 & 210 & 282 & 351 & 418 & 493 & 571 & 603 & & & & & & & Peone et al. (1990) \\
\hline L. Roosevelt, 1990 & 311 & 184 & 295 & 380 & 439 & 511 & 597 & 651 & 698 & 734 & & & & & Griffith and Scholz (1990) \\
\hline L. Roosevelt, 1997 & 2,614 & 173 & 279 & 363 & 425 & 478 & 535 & 618 & 662 & & & & & & McLellan et al. (1997) \\
\hline L. Roosevelt, 1998 & 320 & 162 & 277 & 355 & 420 & 475 & 526 & 572 & 613 & 665 & 716 & 746 & 800 & 829 & Present study \\
\hline
\end{tabular}


Table 11. Comparison of mean annual mortality rates (\%) between Lake Roosevelt and other walleye producing waters.

\begin{tabular}{lcc}
\multicolumn{1}{c}{ Location } & $\begin{array}{c}\text { Mean Annual } \\
\text { Mortality (\%) }\end{array}$ & Source \\
\hline 20 NW Wisconsin Lakes & 47 & Klingbiel (1986) $^{\mathbf{a}}$ \\
32 N. Cent. Wisconsin Lakes & 48 & Klingbiel (1986) $^{\mathbf{a}}$ \\
Leech Lake, MN & 37 & Schupp (1972) \\
Boyd Lake, CO & 48 & Weber (1976) \\
Lake of Woods, MN, 1980-84 & 65 & Payer et al. (1987) \\
W. Blue Lake, Ontario & 80 & Kelso and Ward (1977) \\
Manistee Lake, MI (ages 3 to 7) & 56 & Laarman (1981) $^{\mathbf{a}}$ \\
Lake Oneida, NY, 1960-74 & 34 & Forney (1977) \\
Lake Roosevelt, 1980-83 & 52 & Beckman et al. (1985) \\
Lake Roosevelt, 1997 & 48 & McLellan et al. (1998) \\
\hline Lake Roosevelt, 1998 & $\mathbf{4 6}$ & Present study \\
\hline a Cited in Carlander (1997). & &
\end{tabular}

For the most part, walleye moved little, except when migrating to and dispersing from the spawning area. Dispersal data indicated some walleye make long distance post spawning movements throughout the reservoir before establishing a SHR.

Walleye age, growth, mortality, and condition data indicated that the walleye population was average when compared to other walleye producing waters and relatively stable when compared to previous Lake Roosevelt studies.

Our data indicated there is no need for changes in the management of the Lake Roosevelt walleye population at this time. 


\section{Literature Cited}

Anderson, R.O. and R.M. Neuman. 1996. Length, weight, and associated structural indices. Pages 447-482 in B.R. Murphy and D.W. Willis, editors. Fisheries techniques, $2^{\text {nd }}$ edition. American Fisheries Society, Bethesda, Maryland.

Arnason, A.N. and K.H. Mills. 1981. Bias and loss of precision due to tag loss in JollySeber estimates for mark-recapture experiments. Canadian Journal of Fisheries and Aquatic Sciences 38:1077-1095.

Beckman, L.G., J.F. Novotny, W.R. Persons, and T.T. Terrell. 1985. Assessment of the fisheries and limnology in Lake F.D. Roosevelt 1980-1983. U.S. Fish and Wildlife Service. Final Report to U.S. Bureau of Reclamation. Contract No. WPRS-0-07-10-X0216; FWS-14-06-009-904, May 1985.

Begon, M. 1979. Investigating animal abundance: capture-recapture for biologists. University Park Press, Baltimore, Maryland.

Beamesderfer, R.C. and B.E. Rieman. 1988. Predation by resident fish on juvenile salmonids in a mainstem Columbia River reservoir: estimated abundance and distribution of northern squawfish, walleye, and smallmouth bass. Pages 211-248 in T.P. Poe and B.E. Rieman, editors. Predation by resident fish on juvenile salmonids in John Day Reservoir, 1983-86. Final Report to Bonneville Power Administration, Portland, OR. Contracts DE-AI79-82BP34796 and DE-AI7982BP35097.

Beamesderfer, R.C. and B.E. Rieman. 1991.Abundance and distribution of northern squawfish, walleye, and smallmouth bass in John Day Reservoir, Columbia River. Transactions of the American Fisheries Society 120:439-447.

Beard, T.D., Jr., S.W. Hewett, Q. Yang, R.M. King, and S.J. Gilbert. 1997. Prediction of angler catch rates based on walleye population density. North American Journal of Fisheries Management 17:621-627.

Carlander, K.D. 1997. Handbook of freshwater fishery biology. Volume 3. Iowa State University Press, Ames, Iowa.

Chapman, D.G. and W.S. Overton. 1966. Estimating and testing differences between population levels by the Schnabel estimation method. Journal of Wildlife Management 30:173-180.

Cichosz, T.A., J.P. Shields, and K.D. Underwood. 1997. Lake Roosevelt monitoring/data collection program, 1996 annual report. Pages 1-262 in T.A. Cichosz, J.P. Shields, K.D. Underwood, A. Scholz, and M.B. Tilson. Lake 
Roosevelt fisheries and limnological research, 1996 annual report. Bonneville Power Administration, Portland, Oregon. Project No. 94-043.

Cichosz, T.A., J.P. Shields, and K.D. Underwood. 1999a. Lake Roosevelt monitoring/data collection program. 1997 annual report. Submitted to Bonneville Power Administration, Portland, Oregon.

Cichosz, T.A., J.P. Shields, and K.D. Underwood. 1999b. Lake Roosevelt monitoring/data collection program. 1998 annual report. In preparation. To be submitted to Bonneville Power Administration, Portland, Oregon.

Devries, D.R. and R.V. Frie. 1996. Determination of age and growth. Pages 483-512 in B.R. Murphy and D.W. Willis, editors. Fisheries techniques, $2^{\text {nd }}$ edition. American Fisheries Society, Bethesda, Maryland.

Forney, J.L. 1976. Year-class formation in the walleye (Stizostedion vitreum vitreum) population of Oneida Lake, New York, 1966-73. Journal of the Fisheries Research Board of Canada 33:783-792.

Griffith, J.R. and A.T. Scholz. 1990. Lake Roosevelt fisheries monitoring program, 1990 annual report. Bonneville Power Administration, Portland, Oregon. Project No. 88-63.

Guy, C.S., H.L. Blankenship, and L.A. Nielsen. 1996. Tagging and marking. Pages 353383 in Murphy, B. R. and D.W. Willis, editors. Fisheries techniques, $2^{\text {nd }}$ edition. American Fisheries Society, Bethesda, Maryland.

Hall, J.A., W.R. Persons, and L.G. Beckman. 1985. Post-spawning movement and summer distribution of walleye in Lake Franklin D. Roosevelt, Washington. Appendix 30-1 in L.G. Beckman, J.F. Novotny, W.R. Persons, and T.T. Terrell. Assessment of the fisheries and limnology in Lake F.D. Roosevelt 1980-1983. U.S. Fish and Wildlife Service. Final Report to U.S. Bureau of Reclamation. Contract No. WPRS-0-07-10-X0216; FWS-14-06-009-904, May 1985.

Hightower, J.E. and R.J. Gilbert. 1984. Using the Jolly-Seber model to estimate population size, mortality, and recruitment for a reservoir fish population. Transactions of the American Fisheries Society 113:633-641.

Hildebrand, L. and English, K. 1991. Lower Columbia River fisheries inventory. 1990 studies. Volume I - Main Report. Report prepared for B.C. Hydro, Environmental Resources Division, Vancouver, B.C. by R.L. \& L. Environmental Services Ltd., Edmonton, Alberta in association with LGL Ltd., Sydney, B.C.

Hildebrand, L. 1998. Personal communication. Senior fisheries biologist, R.L. and L. Environmental Services Ltd., Edmonton, Alberta. 
Johnson, R.A. and G.K. Bhattacharyya. 1996. Statistics: principles and methods. Third edition. John Wiley and Sons, Inc., New York.

McLellan, J.G. 1998. Assessment of walleye (Stizostedion vitreum vitreum) abundance, movements, and growth in Lake Roosevelt, Washington. MS Thesis. Eastern Washington University, Department of Biology, Cheney, WA.

McLellan, J.G., A.T. Scholz, H.J. Moffatt, and B.J. Tucker. 1998. Walleye (Stizostedion vitreum vitreum) population dynamics in Lake Roosevelt, Washington, 1997. 1997 Annual Report. Unpublished report submitted to the Lake Roosevelt Monitoring Program, Spokane Tribe of Indians, Wellpinit, WA.

Nigro, A.A., T.T. Terrell, and L.G. Beckman. 1982. Assessment of the limnology and fisheries in Lake F.D. Roosevelt, 1981 annual report. U.S. Fish and Wildlife Service. Report to U.S. Bureau of Reclamation. Contract No. WPRS-0-07-10X0216; FWS-14-06-009-904.

Northwest Power Planning Council. 1987. Columbia River Basin Fish and Wildlife Program. Section 900 Resident Fish. Northwest Power Planning Council, Portland, OR. Pages 125-126.

Otis, D.L., K.P. Burnham, G.C. White, and D.R. Anderson. 1978. Statistical inference from capture data on closed animal populations. Wildlife Monographs, No. 62.

Peone, T., A.T. Scholz, J.R. Griffith, S. Graves, and M.G. Thatcher. 1990. Lake Roosevelt Fisheries Monitoring Program. Annual Report, 1988-89. Bonneville Power Administration, Portland, Oregon.

Pollock, K.H., J.D. Nichols, C. Brownie, and J.E. Hines. 1990. Statistical inference for capture-recapture experiments. Wildlife Monographs, No. 107.

Ricker, W.E. 1975. Computation and interpretation of biological statistics of fish populations. Fisheries Research Board of Canada, Bulletin 191.

Seber, G.A.F. 1982. The estimation of animal abundance and related parameters. Charles Griffin and Company, Ltd. London.

Underwood, K.D. 1998. Personal communication, Lake Roosevelt Monitoring Program, Spokane Tribe of Indians, Wellpinit, Washington.

Washington Department of Fish and Wildlife. 1995. Walleyes in Washington. Special Report FM 95-2. Olympia, WA.

White, G.C., D.R. Anderson, K.P. Burnham, D.L. Otis. 1982. Capture-recapture and removal methods for sampling closed populations. Los Alamos National Laboratory, Los Alamos, NM. LA-8787-NERP. 


\section{Appendices}




\section{Appendix A.}

Table A1. Recaptures of Lake Roosevelt walleye during 1998. Multiple recaptures are in bold. Section numbers correspond to Figure 1.

\begin{tabular}{|c|c|c|c|c|c|c|c|c|c|c|}
\hline \multirow[b]{2}{*}{ Tag \#/color } & \multicolumn{5}{|c|}{ Original Capture Data } & \multicolumn{5}{|c|}{ Recapture Data } \\
\hline & Date & Section & TL (mm) & WT (g) & Crew & Date & Section & TL (mm) & WT (g) & Crew \\
\hline OR 46005 & $5 / 8 / 98$ & $\mathrm{H}$ & 444 & 850 & STOI & $6 / 2 / 98$ & S 1 & 511 & & ANG \\
\hline OR 46110 & $8 / 20 / 97$ & $\mathbf{H}$ & 240 & 143 & STOI & $7 / 27 / 98$ & S 1 & NL & & ANG \\
\hline OR 46110 & $8 / 20 / 97$ & $\mathbf{H}$ & 240 & 143 & STOI & $5 / 23 / 98$ & $\mathbf{H}$ & 283 & 196 & EWU \\
\hline OR 46129 & $8 / 21 / 97$ & 2 & 233 & 101 & EWU & $6 / 27 / 98$ & $\mathrm{H}$ & 343 & & ANG \\
\hline OR 46140 & $8 / 22 / 97$ & $\mathrm{SP}$ & 257 & 148 & STOI & $7 / 27 / 98$ & S 1 & NL & & ANG \\
\hline OR 46203 & $8 / 7 / 97$ & 6 & 208 & 75 & EWU & $8 / 13 / 98$ & 5 & 305 & & ANG \\
\hline OR 46212 & $8 / 9 / 97$ & 8 & 394 & 610 & STOI & $6 / 20 / 98$ & 8 & 417 & & KFWT98 \\
\hline OR 46220 & $8 / 10 / 97$ & 7 & 297 & 213 & STOI & $6 / 13 / 98$ & 7 & NL & 681 & ANG \\
\hline OR 46223 & $8 / 10 / 97$ & 7 & 289 & 181 & STOI & $7 / 8 / 98$ & 7 & 346 & 400 & STOI \\
\hline OR 46308 & $6 / 26 / 97$ & 8 & 351 & 308 & STOI & $6 / 20 / 98$ & 10 & 381 & & ANG \\
\hline OR 46310 & $8 / 26 / 97$ & 8 & 315 & 260 & STOI & $6 / 20 / 98$ & 9 & 403 & & KFWT98 \\
\hline OR 46325 & $6 / 26 / 97$ & 8 & 513 & 1120 & STOI & $6 / 22 / 98$ & 8 & 533 & & ANG \\
\hline OR 46377 & $8 / 7 / 97$ & 6 & 219 & 84 & STOI & $9 / 2 / 98$ & 6 & 357 & 371 & EWU \\
\hline OR 46703 & $8 / 22 / 97$ & SP & 282 & 178 & STOI & $4 / 4 / 98$ & S 1 & 332 & 620 & SRAD1 \\
\hline OR 46706 & $8 / 22 / 97$ & $\mathrm{SP}$ & 362 & 410 & EWU & $8 / 26 / 98$ & $\mathrm{BC}$ & 432 & & ANG \\
\hline OR 46786 & $7 / 21 / 98$ & S 2 & 237 & 125 & STOI & $9 / 1 / 98$ & S 1 & NL & & ANG \\
\hline OR 46916 & $8 / 6 / 97$ & S 2 & 234 & 90 & STOI & $9 / 12 / 98$ & 6 & 394 & & ANG \\
\hline OR 46928 & $8 / 6 / 97$ & S 2 & 258 & 144 & STOI & $8 / 15 / 98$ & S 1 & 381 & 681 & ANG \\
\hline OR 48002 & $5 / 30 / 98$ & S 2 & 334 & 500 & EWU & $7 / 16 / 98$ & S 1 & NL & & ANG \\
\hline OR 48015 & $5 / 30 / 98$ & S 1 & 382 & 300 & EWU & $6 / 15 / 98$ & S 1 & 330 & & ANG \\
\hline OR 48021 & $5 / 30 / 98$ & S 1 & 382 & 200 & EWU & $7 / 16 / 98$ & S 1 & NL & & ANG \\
\hline OR 48186 & 7/9/98 & 4 & 219 & 84 & EWU & $8 / 12 / 98$ & 4 & 251 & 116 & EWU \\
\hline OR 48199 & $7 / 13 / 98$ & S 2 & 213 & 78 & EWU & Unknown & Spokane Arm & NL & & ANG \\
\hline OR 48244 & $7 / 16 / 98$ & 4 & 213 & 74 & EWU & $8 / 12 / 98$ & S 1 & 236 & & EWU \\
\hline OR 48383 & 7/7/98 & K & 382 & 514 & EWU & $8 / 6 / 98$ & K & 381 & & ANG \\
\hline OR 48407 & $6 / 30 / 98$ & $\mathrm{SP}$ & 393 & 540 & EWU & $8 / 26 / 98$ & $\mathrm{SP}$ & 440 & 773 & EWU \\
\hline OR 48452 & $6 / 30 / 98$ & $\mathrm{SP}$ & 207 & 75 & EWU & $7 / 22 / 98$ & $\mathrm{SP}$ & 220 & 75 & EWU \\
\hline OR 48459 & $6 / 30 / 98$ & $\mathrm{SP}$ & 196 & 65 & EWU & $7 / 22 / 98$ & $\mathrm{SP}$ & 225 & 85 & EWU \\
\hline OR 48521 & $6 / 21 / 98$ & 9 & 377 & & KFWT98 & $9 / 2 / 98$ & $\mathrm{BC}$ & NL & & ANG \\
\hline OR 48560 & $6 / 25 / 98$ & $\mathrm{H}$ & 226 & 99 & EWU & $7 / 20 / 98$ & $\mathrm{H}$ & 253 & 142 & EWU \\
\hline OR 48577 & $6 / 30 / 98$ & $\mathrm{SP}$ & 318 & 250 & EWU & $7 / 1 / 98$ & $\mathrm{SP}$ & 316 & 248 & EWU \\
\hline OR 48654 & $6 / 20 / 98$ & 9 & 389 & & KFWT98 & $6 / 27 / 98$ & 9 & 394 & 636 & ANG \\
\hline OR 48669 & $6 / 20 / 98$ & 9 & 370 & & KFWT98 & $9 / 13 / 98$ & 7 & 394 & & ANG \\
\hline OR 48879 & $7 / 27 / 98$ & 7 & 307 & 240 & EWU & Aug-98 & K & 356 & & ANG \\
\hline OR 49611 & $7 / 20 / 98$ & $\mathrm{H}$ & 247 & & EWU & $8 / 5 / 98$ & $\mathrm{H}$ & 251 & 131 & EWU \\
\hline OR 49726 & $7 / 16 / 98$ & 4 & 312 & 225 & EWU & $8 / 2 / 98$ & S 1 & NL & & ANG \\
\hline OR 49811 & 7/8/98 & 6 & 344 & 335 & EWU & $8 / 7 / 98$ & 5 & 356 & & ANG \\
\hline OR 49853 & $7 / 13 / 98$ & S 2 & 220 & 88 & EWU & Unknown & Spokane Arm & NL & & ANG \\
\hline OR 49859 & 7/13/98 & S 2 & 222 & 93 & EWU & $8 / 3 / 98$ & S 2 & 224 & 92 & EWU \\
\hline OR 49984 & $7 / 13 / 98$ & S 3 & 325 & 286 & EWU & $8 / 28 / 98$ & S 2 & 356 & & ANG \\
\hline OR 49987 & $7 / 13 / 98$ & S 3 & 208 & 74 & EWU & $8 / 6 / 98$ & S 3 & 226 & 161 & EWU \\
\hline OR 49993 & $7 / 15 / 98$ & S 2 & 362 & 389 & EWU & $8 / 1 / 98$ & S 1 & 381 & & ANG \\
\hline OR 49996 & $7 / 15 / 98$ & S 2 & 318 & 254 & EWU & $8 / 3 / 98$ & S 3 & 325 & & ANG \\
\hline OR 49999 & $7 / 15 / 98$ & S 2 & 226 & 89 & EWU & $9 / 14 / 98$ & S 1 & 254 & & ANG \\
\hline OR 51026 & 7/8/98 & 7 & 291 & 290 & STOI & $7 / 27 / 98$ & 7 & 307 & 224 & EWU \\
\hline OR 51110 & 4/4/98 & S 1 & 308 & 500 & SRWA1 & $6 / 14 / 98$ & Spokane Arm & 318 & & ANG \\
\hline OR 51110 & 4/4/98 & S 1 & 308 & 500 & SRAD1 & $5 / 18 / 98$ & S 3 & 313 & 350 & STOI \\
\hline OR 51111 & 4/4/98 & S 2 & 453 & 1150 & SRAD1 & $5 / 19 / 98$ & S 2 & 451 & 625 & EWU \\
\hline OR 51111 & 4/4/98 & S 2 & 453 & 1150 & SRAD1 & 4/29/98 & S 3 & 454 & 672 & EWU \\
\hline OR 51120 & $4 / 4 / 98$ & S 1 & 324 & 600 & SRWA1 & $6 / 25 / 98$ & S 1 & 330 & 114 & ANG \\
\hline OR 51135 & $5 / 2 / 98$ & S 2 & 384 & 750 & EWU & $6 / 2 / 98$ & S 1 & 356 & & ANG \\
\hline
\end{tabular}




\begin{tabular}{|c|c|c|c|c|c|c|c|c|c|c|}
\hline OR 51190 & $5 / 5 / 98$ & $\mathrm{SP}$ & 300 & 250 & STOI & $7 / 1 / 98$ & $\mathrm{SP}$ & 308 & 244 & EWU \\
\hline OR 51199 & $5 / 5 / 98$ & $\mathrm{SP}$ & 216 & 150 & STOI & $7 / 22 / 98$ & $\mathrm{SP}$ & 265 & 146 & EWU \\
\hline OR 51207 & $5 / 13 / 98$ & S 2 & 361 & 430 & STOI & $5 / 19 / 98$ & S 2 & 354 & 377 & EWU \\
\hline OR 51207 & $5 / 13 / 98$ & S 2 & 361 & 430 & STOI & $7 / 21 / 98$ & S 2 & 370 & 550 & STOI \\
\hline OR 51210 & $5 / 13 / 98$ & $\mathrm{~S} 2$ & 190 & 50 & STOI & $6 / 17 / 98$ & S 2 & 203 & 62 & EWU \\
\hline OR 51214 & $5 / 13 / 98$ & $\mathrm{~S} 1$ & 314 & 280 & STOI & $7 / 15 / 98$ & $\mathrm{~S} 1$ & 330 & 255 & EWU \\
\hline OR 51215 & $5 / 13 / 98$ & $\mathrm{~S} 1$ & 300 & 250 & STOI & $9 / 8 / 98$ & S 1 & NL & & ANG \\
\hline OR 51227 & $5 / 13 / 98$ & S 1 & 370 & 450 & STOI & $6 / 4 / 98$ & S 1 & 375 & & ANG \\
\hline OR 51227 & $5 / 13 / 98$ & S 1 & 370 & 450 & STOI & 9/8/98 & S 1 & NL & & ANG \\
\hline OR 51229 & $5 / 13 / 98$ & $\mathrm{~S} 1$ & 344 & 400 & STOI & $5 / 19 / 98$ & S 2 & 345 & 310 & EWU \\
\hline OR 51231 & $5 / 13 / 98$ & S 1 & 321 & 320 & STOI & $9 / 8 / 98$ & S 1 & NL & & ANG \\
\hline OR 51242 & $5 / 14 / 98$ & 6 & 361 & 400 & STOI & $7 / 10 / 98$ & 6 & 381 & 681 & ANG \\
\hline OR 51259 & $5 / 15 / 98$ & 7 & 338 & 410 & STOI & $7 / 8 / 98$ & 7 & 345 & 460 & STOI \\
\hline OR 51276 & $5 / 18 / 98$ & S 3 & 313 & 390 & STOI & $7 / 21 / 98$ & S 3 & 344 & 500 & STOI \\
\hline OR 51294 & $5 / 19 / 98$ & $\mathrm{H}$ & 529 & 1750 & STOI & $7 / 31 / 98$ & 6 & 440 & 800 & WDFW \\
\hline OR 51297 & $5 / 19 / 98$ & $\mathrm{H}$ & 300 & 350 & STOI & $6 / 6 / 98$ & $\mathrm{H}$ & 279 & 492 & ANG \\
\hline OR 51299 & $5 / 19 / 98$ & $\mathrm{H}$ & 288 & 260 & STOI & $6 / 14 / 98$ & $\mathrm{H}$ & 368 & 227 & ANG \\
\hline OR 51302 & $5 / 19 / 98$ & $\mathrm{H}$ & 552 & 1500 & STOI & $9 / 7 / 98$ & S 1 & 584 & 2043 & ANG \\
\hline OR 51307 & $5 / 19 / 98$ & $\mathrm{H}$ & 330 & 400 & STOI & $5 / 25 / 98$ & $\mathrm{H}$ & NL & & ANG \\
\hline OR 51308 & $5 / 19 / 98$ & $\mathrm{H}$ & 315 & 350 & STOI & $7 / 10 / 98$ & $\mathrm{H}$ & 350 & 510 & STOI \\
\hline OR 51312 & $5 / 19 / 98$ & $\mathrm{H}$ & 305 & 312 & STOI & $6 / 14 / 98$ & $\mathrm{H}$ & 368 & 227 & ANG \\
\hline OR 51335 & 7/9/98 & 5 & 348 & 370 & STOI & Unknown & 6 & 305 & 341 & ANG \\
\hline OR 51348 & 7/9/98 & 5 & 222 & 130 & STOI & $7 / 29 / 98$ & 5 & 237 & & EWU \\
\hline OR 51552 & $7 / 22 / 98$ & $\mathrm{H}$ & 295 & & STOI & $8 / 12 / 98$ & $\mathrm{H}$ & 326 & 317 & EWU \\
\hline OR 51557 & $7 / 22 / 98$ & $\mathrm{H}$ & 325 & & STOI & $8 / 14 / 98$ & S 1 & 330 & 454 & ANG \\
\hline OR 52005 & $6 / 24 / 98$ & $\mathrm{H}$ & 322 & 252 & EWU & $6 / 28 / 98$ & $\mathrm{H}$ & 356 & & ANG \\
\hline OR 52011 & $6 / 24 / 98$ & $\mathrm{H}$ & 392 & 504 & EWU & $6 / 25 / 98$ & $\mathrm{H}$ & 395 & 497 & EWU \\
\hline OR 52016 & $6 / 24 / 98$ & $\mathrm{H}$ & 330 & 261 & EWU & $6 / 25 / 98$ & $\mathrm{H}$ & 336 & 252 & EWU \\
\hline OR 52023 & $6 / 24 / 98$ & $\mathrm{H}$ & 347 & 339 & EWU & $6 / 28 / 98$ & $\mathrm{H}$ & 356 & & ANG \\
\hline OR 52026 & $6 / 24 / 98$ & $\mathrm{H}$ & 399 & 466 & EWU & 9/7/98 & $\mathrm{BC}$ & NL & & ANG \\
\hline OR 52027 & $6 / 24 / 98$ & $\mathrm{H}$ & 330 & 286 & EWU & 7/20/98 & $\mathrm{H}$ & 350 & 334 & EWU \\
\hline OR 52028 & $6 / 24 / 98$ & $\mathrm{H}$ & 399 & 488 & EWU & $6 / 28 / 98$ & $\mathrm{H}$ & 356 & & ANG \\
\hline OR 52040 & $6 / 24 / 98$ & $\mathrm{H}$ & 401 & 467 & EWU & $6 / 28 / 98$ & $\mathrm{H}$ & 356 & & ANG \\
\hline OR 52068 & $6 / 24 / 98$ & $\mathrm{H}$ & 229 & 113 & EWU & 7/20/98 & $\mathrm{H}$ & 252 & 134 & EWU \\
\hline OR 52080 & $6 / 24 / 98$ & $\mathrm{H}$ & 231 & 107 & EWU & $6 / 25 / 98$ & $\mathrm{H}$ & 233 & 87 & EWU \\
\hline OR 52108 & $6 / 24 / 98$ & $\mathrm{H}$ & 170 & 40 & EWU & 7/20/98 & $\mathrm{H}$ & 195 & 60 & EWU \\
\hline OR 52118 & $6 / 24 / 98$ & $\mathrm{H}$ & 194 & 60 & EWU & $7 / 20 / 98$ & $\mathrm{H}$ & 218 & 85 & EWU \\
\hline OR 52136 & $6 / 24 / 98$ & $\mathrm{H}$ & 194 & 81 & EWU & $8 / 5 / 98$ & $\mathrm{H}$ & 232 & 102 & EWU \\
\hline OR 52148 & $6 / 24 / 98$ & $\mathrm{H}$ & 186 & 46 & EWU & $7 / 20 / 98$ & $\mathrm{H}$ & 200 & 55 & EWU \\
\hline OR 52163 & $6 / 24 / 98$ & $\mathrm{H}$ & 162 & 35 & EWU & $7 / 20 / 98$ & $\mathrm{H}$ & 183 & 47 & EWU \\
\hline OR 52182 & $6 / 24 / 98$ & 4 & 198 & 67 & EWU & $7 / 16 / 98$ & 4 & 221 & 90 & EWU \\
\hline OR 52184 & $6 / 24 / 98$ & 4 & 407 & 511 & EWU & $7 / 30 / 98$ & 4 & NL & & ANG \\
\hline OR 52362 & 8/3/98 & $\mathrm{S} 2$ & 259 & 123 & EWU & Unknown & Spokane Arm & $\mathrm{NL}$ & & ANG \\
\hline OR 52586 & $6 / 21 / 98$ & 9 & 365 & & EWU & $7 / 27 / 98$ & 7 & 377 & 394 & EWU \\
\hline OR 52690 & $6 / 21 / 98$ & 8 & 380 & & KFWT98 & $6 / 27 / 98$ & 9 & 394 & 636 & ANG \\
\hline OR 52707 & $6 / 3 / 98$ & 8 & 337 & 305 & EWU & $7 / 7 / 98$ & 8 & 345 & 410 & STOI \\
\hline OR 52725 & $6 / 3 / 98$ & 7 & 398 & 590 & EWU & $7 / 27 / 98$ & S 1 & NL & & ANG \\
\hline OR 52727 & $6 / 3 / 98$ & 7 & 376 & 478 & EWU & 7/7/98 & 7 & 381 & & ANG \\
\hline OR 52741 & $6 / 6 / 98$ & 5 & 341 & 297 & EWU & $7 / 27 / 98$ & S 1 & $\mathrm{NL}$ & & ANG \\
\hline OR 52745 & $6 / 6 / 98$ & 5 & 400 & 490 & EWU & $6 / 20 / 98$ & 9 & 396 & & KFWT98 \\
\hline OR 52763 & $6 / 6 / 98$ & 6 & 377 & 515 & EWU & $7 / 29 / 98$ & 6 & 418 & 616 & EWU \\
\hline OR 52780 & $6 / 12 / 98$ & S 3 & 391 & 493 & EWU & $7 / 27 / 98$ & S 1 & NL & & ANG \\
\hline OR 52865 & $6 / 17 / 98$ & $\mathrm{~S} 2$ & 231 & 109 & EWU & $7 / 16 / 98$ & S 2 & 256 & 142 & EWU \\
\hline OR 52898 & $6 / 17 / 98$ & $\mathrm{~S} 2$ & 190 & 51 & EWU & $7 / 16 / 98$ & S 2 & 224 & 84 & EWU \\
\hline OR 52904 & $5 / 19 / 98$ & $\mathrm{~S} 1$ & 285 & 166 & EWU & $6 / 2 / 98$ & S 1 & NL & & ANG \\
\hline OR 52948 & $5 / 20 / 98$ & S 3 & 364 & 338 & EWU & $8 / 6 / 98$ & S 3 & 396 & 471 & EWU \\
\hline OR 52950 & $5 / 20 / 98$ & S 3 & 395 & 472 & EWU & $6 / 17 / 98$ & S 2 & 406 & & ANG \\
\hline OR 52987 & $6 / 20 / 98$ & 10 & 360 & & KFWT98 & $9 / 3 / 98$ & 10 & 394 & & ANG \\
\hline
\end{tabular}




\begin{tabular}{|c|c|c|c|c|c|c|c|c|c|c|}
\hline OR 53015 & $6 / 21 / 98$ & 9 & 378 & & KFWT98 & $8 / 29 / 98$ & NP & NL & 863 & ANG \\
\hline OR 53043 & $8 / 6 / 98$ & S 3 & 325 & 272 & EWU & $9 / 14 / 98$ & S 1 & 279 & & ANG \\
\hline OR 53248 & $7 / 29 / 98$ & 7 & 245 & 133 & EWU & $9 / 25 / 98$ & 10 & 305 & & ANG \\
\hline OR 53252 & 7/29/98 & 6 & 235 & 105 & EWU & $9 / 1 / 98$ & 6 & 255 & 159 & CCT \\
\hline OR 53277 & $8 / 5 / 97$ & 6 & 223 & 92 & EWU & $7 / 29 / 98$ & 6 & 321 & & EWU \\
\hline OR 53294 & $7 / 29 / 98$ & 8 & 362 & & EWU & $8 / 13 / 98$ & 5 & 305 & 341 & ANG \\
\hline OR 53354 & 7/29/98 & 6 & 230 & 101 & EWU & $10 / 8 / 98$ & 6 & 285 & 130 & STOI \\
\hline OR 53769 & $6 / 21 / 98$ & 8 & 406 & & KFWT98 & $8 / 5 / 98$ & $\mathrm{BC}$ & $406 \mathrm{FL}$ & & ANG \\
\hline OR 53782 & $6 / 21 / 98$ & 8 & 448 & & KFWT98 & $6 / 21 / 98$ & 8 & 452 & & KFWT98 \\
\hline OR 53792 & $6 / 21 / 98$ & 8 & 666 & & KFWT98 & $7 / 16 / 98$ & 5 & 406 & 454 & ANG \\
\hline OR 54012 & $5 / 22 / 98$ & S 3 & 287 & 212 & EWU & 7/16/98 & S 1 & NL & & ANG \\
\hline OR 54012 & $5 / 22 / 98$ & S 3 & 287 & 212 & EWU & $6 / 6 / 98$ & S 2 & 305 & & ANG \\
\hline OR 54024 & $5 / 22 / 98$ & S 3 & 347 & 292 & EWU & $6 / 6 / 98$ & Spokane Arm & 356 & & ANG \\
\hline OR 54034 & $5 / 22 / 98$ & S 3 & 318 & 247 & EWU & $8 / 3 / 98$ & S 2 & 305 & & ANG \\
\hline OR 54034 & $5 / 22 / 98$ & S 3 & 318 & 247 & EWU & Unknown & Unknown & 305 & & ANG \\
\hline OR 54037 & $5 / 23 / 98$ & $\mathrm{H}$ & 340 & 393 & EWU & $6 / 24 / 98$ & $\mathrm{H}$ & 348 & 356 & EWU \\
\hline OR 54038 & $5 / 23 / 98$ & $\mathrm{H}$ & 278 & 194 & EWU & $7 / 16 / 98$ & S 1 & NL & & ANG \\
\hline OR 54045 & $5 / 23 / 98$ & $\mathrm{H}$ & 391 & 527 & EWU & $6 / 24 / 98$ & $\mathrm{H}$ & 405 & 571 & EWU \\
\hline OR 54051 & $5 / 15 / 98$ & S 3 & 521 & 1034 & EWU & $7 / 16 / 98$ & S 1 & 514 & & ANG \\
\hline OR 54063 & $5 / 15 / 98$ & S 3 & 334 & 301 & EWU & $6 / 12 / 98$ & S 3 & 406 & 681 & ANG \\
\hline OR 54074 & $5 / 15 / 98$ & S 3 & 428 & 619 & EWU & $5 / 16 / 98$ & S 3 & 422 & 648 & EWU \\
\hline OR 54084 & $5 / 15 / 98$ & S 3 & 412 & 589 & EWU & $6 / 20 / 98$ & 9 & 408 & & KFWT98 \\
\hline OR 54089 & $5 / 15 / 98$ & S 3 & 364 & 444 & EWU & $6 / 6 / 98$ & Spokane Arm & 356 & & ANG \\
\hline OR 54099 & $5 / 15 / 98$ & S 3 & 345 & 324 & EWU & $5 / 16 / 98$ & S 3 & 341 & 317 & EWU \\
\hline OR 54117 & $6 / 21 / 98$ & 9 & 359 & & KFWT98 & $7 / 13 / 98$ & S 3 & 336 & 286 & EWU \\
\hline OR 54185 & $6 / 21 / 98$ & 9 & 440 & & KFWT98 & $7 / 25 / 98$ & 8 & 445 & & ANG \\
\hline OR 54237 & $6 / 21 / 98$ & 8 & 368 & & KFWT98 & $7 / 25 / 98$ & 8 & 394 & & ANG \\
\hline OR 54259 & $6 / 24 / 98$ & $\mathrm{H}$ & 311 & 212 & EWU & $6 / 28 / 98$ & $\mathrm{H}$ & 356 & & ANG \\
\hline OR 54268 & $6 / 24 / 98$ & $\mathrm{H}$ & 194 & 51 & EWU & $6 / 25 / 98$ & $\mathrm{H}$ & 193 & 61 & EWU \\
\hline OR 54282 & $6 / 24 / 98$ & $\mathrm{H}$ & 232 & 102 & EWU & $7 / 22 / 98$ & $\mathrm{H}$ & 285 & & STOI \\
\hline OR 54311 & $6 / 18 / 98$ & $\mathrm{~S} 1$ & 384 & 432 & EWU & $9 / 8 / 98$ & S 1 & $\mathrm{NL}$ & & ANG \\
\hline OR 54356 & $6 / 20 / 98$ & 8 & 359 & 392 & KFWT98 & $8 / 25 / 98$ & $\mathrm{BC}$ & $394 \mathrm{FL}$ & & ANG \\
\hline OR 54393 & $6 / 20 / 98$ & 8 & 399 & & KFWT98 & $7 / 11 / 98$ & 10 & 400 & 454 & ANG \\
\hline OR 54425 & $5 / 15 / 98$ & S 3 & 448 & 770 & EWU & $5 / 16 / 98$ & S 3 & 455 & 741 & EWU \\
\hline OR 54427 & $5 / 15 / 98$ & S 3 & 478 & 935 & EWU & $5 / 20 / 98$ & S 3 & 478 & & EWU \\
\hline OR 54452 & $5 / 23 / 98$ & $\mathrm{H}$ & 172 & 60 & EWU & $7 / 20 / 98$ & $\mathrm{H}$ & 243 & 109 & EWU \\
\hline OR 54453 & $5 / 23 / 98$ & $\mathrm{H}$ & 200 & 62 & EWU & $10 / 29 / 98$ & $\mathrm{H}$ & 331 & & EWU \\
\hline OR 54456 & $5 / 23 / 98$ & $\mathrm{H}$ & 213 & 79 & EWU & $6 / 24 / 98$ & $\mathrm{H}$ & 227 & 92 & EWU \\
\hline OR 54467 & $6 / 2 / 98$ & 9 & 421 & 511 & EWU & $6 / 20 / 98$ & 9 & 417 & & KFWT98 \\
\hline OR 54470 & $6 / 2 / 98$ & 8 & 377 & 321 & EWU & $6 / 20 / 98$ & 8 & 378 & & KFWT98 \\
\hline OR 54477 & $6 / 3 / 98$ & 8 & 467 & & EWU & $9 / 16 / 98$ & $\mathrm{BC}$ & NL & & ANG \\
\hline OR 54493 & $6 / 3 / 98$ & 8 & 396 & 579 & EWU & $6 / 21 / 98$ & 9 & 396 & & KFWT98 \\
\hline OR 54516 & $5 / 22 / 98$ & S 3 & 487 & 851 & EWU & $9 / 5 / 98$ & S 1 & 489 & & ANG \\
\hline OR 54521 & $5 / 22 / 98$ & S 3 & 360 & 327 & EWU & $6 / 14 / 98$ & Spokane Arm & 356 & & ANG \\
\hline OR 54525 & $5 / 22 / 98$ & S 3 & 376 & 420 & EWU & $6 / 7 / 98$ & S 3 & 394 & 341 & ANG \\
\hline OR 54526 & $5 / 22 / 98$ & S 3 & 360 & 336 & EWU & $6 / 14 / 98$ & Spokane Arm & 356 & & ANG \\
\hline OR 54541 & $5 / 22 / 98$ & S 3 & 335 & 317 & EWU & $6 / 11 / 98$ & S 2 & 330 & & ANG \\
\hline OR 54555 & $5 / 16 / 98$ & S 3 & 455 & 820 & EWU & $5 / 22 / 98$ & S 3 & 454 & 737 & EWU \\
\hline OR 54556 & $5 / 16 / 98$ & S 3 & 330 & 278 & EWU & $6 / 18 / 98$ & S 2 & 330 & & ANG \\
\hline OR 54559 & $5 / 16 / 98$ & S 3 & 299 & 249 & EWU & $6 / 2 / 98$ & S 3 & 279 & & ANG \\
\hline OR 54573 & $5 / 16 / 98$ & S 3 & 485 & 932 & EWU & $6 / 14 / 98$ & Spokane Arm & 470 & & ANG \\
\hline OR 54576 & $5 / 16 / 98$ & S 3 & 298 & 232 & EWU & $5 / 20 / 98$ & S 3 & 298 & & EWU \\
\hline OR 54585 & $5 / 19 / 98$ & $\mathrm{~S} 2$ & 307 & 199 & EWU & $6 / 17 / 98$ & S 2 & 314 & 241 & EWU \\
\hline OR 54616 & $5 / 16 / 98$ & S 3 & 478 & 857 & EWU & $6 / 14 / 98$ & Spokane Arm & 470 & & ANG \\
\hline OR 54616 & $5 / 16 / 98$ & S 3 & 478 & 857 & EWU & $5 / 22 / 98$ & S 3 & 477 & 797 & EWU \\
\hline OR 54622 & $5 / 16 / 98$ & S 3 & 500 & 841 & EWU & $7 / 16 / 98$ & $\mathrm{~S} 1$ & NL & & ANG \\
\hline OR 54626 & $5 / 16 / 98$ & S 3 & 395 & 488 & EWU & $5 / 16 / 98$ & S 3 & 392 & 488 & EWU \\
\hline OR 54640 & $5 / 16 / 98$ & S 3 & 423 & 556 & EWU & $7 / 16 / 98$ & S 1 & NL & & ANG \\
\hline
\end{tabular}




\begin{tabular}{|c|c|c|c|c|c|c|c|c|c|c|}
\hline OR 54641 & $5 / 16 / 98$ & S 3 & 480 & 1018 & EWU & $6 / 25 / 98$ & Unkown & NL & & ANG \\
\hline OR 54647 & $5 / 16 / 98$ & S 3 & 408 & 481 & EWU & 7/13/98 & S 3 & 409 & 496 & EWU \\
\hline OR 54660 & $5 / 16 / 98$ & S 3 & 401 & & EWU & $7 / 9 / 98$ & 2 & 400 & & ANG \\
\hline OR 54665 & $5 / 16 / 98$ & S 3 & 362 & 347 & EWU & $6 / 20 / 98$ & S 1 & 381 & & ANG \\
\hline OR 55002 & $4 / 29 / 97$ & S 3 & 492 & 1000 & EWU & 4/22/98 & S 3 & 526 & 1358 & EWU \\
\hline OR 55002 & 4/29/97 & S 3 & 492 & 1000 & EWU & $5 / 16 / 98$ & S 3 & 519 & 1359 & EWU \\
\hline OR 55016 & $5 / 13 / 97$ & S 3 & 422 & 650 & EWU & Aug-97 & 7 & NL & & ANG \\
\hline OR 55023 & $5 / 13 / 97$ & S 3 & 395 & 500 & EWU & $5 / 20 / 98$ & S 3 & 411 & 541 & EWU \\
\hline OR 55032 & $5 / 13 / 97$ & S 3 & 508 & 1050 & EWU & $3 / 20 / 98$ & S 2 & 521 & & ANG \\
\hline OR 55115 & $8 / 25 / 97$ & $\mathrm{H}$ & 361 & 388 & EWU & $7 / 16 / 98$ & S 1 & NL & & ANG \\
\hline OR 55135 & $8 / 25 / 97$ & $\mathrm{H}$ & 306 & 250 & EWU & 7/7/98 & $\mathrm{H}$ & 381 & & ANG \\
\hline OR 55150 & $10 / 17 / 97$ & S 3 & 384 & 424 & EWU & $6 / 4 / 98$ & S 2 & 356 & & ANG \\
\hline OR 55162 & $8 / 25 / 97$ & $\mathrm{H}$ & 274 & 182 & EWU & $6 / 15 / 98$ & S 1 & 330 & & ANG \\
\hline OR 55253 & $8 / 21 / 97$ & 7 & 296 & 211 & EWU & Aug-98 & K & 356 & & ANG \\
\hline OR 55288 & $8 / 21 / 97$ & 6 & 310 & 289 & EWU & $5 / 14 / 98$ & 6 & 325 & 330 & STOI \\
\hline OR 55295 & $8 / 21 / 97$ & 6 & 310 & 338 & EWU & 7/1/98 & 6 & 330 & & ANG \\
\hline OR 55296 & $8 / 21 / 97$ & 6 & 218 & 83 & EWU & 7/8/98 & 6 & 238 & 94 & EWU \\
\hline OR 55321 & 8/19/97 & S 3 & 350 & 338 & EWU & $3 / 12 / 98$ & S 1 & 400 & & ANG \\
\hline OR 55322 & 8/19/97 & S 3 & 343 & 303 & EWU & $7 / 20 / 98$ & S 3 & 393 & 630 & STOI \\
\hline OR 55347 & 8/19/97 & S 3 & 399 & 498 & EWU & $5 / 20 / 98$ & S 3 & 403 & & EWU \\
\hline OR 55349 & 8/19/97 & S 3 & 318 & 266 & EWU & $7 / 16 / 98$ & S 1 & NL & & ANG \\
\hline OR 55409 & $8 / 5 / 97$ & 8 & 366 & 380 & EWU & $6 / 20 / 98$ & 8 & 360 & & KFWT98 \\
\hline OR 55437 & $8 / 5 / 97$ & 8 & 312 & 227 & EWU & $6 / 3 / 98$ & 8 & 362 & 382 & EWU \\
\hline OR 55487 & $8 / 4 / 97$ & 8 & 561 & 1694 & EWU & $5 / 13 / 98$ & S 2 & 578 & 1750 & STOI \\
\hline OR 55504 & $6 / 21 / 97$ & 8 & 387 & & KFWT97 & $6 / 20 / 98$ & 8 & 430 & & KFWT98 \\
\hline OR 55517 & $6 / 22 / 97$ & 8 & 421 & & KFWT97 & $6 / 20 / 98$ & 9 & 432 & & KFWT98 \\
\hline OR 55519 & $6 / 22 / 97$ & 8 & 357 & & EWU & $4 / 25 / 98$ & S 3 & 514 & 1410 & EWU \\
\hline OR 55630 & $6 / 22 / 97$ & 8 & 364 & & KFWT97 & $6 / 23 / 98$ & Unknown & $\mathrm{NL}$ & & ANG \\
\hline OR 55633 & 7/29/97 & $\mathrm{S} 1$ & 207 & 70 & EWU & $6 / 5 / 98$ & Spokane Arm & 356 & & ANG \\
\hline OR 55645 & 7/30/97 & $\mathrm{S} 2$ & 360 & 455 & EWU & $6 / 11 / 98$ & S 2 & 394 & & ANG \\
\hline OR 55656 & 9/4/97 & $\mathrm{S} 2$ & 345 & 331 & EWU & $6 / 2 / 98$ & S 2 & 381 & & ANG \\
\hline OR 55657 & $9 / 4 / 97$ & $\mathrm{~S} 2$ & 345 & 331 & EWU & 7/8/98 & $\mathrm{K}$ & 318 & & ANG \\
\hline OR 55683 & $9 / 4 / 97$ & $\mathrm{~S} 2$ & 275 & 159 & EWU & $5 / 13 / 98$ & S 2 & 285 & 230 & STOI \\
\hline OR 55704 & 9/8/97 & $\mathrm{S} 2$ & 174 & 45 & EWU & 7/11/98 & S 1 & 229 & & ANG \\
\hline OR 55734 & 9/9/97 & 7 & 309 & 239 & EWU & 7/8/98 & 7 & 316 & 260 & STOI \\
\hline OR 55740 & 9/9/97 & 7 & 399 & 575 & EWU & 7/8/98 & 7 & 410 & 800 & STOI \\
\hline OR 55751 & $9 / 5 / 97$ & $\mathrm{H}$ & 314 & 240 & EWU & $6 / 9 / 98$ & $\mathrm{H}$ & 330 & & ANG \\
\hline OR 55755 & $9 / 5 / 97$ & $\mathrm{H}$ & 307 & 251 & EWU & $7 / 10 / 98$ & $\mathrm{H}$ & 351 & 500 & STOI \\
\hline OR 55758 & $9 / 5 / 97$ & $\mathrm{H}$ & 308 & 221 & EWU & $9 / 21 / 97$ & $\mathrm{H}$ & 356 & & ANG \\
\hline OR 55769 & $9 / 5 / 97$ & $\mathrm{H}$ & 254 & 122 & EWU & $8 / 22 / 98$ & 10 & 337 & 318 & ANG \\
\hline OR 55789 & 9/8/97 & S 3 & 429 & 610 & EWU & $7 / 21 / 98$ & S 3 & 440 & 800 & STOI \\
\hline OR 55790 & 9/8/97 & S 3 & 417 & 553 & EWU & $6 / 7 / 98$ & S 2 & 394 & & ANG \\
\hline OR 55837 & 6/18/97 & $\mathrm{H}$ & 541 & 1590 & EWU & $6 / 24 / 97$ & $\mathrm{H}$ & 546 & & ANG \\
\hline OR 55870 & $8 / 20 / 97$ & 8 & 358 & 427 & EWU & $8 / 21 / 98$ & 8 & 394 & & ANG \\
\hline OR 55873 & $8 / 20 / 97$ & 8 & 448 & 707 & EWU & $6 / 3 / 98$ & 8 & 465 & 805 & EWU \\
\hline OR 55884 & $8 / 20 / 97$ & 8 & 275 & 164 & EWU & $6 / 27 / 98$ & 8 & 305 & & ANG \\
\hline OR 55888 & $8 / 20 / 97$ & 8 & 272 & 168 & EWU & $7 / 28 / 98$ & 8 & 330 & 331 & EWU \\
\hline OR 55890 & $8 / 20 / 97$ & 8 & 337 & 340 & EWU & 6/3/98 & 8 & 362 & 364 & EWU \\
\hline OR 55895 & $8 / 20 / 97$ & 8 & 389 & 494 & EWU & $6 / 20 / 98$ & 9 & 422 & & KFWT98 \\
\hline OR 55896 & $8 / 20 / 97$ & 8 & 347 & 357 & EWU & $5 / 16 / 98$ & 8 & 277 & 560 & STOI \\
\hline OR 55898 & $8 / 20 / 97$ & 8 & 506 & 1205 & EWU & $3 / 30 / 98$ & S 2 & 521 & & ANG \\
\hline OR 55924 & $5 / 31 / 97$ & $\mathrm{~S} 2$ & 446 & 890 & SRWA97 & $6 / 14 / 98$ & Spokane Arm & 457 & & ANG \\
\hline OR 55927 & $5 / 31 / 97$ & $\mathrm{~S} 2$ & 421 & 690 & SRAD97 & $4 / 22 / 98$ & S 3 & 444 & 623 & EWU \\
\hline OR 55947 & $5 / 31 / 97$ & $\mathrm{~S} 2$ & 462 & 1000 & SRAD97 & $4 / 29 / 98$ & S 3 & 480 & 971 & EWU \\
\hline OR 55988 & $5 / 31 / 97$ & S 2 & 473 & 880 & SRAD97 & $4 / 18 / 98$ & S 3 & 481 & 804 & EWU \\
\hline OR 56002 & $4 / 4 / 98$ & $\mathrm{~S} 2$ & 365 & 350 & EWU & $6 / 24 / 98$ & S 2 & 368 & & ANG \\
\hline OR 56007 & $4 / 4 / 98$ & $\mathrm{~S} 2$ & 466 & 777 & EWU & $5 / 2 / 98$ & S 2 & 467 & 712 & SRAD2 \\
\hline OR 56013 & $4 / 4 / 98$ & S 2 & 452 & 672 & EWU & $5 / 16 / 98$ & S 3 & 448 & 754 & EWU \\
\hline
\end{tabular}




\begin{tabular}{|c|c|c|c|c|c|c|c|c|c|c|}
\hline OR 56041 & $4 / 15 / 98$ & S 3 & 578 & 1915 & EWU & 7/16/98 & S 1 & NL & & ANG \\
\hline OR 56046 & $4 / 15 / 98$ & S 3 & 478 & 847 & EWU & $4 / 25 / 98$ & S 3 & 483 & 790 & EWU \\
\hline OR 56056 & $4 / 17 / 98$ & S 3 & 484 & 589 & EWU & $4 / 29 / 98$ & S 3 & 487 & 959 & EWU \\
\hline OR 56057 & $4 / 17 / 98$ & S 3 & 470 & 776 & EWU & $5 / 13 / 98$ & S 3 & 468 & 688 & EWU \\
\hline OR 56084 & $4 / 17 / 98$ & S 3 & 557 & 1562 & EWU & $4 / 25 / 98$ & S 3 & 556 & 1524 & EWU \\
\hline OR 56091 & $4 / 17 / 98$ & S 3 & 489 & 908 & EWU & $4 / 25 / 98$ & S 3 & 585 & 884 & EWU \\
\hline OR 56101 & $4 / 22 / 98$ & S 3 & 523 & 1160 & EWU & $5 / 15 / 98$ & S 3 & 515 & 1070 & EWU \\
\hline OR 56103 & $4 / 22 / 98$ & S 3 & 513 & 1167 & EWU & $7 / 27 / 98$ & S 1 & NL & & ANG \\
\hline OR 56108 & $4 / 22 / 98$ & S 3 & 503 & 1173 & EWU & $5 / 16 / 98$ & S 3 & 499 & 1096 & EWU \\
\hline OR 56113 & $4 / 22 / 98$ & S 3 & 520 & 1136 & EWU & $4 / 25 / 98$ & S 3 & 519 & 1136 & EWU \\
\hline OR 56114 & $4 / 22 / 98$ & S 3 & 545 & 1246 & EWU & $4 / 29 / 98$ & S 3 & 545 & 1238 & EWU \\
\hline OR 56119 & $4 / 22 / 98$ & S 3 & 402 & 495 & EWU & $7 / 27 / 98$ & S 1 & NL & & ANG \\
\hline OR 56121 & $4 / 22 / 98$ & S 3 & 395 & 454 & EWU & $6 / 6 / 98$ & Spokane Arm & 380 & & ANG \\
\hline OR 56124 & $4 / 22 / 98$ & S 3 & 419 & 539 & EWU & $5 / 22 / 98$ & S 3 & 411 & 529 & EWU \\
\hline OR 56125 & $4 / 22 / 98$ & S 3 & 419 & 538 & EWU & $6 / 2 / 98$ & S 1 & 514 & & ANG \\
\hline OR 56148 & $4 / 22 / 98$ & S 3 & 499 & 1038 & EWU & $6 / 2 / 98$ & S 3 & 457 & & ANG \\
\hline OR 56150 & $4 / 22 / 98$ & S 3 & 526 & 1029 & EWU & $4 / 25 / 98$ & S 3 & 526 & 1041 & EWU \\
\hline OR 56163 & $4 / 21 / 98$ & S 3 & 612 & 2055 & EWU & $6 / 17 / 98$ & S 1 & 610 & 2270 & ANG \\
\hline OR 56164 & $4 / 21 / 98$ & S 3 & 374 & 418 & EWU & $6 / 6 / 98$ & Spokane Arm & 356 & & ANG \\
\hline OR 56165 & $4 / 21 / 98$ & S 3 & 396 & 479 & EWU & $7 / 27 / 98$ & S 1 & NL & & ANG \\
\hline OR 56180 & $4 / 22 / 98$ & S 3 & 463 & 836 & EWU & $5 / 2 / 98$ & S 2 & 460 & 560 & SRAD2 \\
\hline OR 56188 & $4 / 22 / 98$ & S 3 & 506 & 1125 & EWU & $4 / 25 / 98$ & S 3 & 507 & 1089 & EWU \\
\hline OR 56199 & $4 / 22 / 98$ & S 3 & 402 & 495 & EWU & $7 / 27 / 98$ & S 1 & NL & & ANG \\
\hline OR 56202 & $4 / 22 / 98$ & S 3 & 475 & 791 & EWU & $6 / 14 / 98$ & Spokane Arm & 457 & & ANG \\
\hline OR 56267 & $4 / 22 / 98$ & S 3 & 393 & 441 & EWU & $6 / 6 / 98$ & Spokane Arm & 381 & & ANG \\
\hline OR 56267 & $4 / 22 / 98$ & S 3 & 393 & 441 & EWU & $5 / 13 / 98$ & S 3 & 390 & 420 & EWU \\
\hline OR 56268 & $4 / 22 / 98$ & S 3 & 437 & 679 & EWU & $4 / 29 / 98$ & S 3 & 438 & 648 & EWU \\
\hline OR 56286 & $4 / 25 / 98$ & S 3 & 358 & 351 & EWU & $6 / 9 / 98$ & S 2 & 330 & & ANG \\
\hline OR 56346 & $5 / 13 / 98$ & S 3 & 459 & 813 & EWU & $6 / 21 / 98$ & 4 & 457 & & ANG \\
\hline OR 56350 & $5 / 13 / 98$ & S 3 & 448 & 794 & EWU & $5 / 16 / 98$ & S 3 & 455 & 805 & EWU \\
\hline OR 56355 & $5 / 2 / 98$ & S 3 & 406 & 520 & SRWA2 & $6 / 17 / 98$ & S 2 & 406 & & ANG \\
\hline OR 56373 & $5 / 2 / 98$ & S 3 & 396 & 436 & EWU & $6 / 7 / 98$ & S 3 & 394 & 341 & ANG \\
\hline OR 56376 & $5 / 2 / 98$ & S 3 & 420 & 570 & EWU & $5 / 20 / 98$ & S 3 & 421 & 582 & EWU \\
\hline OR 56378 & $5 / 2 / 98$ & S 3 & 474 & 837 & EWU & $5 / 15 / 98$ & S 3 & 447 & 782 & EWU \\
\hline OR 56384 & $5 / 2 / 98$ & S 3 & 397 & 438 & EWU & $6 / 22 / 98$ & $\mathrm{~S} 2$ & NL & & ANG \\
\hline OR 56392 & $5 / 2 / 98$ & S 3 & 392 & 445 & EWU & $7 / 27 / 98$ & S 1 & NL & & ANG \\
\hline OR 56412 & $5 / 13 / 98$ & S 3 & 384 & 430 & EWU & $5 / 15 / 98$ & S 3 & 386 & 450 & EWU \\
\hline OR 56437 & $5 / 13 / 98$ & S 3 & 427 & 612 & EWU & $5 / 15 / 98$ & S 3 & 425 & 635 & EWU \\
\hline OR 56438 & $5 / 13 / 98$ & S 3 & 510 & 958 & EWU & $6 / 14 / 98$ & Spokane Arm & 495 & & ANG \\
\hline OR 56453 & $5 / 20 / 98$ & S 3 & 368 & 410 & EWU & $7 / 16 / 98$ & S 1 & NL & & ANG \\
\hline OR 56482 & $5 / 20 / 98$ & S 3 & 388 & & EWU & $6 / 21 / 98$ & S 1 & 356 & & ANG \\
\hline OR 56492 & $5 / 20 / 98$ & S 3 & 310 & & EWU & $7 / 13 / 98$ & S 3 & 331 & 259 & EWU \\
\hline OR 56657 & $4 / 25 / 98$ & S 3 & 434 & 588 & EWU & $5 / 30 / 98$ & S 2 & 428 & 521 & SRAD3 \\
\hline OR 56663 & $4 / 25 / 98$ & S 3 & 369 & 355 & EWU & $8 / 7 / 98$ & $\mathrm{BC}$ & $368 \mathrm{FL}$ & & ANG \\
\hline OR 56664 & $4 / 25 / 98$ & S 3 & 387 & 471 & EWU & $5 / 2 / 98$ & S 3 & 385 & 455 & SRAD2 \\
\hline OR 56675 & $4 / 25 / 98$ & S 3 & 490 & 826 & EWU & $7 / 25 / 98$ & 3 & 514 & 1022 & ANG \\
\hline OR 56685 & $4 / 25 / 98$ & S 3 & 490 & 905 & EWU & $4 / 29 / 98$ & S 3 & 487 & 893 & EWU \\
\hline OR 56687 & $4 / 25 / 98$ & S 3 & 467 & 969 & EWU & $5 / 15 / 98$ & S 3 & 457 & 801 & EWU \\
\hline OR 56700 & $4 / 25 / 98$ & S 3 & 487 & 785 & EWU & $5 / 16 / 98$ & S 3 & 480 & 775 & EWU \\
\hline OR 56701 & $4 / 17 / 98$ & S 3 & 532 & 1217 & EWU & $4 / 21 / 98$ & S 3 & 532 & 1215 & EWU \\
\hline OR 56718 & $4 / 17 / 98$ & S 3 & 359 & 345 & EWU & $5 / 16 / 98$ & S 3 & 358 & 354 & EWU \\
\hline OR 56720 & $4 / 17 / 98$ & S 3 & 444 & 685 & EWU & $5 / 18 / 98$ & S 3 & 435 & 950 & STOI \\
\hline OR 56728 & 4/18/98 & S 3 & 457 & 639 & EWU & $10 / 11 / 98$ & Lake Roosevelt & 438 & & ANG \\
\hline OR 56736 & 4/18/98 & S 3 & 401 & 485 & EWU & $10 / 21 / 98$ & 8 & 427 & 739 & EWU \\
\hline OR 56752 & $4 / 15 / 98$ & S 3 & 470 & 746 & EWU & $7 / 16 / 98$ & S 1 & NL & & ANG \\
\hline OR 56760 & $4 / 15 / 98$ & S 3 & 518 & 1168 & EWU & $5 / 18 / 98$ & S 3 & 384 & 640 & STOI \\
\hline OR 56762 & 4/15/98 & S 3 & 488 & 898 & EWU & $4 / 21 / 98$ & S 3 & 487 & 724 & EWU \\
\hline OR 56765 & 4/15/98 & S 3 & 506 & 1111 & EWU & $8 / 8 / 98$ & S 2 & 530 & & ANG \\
\hline
\end{tabular}




\begin{tabular}{|c|c|c|c|c|c|c|c|c|c|c|}
\hline OR 56773 & 4/15/98 & S 3 & 510 & 1077 & EWU & $4 / 17 / 98$ & S 3 & 503 & 1069 & EWU \\
\hline OR 56775 & $4 / 15 / 98$ & S 3 & 445 & 683 & EWU & $5 / 16 / 98$ & S 3 & 440 & 667 & EWU \\
\hline OR 56776 & $4 / 15 / 98$ & S 3 & 521 & 1320 & EWU & $7 / 16 / 98$ & S 1 & NL & & ANG \\
\hline OR 56782 & 4/15/98 & S 3 & 408 & 547 & EWU & $6 / 6 / 98$ & Spokane Arm & 404 & & ANG \\
\hline OR 56782 & 4/15/98 & S 3 & 408 & 547 & EWU & $4 / 25 / 98$ & S 3 & 407 & 523 & EWU \\
\hline OR 56789 & $4 / 15 / 98$ & S 3 & 470 & 825 & EWU & $4 / 29 / 98$ & S 3 & 470 & 775 & EWU \\
\hline OR 56791 & 4/17/98 & S 3 & 427 & 654 & EWU & $4 / 29 / 98$ & S 3 & 422 & 620 & EWU \\
\hline OR 56792 & 4/17/98 & S 3 & 662 & 2634 & EWU & $5 / 20 / 98$ & S 3 & 657 & 2615 & EWU \\
\hline OR 56797 & $4 / 17 / 98$ & S 3 & 403 & 488 & EWU & $5 / 16 / 98$ & S 3 & 396 & 480 & EWU \\
\hline OR 56798 & 4/17/98 & S 3 & 500 & 1024 & EWU & $7 / 16 / 98$ & S 1 & NL & & ANG \\
\hline OR 56840 & $4 / 29 / 98$ & S 3 & 502 & 986 & EWU & $7 / 25 / 98$ & 8 & 514 & & ANG \\
\hline OR 56870 & $12 / 2 / 97$ & 8 & 482 & 928 & EWU & $6 / 11 / 98$ & 9 & 464 & & ANG \\
\hline OR 56945 & $10 / 28 / 97$ & 8 & 355 & 401 & EWU & $6 / 20 / 98$ & 9 & 358 & & KFWT98 \\
\hline OR 56957 & $10 / 1 / 97$ & 8 & 442 & 804 & EWU & $6 / 21 / 98$ & 9 & 464 & & KFWT98 \\
\hline OR 56960 & 10/1/97 & 8 & 412 & 571 & EWU & Unknown & Unknown & 403 & & ANG \\
\hline OR 56992 & $10 / 22 / 97$ & 8 & 524 & 1158 & EWU & $6 / 2 / 98$ & $\mathrm{~S} 1$ & 578 & & ANG \\
\hline OR 56998 & $10 / 24 / 97$ & $\mathrm{H}$ & 321 & 274 & EWU & $6 / 14 / 98$ & $\mathrm{H}$ & 368 & 227 & ANG \\
\hline OR 57044 & $6 / 21 / 97$ & 8 & 383 & & KFWT97 & $6 / 21 / 98$ & 8 & 413 & & KFWT98 \\
\hline OR 57078 & $6 / 22 / 97$ & 8 & 504 & & KFWT97 & $6 / 27 / 98$ & S 1 & 508 & & ANG \\
\hline OR 57087 & $6 / 21 / 97$ & 9 & 371 & & KFWT97 & $6 / 20 / 98$ & 8 & 391 & & KFWT98 \\
\hline OR 57108 & $11 / 11 / 97$ & S 3 & 447 & 740 & EWU & $4 / 29 / 98$ & S 3 & 449 & 719 & EWU \\
\hline OR 57110 & $11 / 11 / 97$ & S 3 & 418 & 629 & EWU & $4 / 15 / 98$ & S 3 & 416 & 599 & EWU \\
\hline OR 57112 & 11/11/97 & S 3 & 422 & 561 & EWU & 4/17/98 & S 3 & 429 & 564 & EWU \\
\hline OR 57112 & 11/11/97 & S 3 & 422 & 561 & EWU & $4 / 22 / 98$ & S 3 & 426 & 553 & EWU \\
\hline OR 57119 & $11 / 4 / 97$ & 8 & 480 & 841 & EWU & $6 / 21 / 98$ & 9 & 489 & & KFWT98 \\
\hline OR 57154 & $10 / 10 / 97$ & 8 & 389 & 545 & EWU & $6 / 20 / 98$ & 8 & 399 & & KFWT98 \\
\hline OR 57170 & $10 / 15 / 97$ & 8 & 504 & 1153 & EWU & $7 / 25 / 98$ & S 1 & 660 & 2043 & ANG \\
\hline OR 57207 & $4 / 21 / 98$ & S 3 & 387 & 461 & EWU & $6 / 13 / 98$ & S 1 & 384 & & ANG \\
\hline OR 57210 & $4 / 21 / 98$ & S 3 & 416 & 543 & EWU & 7/16/98 & S 1 & $\mathrm{NL}$ & & ANG \\
\hline OR 57231 & $4 / 21 / 98$ & S 3 & 738 & 4850 & EWU & $4 / 29 / 98$ & S 3 & 736 & 4950 & EWU \\
\hline OR 57237 & $4 / 21 / 98$ & S 3 & 432 & 464 & EWU & $7 / 16 / 98$ & S 1 & 394 & & ANG \\
\hline OR 57239 & $4 / 21 / 98$ & S 3 & 469 & 649 & EWU & $6 / 21 / 98$ & 5 & 457 & & ANG \\
\hline OR 57243 & 4/21/98 & S 3 & 453 & 655 & EWU & $4 / 25 / 98$ & S 3 & 455 & 725 & EWU \\
\hline OR 57246 & 4/21/98 & S 3 & 567 & 1446 & EWU & $4 / 22 / 98$ & S 3 & 559 & 1720 & EWU \\
\hline OR 57248 & $4 / 21 / 98$ & S 3 & 488 & 713 & EWU & $5 / 2 / 98$ & S 3 & 482 & 883 & SRAD2 \\
\hline OR 57277 & $4 / 21 / 98$ & S 3 & 335 & 222 & EWU & $7 / 4 / 98$ & S 1 & 368 & & ANG \\
\hline OR 57283 & 4/21/98 & S 3 & 544 & 1205 & EWU & $5 / 15 / 98$ & S 3 & 542 & 1387 & EWU \\
\hline OR 57284 & $4 / 21 / 98$ & S 3 & 368 & 275 & EWU & $6 / 12 / 98$ & S 3 & 366 & 376 & EWU \\
\hline OR 57312 & $8 / 21 / 97$ & 6 & 319 & 285 & EWU & 7/16/98 & S 1 & NL & & ANG \\
\hline OR 57348 & $8 / 22 / 97$ & 4 & 284 & 191 & EWU & $7 / 16 / 98$ & S 1 & 330 & & ANG \\
\hline OR 57348 & 8/22/97 & 4 & 284 & 191 & EWU & 6/18/98 & S 1 & 330 & 277 & EWU \\
\hline OR 57370 & 8/19/97 & S 3 & 332 & 299 & EWU & $1 / 28 / 98$ & S 2 & 356 & 369 & ANG \\
\hline OR 57379 & 8/19/97 & S 3 & 264 & 165 & EWU & 7/13/98 & S 3 & 315 & 268 & EWU \\
\hline OR 57381 & 8/19/97 & S 3 & 250 & 135 & EWU & $2 / 25 / 98$ & S 1 & 292 & 227 & ANG \\
\hline OR 57389 & $8 / 20 / 97$ & 8 & 377 & 402 & EWU & $4 / 15 / 98$ & 9 & 368 & & ANG \\
\hline OR 57390 & 8/20/97 & 9 & 363 & 349 & EWU & $8 / 26 / 98$ & $\mathrm{BC}$ & 432 & & ANG \\
\hline OR 57396 & 8/20/97 & 8 & 360 & 365 & EWU & $6 / 20 / 98$ & 8 & 383 & & KFWT98 \\
\hline OR 57505 & $8 / 22 / 97$ & 4 & 240 & 132 & EWU & $7 / 30 / 98$ & 4 & $\mathrm{NL}$ & & ANG \\
\hline OR 57512 & $8 / 22 / 97$ & 4 & 240 & 120 & EWU & $8 / 2 / 98$ & S 1 & NL & & ANG \\
\hline OR 57513 & $8 / 22 / 97$ & 4 & 258 & 143 & EWU & $9 / 1 / 98$ & S 1 & NL & & ANG \\
\hline OR 57518 & $8 / 22 / 97$ & 4 & 235 & 118 & EWU & $7 / 16 / 98$ & S 1 & NL & & ANG \\
\hline OR 57529 & $8 / 22 / 97$ & S 1 & 275 & 166 & EWU & $7 / 16 / 98$ & S 1 & NL & & ANG \\
\hline OR 57534 & $8 / 22 / 97$ & $\mathrm{~S} 1$ & 255 & 130 & EWU & 7/16/98 & S 1 & 305 & & ANG \\
\hline OR 57535 & $8 / 22 / 97$ & S 1 & 256 & 135 & EWU & $7 / 14 / 98$ & $\mathrm{~S} 2$ & 318 & 284 & ANG \\
\hline OR 57541 & $8 / 22 / 97$ & $\mathrm{~S} 2$ & 275 & 127 & EWU & $4 / 4 / 98$ & S 1 & 318 & 223 & SRAD1 \\
\hline OR 57551 & 8/22/97 & S 2 & 287 & 197 & EWU & 6/17/98 & S 2 & 325 & 232 & EWU \\
\hline OR 57551 & $8 / 22 / 97$ & S 2 & 287 & 197 & EWU & $5 / 13 / 98$ & S 2 & 322 & 300 & STOI \\
\hline OR 57554 & $8 / 22 / 97$ & $\mathrm{~S} 2$ & 339 & 325 & EWU & $5 / 24 / 98$ & S 2 & 381 & & ANG \\
\hline
\end{tabular}




\begin{tabular}{|c|c|c|c|c|c|c|c|c|c|c|}
\hline OR 57557 & $8 / 22 / 97$ & $\mathrm{~S} 2$ & 277 & 160 & EWU & $3 / 28 / 98$ & S 2 & 298 & & ANG \\
\hline OR 57565 & $8 / 22 / 97$ & $\mathrm{~S} 2$ & 273 & 153 & EWU & $7 / 16 / 98$ & S 1 & NL & & ANG \\
\hline OR 57569 & $8 / 22 / 97$ & $\mathrm{~S} 2$ & 269 & 150 & EWU & $8 / 8 / 98$ & S 1 & 291 & & ANG \\
\hline OR 57572 & $8 / 25 / 97$ & $\mathrm{H}$ & 305 & 290 & EWU & $6 / 24 / 98$ & $\mathrm{H}$ & 345 & 397 & EWU \\
\hline OR 57586 & $8 / 25 / 97$ & $\mathrm{H}$ & 305 & & EWU & $6 / 28 / 98$ & $\mathrm{H}$ & 356 & 341 & ANG \\
\hline OR 57629 & $8 / 4 / 97$ & 9 & 503 & 1220 & EWU & $2 / 10 / 98$ & 7 & NL & 1361 & ANG \\
\hline OR 57647 & $8 / 4 / 97$ & 9 & 260 & 143 & EWU & $6 / 19 / 98$ & 9 & 368 & & ANG \\
\hline OR 57670 & 7/14/97 & 8 & 331 & 319 & EWU & $6 / 27 / 98$ & 10 & NL & & ANG \\
\hline OR 57670 & 7/14/97 & 8 & 331 & 319 & EWU & $8 / 8 / 98$ & 10 & 384 & 499 & ANG \\
\hline OR 57710 & $7 / 28 / 97$ & 5 & 212 & 69 & EWU & $6 / 24 / 98$ & 4 & NL & & ANG \\
\hline OR 57716 & $7 / 28 / 97$ & 5 & 213 & 59 & EWU & $6 / 18 / 98$ & 4 & 305 & & ANG \\
\hline OR 57777 & $7 / 28 / 97$ & 6 & 272 & 175 & EWU & $8 / 5 / 98$ & 6 & 368 & & ANG \\
\hline OR 57799 & $7 / 28 / 97$ & 6 & 222 & 65 & EWU & $6 / 5 / 98$ & 6 & NL & & ANG \\
\hline OR 57840 & $8 / 5 / 97$ & 6 & 289 & 176 & EWU & $5 / 14 / 98$ & 6 & 333 & 360 & STOI \\
\hline OR 57840 & $8 / 5 / 97$ & 6 & 289 & 176 & EWU & 7/9/98 & 6 & 343 & 420 & STOI \\
\hline OR 57848 & $8 / 5 / 97$ & 6 & 280 & 173 & EWU & $8 / 20 / 98$ & 10 & 356 & & ANG \\
\hline OR 57870 & $8 / 6 / 97$ & $\mathrm{H}$ & 236 & 126 & EWU & $6 / 24 / 98$ & $\mathrm{H}$ & 313 & 256 & EWU \\
\hline OR 57883 & $8 / 6 / 98$ & 1 & 226 & 82 & EWU & $10 / 21 / 98$ & 4 & 343 & & ANG \\
\hline OR 57916 & $8 / 5 / 97$ & 6 & 229 & 103 & EWU & $5 / 14 / 98$ & 6 & 298 & 260 & STOI \\
\hline OR 57933 & $8 / 5 / 97$ & 5 & 281 & & EWU & $7 / 17 / 98$ & 6 & NL & & ANG \\
\hline OR 57953 & $6 / 21 / 97$ & 8 & 400 & & KFWT97 & $5 / 15 / 98$ & S 3 & 439 & 702 & EWU \\
\hline OR 57959 & $6 / 21 / 97$ & 8 & 396 & & KFWT97 & $6 / 20 / 98$ & 8 & 418 & & KFWT98 \\
\hline OR 58021 & 7/30/97 & $\mathrm{S} 2$ & 238 & 125 & EWU & $7 / 29 / 98$ & S 2 & 318 & & ANG \\
\hline OR 58034 & 7/30/97 & $\mathrm{S} 2$ & 235 & 100 & EWU & $6 / 27 / 98$ & S 2 & 330 & & ANG \\
\hline OR 58040 & $7 / 31 / 97$ & $\mathrm{~S} 2$ & 220 & 75 & EWU & Unknown & Spokane Arm & NL & & ANG \\
\hline OR 58051 & $6 / 22 / 97$ & 9 & 374 & & KFWT97 & $6 / 20 / 98$ & 8 & 405 & & KFWT98 \\
\hline OR 58109 & $6 / 22 / 97$ & 9 & 359 & & KFWT98 & $8 / 15 / 98$ & 4 & 381 & & ANG \\
\hline OR 58138 & $6 / 22 / 97$ & 9 & 400 & & KFWT97 & $4 / 22 / 98$ & S 3 & 403 & 575 & EWU \\
\hline OR 58152 & $6 / 22 / 97$ & 9 & 371 & & KFWT97 & $6 / 20 / 98$ & 10 & 412 & & KFWT98 \\
\hline OR 58316 & 9/10/97 & 8 & 284 & 190 & EWU & 7/7/98 & 9 & 308 & 209 & EWU \\
\hline OR 58349 & $9 / 11 / 97$ & $\mathrm{SP}$ & 308 & 232 & EWU & $6 / 30 / 98$ & $\mathrm{SP}$ & 347 & 350 & EWU \\
\hline OR 58372 & 7/8/97 & $\mathrm{H}$ & 331 & 322 & EWU & $7 / 30 / 98$ & 4 & 505 & & ANG \\
\hline OR 58434 & $9 / 5 / 97$ & $\mathrm{H}$ & 345 & 340 & EWU & $7 / 16 / 98$ & S 1 & $\mathrm{NL}$ & & ANG \\
\hline OR 58435 & $9 / 5 / 97$ & $\mathrm{H}$ & 369 & 494 & EWU & $5 / 25 / 98$ & $\mathrm{H}$ & NL & & ANG \\
\hline OR 58444 & $9 / 5 / 97$ & $\mathrm{H}$ & 297 & 217 & EWU & $6 / 24 / 98$ & $\mathrm{H}$ & 332 & 300 & EWU \\
\hline OR 58492 & $9 / 4 / 97$ & $\mathrm{~S} 1$ & 296 & 189 & EWU & $6 / 14 / 98$ & S 1 & 305 & & ANG \\
\hline OR 58501 & $4 / 25 / 98$ & S 3 & 389 & 476 & EWU & $6 / 21 / 98$ & 8 & 384 & & KFWT98 \\
\hline OR 58534 & $4 / 29 / 98$ & S 3 & 525 & 1110 & EWU & Jun-98 & S 3 & 537 & 1447 & ANG \\
\hline OR 58546 & 4/29/98 & S 3 & 470 & 701 & EWU & $5 / 22 / 98$ & S 3 & 464 & 729 & EWU \\
\hline OR 58551 & 4/25/98 & S 3 & 347 & 306 & EWU & $5 / 16 / 98$ & S 3 & 340 & 324 & EWU \\
\hline OR 58551 & 4/25/98 & S 3 & 347 & 306 & EWU & $5 / 20 / 98$ & S 3 & 341 & & EWU \\
\hline OR 58552 & $4 / 25 / 98$ & S 3 & 512 & 1507 & EWU & $4 / 25 / 98$ & S 3 & 519 & 1358 & EWU \\
\hline OR 58563 & $4 / 25 / 98$ & S 3 & 622 & 2138 & EWU & $4 / 25 / 98$ & S 3 & 622 & 2144 & EWU \\
\hline OR 58568 & $4 / 25 / 98$ & S 3 & 555 & 1230 & EWU & $5 / 15 / 98$ & S 3 & 371 & 434 & EWU \\
\hline OR 58577 & $4 / 25 / 98$ & S 3 & 527 & 1269 & EWU & $6 / 3 / 98$ & S 1 & 546 & & ANG \\
\hline OR 58578 & $4 / 25 / 98$ & S 3 & 516 & 1219 & EWU & $5 / 15 / 98$ & S 3 & 514 & 1125 & EWU \\
\hline OR 58596 & $4 / 25 / 98$ & S 3 & 283 & 193 & EWU & $6 / 17 / 98$ & S 2 & 406 & & ANG \\
\hline OR 58599 & $4 / 25 / 98$ & S 3 & 387 & 425 & EWU & 7/16/98 & S 1 & 381 & & ANG \\
\hline OR 58599 & $4 / 25 / 98$ & S 3 & 387 & 425 & EWU & 4/29/98 & S 3 & 386 & 418 & EWU \\
\hline OR 58600 & $4 / 25 / 98$ & S 3 & 384 & 442 & EWU & $6 / 6 / 98$ & Spokane Arm & 356 & & ANG \\
\hline OR 58707 & $4 / 18 / 98$ & S 3 & 491 & 422 & EWU & $6 / 21 / 98$ & 8 & 384 & & KFWT98 \\
\hline OR 58710 & $4 / 18 / 98$ & S 3 & 423 & 572 & EWU & $6 / 30 / 98$ & $\mathrm{BC}$ & NL & & ANG \\
\hline OR 58720 & 4/18/98 & S 3 & 472 & 678 & EWU & $4 / 25 / 98$ & S 3 & 472 & 697 & EWU \\
\hline OR 58725 & 4/18/98 & S 3 & 453 & 744 & EWU & $4 / 25 / 98$ & S 3 & 446 & 787 & EWU \\
\hline OR 58728 & $4 / 18 / 98$ & S 3 & 587 & 2301 & EWU & $4 / 21 / 98$ & S 3 & 595 & 2199 & EWU \\
\hline OR 58741 & $4 / 18 / 98$ & S 3 & 344 & 266 & EWU & $5 / 20 / 98$ & S 3 & 342 & & EWU \\
\hline OR 58745 & $4 / 21 / 98$ & S 3 & 480 & 851 & EWU & $6 / 12 / 98$ & S 3 & 483 & 1135 & ANG \\
\hline OR 58752 & $4 / 21 / 98$ & S 3 & 521 & 1229 & EWU & $5 / 15 / 98$ & S 3 & 519 & 1111 & EWU \\
\hline
\end{tabular}




\begin{tabular}{|c|c|c|c|c|c|c|c|c|c|c|}
\hline OR 58754 & $4 / 21 / 98$ & S 3 & 572 & 1807 & EWU & $6 / 11 / 98$ & S 1 & 584 & 2242 & ANG \\
\hline OR 58760 & $4 / 21 / 98$ & S 3 & 386 & 473 & EWU & $6 / 18 / 98$ & S 1 & NL & & ANG \\
\hline OR 58769 & $4 / 21 / 98$ & S 3 & 407 & 497 & EWU & $5 / 15 / 98$ & S 3 & 407 & 540 & EWU \\
\hline OR 58774 & $4 / 21 / 98$ & S 3 & 457 & 755 & EWU & $4 / 22 / 98$ & S 3 & 459 & 753 & EWU \\
\hline OR 58775 & $4 / 21 / 98$ & S 3 & 496 & 936 & EWU & $5 / 20 / 98$ & S 3 & 491 & 1111 & EWU \\
\hline OR 58780 & $4 / 21 / 98$ & S 3 & 561 & 1409 & EWU & $4 / 25 / 98$ & S 3 & 560 & 1364 & EWU \\
\hline OR 58782 & $4 / 21 / 98$ & S 3 & 417 & 571 & EWU & $7 / 16 / 98$ & S 1 & NL & & ANG \\
\hline OR 58782 & $4 / 21 / 98$ & S 3 & 417 & 571 & EWU & $5 / 22 / 98$ & S 3 & 416 & 529 & EWU \\
\hline OR 58785 & $4 / 21 / 98$ & S 3 & 457 & 701 & EWU & $5 / 20 / 98$ & S 3 & 450 & 703 & EWU \\
\hline OR 58798 & $4 / 21 / 98$ & S 3 & 447 & 676 & EWU & $4 / 25 / 98$ & S 3 & 447 & 680 & EWU \\
\hline OR 58810 & $9 / 26 / 97$ & S 3 & 378 & 402 & EWU & $6 / 8 / 98$ & S 2 & 330 & & ANG \\
\hline OR 58850 & $9 / 23 / 97$ & $\mathrm{H}$ & 275 & 185 & EWU & $6 / 27 / 98$ & $\mathrm{H}$ & 343 & & ANG \\
\hline OR 58857 & $10 / 3 / 97$ & 2 & 351 & 327 & EWU & $7 / 13 / 98$ & S 3 & 374 & 426 & EWU \\
\hline OR 58873 & $10 / 3 / 97$ & S 3 & 376 & 412 & EWU & $8 / 2 / 98$ & S 1 & 400 & & ANG \\
\hline OR 59075 & $7 / 14 / 97$ & 3 & 330 & 350 & EWU & $6 / 21 / 98$ & 8 & 369 & & KFWT98 \\
\hline OR 59111 & 4/4/98 & S 2 & 391 & 487 & EWU & $6 / 15 / 98$ & Spokane Arm & NL & & ANG \\
\hline OR 59112 & $4 / 4 / 98$ & $\mathrm{~S} 2$ & 463 & 784 & EWU & $4 / 22 / 98$ & S 3 & 462 & 737 & EWU \\
\hline OR 59125 & 4/4/98 & S 2 & 436 & 704 & EWU & $5 / 22 / 98$ & S 3 & 434 & 702 & EWU \\
\hline OR 59134 & 4/4/98 & S 1 & 363 & 368 & EWU & $5 / 16 / 98$ & S 3 & 355 & 353 & EWU \\
\hline OR 59137 & 4/4/98 & S 1 & 298 & 175 & EWU & $6 / 12 / 98$ & S 1 & 305 & & ANG \\
\hline OR 59154 & $9 / 18 / 97$ & S 3 & 310 & 222 & EWU & Aug-98 & $\mathrm{K}$ & 356 & & ANG \\
\hline OR 59169 & $9 / 18 / 97$ & 2 & 389 & 482 & EWU & $5 / 20 / 98$ & S 3 & 394 & 466 & EWU \\
\hline OR 59191 & 9/18/97 & S 3 & 278 & 153 & EWU & $8 / 29 / 98$ & $\mathrm{BC}$ & NL & & ANG \\
\hline OR 59201 & $4 / 29 / 98$ & S 3 & 367 & 426 & EWU & $9 / 14 / 98$ & $\mathrm{BC}$ & NL & 1419 & ANG \\
\hline OR 59203 & $4 / 29 / 98$ & S 3 & 507 & 950 & EWU & $10 / 11 / 98$ & NP & NL & & ANG \\
\hline OR 59220 & $4 / 29 / 98$ & S 3 & 389 & 437 & EWU & $7 / 16 / 98$ & S 1 & NL & & ANG \\
\hline OR 59252 & $4 / 29 / 98$ & S 3 & 600 & 2361 & EWU & $4 / 29 / 98$ & S 3 & 600 & 2264 & EWU \\
\hline OR 59273 & $4 / 29 / 98$ & S 3 & 390 & 472 & EWU & $6 / 21 / 98$ & 4 & 400 & & ANG \\
\hline OR 59276 & $4 / 29 / 98$ & S 3 & 401 & 485 & EWU & $7 / 16 / 98$ & S 1 & NL & & ANG \\
\hline OR 59311 & $4 / 25 / 98$ & S 3 & 679 & 2463 & EWU & $4 / 29 / 98$ & S 3 & 676 & 3300 & EWU \\
\hline OR 59320 & $4 / 25 / 98$ & S 3 & 480 & 889 & EWU & $7 / 11 / 98$ & S 2 & 508 & & ANG \\
\hline OR 59321 & $4 / 25 / 98$ & S 3 & 522 & 1280 & EWU & $5 / 16 / 98$ & S 3 & 518 & 1306 & EWU \\
\hline OR 59344 & $4 / 29 / 98$ & S 3 & 432 & 597 & EWU & $7 / 22 / 98$ & $\mathrm{SP}$ & 352 & 389 & EWU \\
\hline OR 59359 & $6 / 21 / 97$ & 8 & 409 & & KFWT97 & 4/18/98 & S 3 & 439 & 633 & EWU \\
\hline OR 59368 & $6 / 21 / 97$ & 8 & 411 & & KFWT97 & 7/16/98 & S 1 & NL & & ANG \\
\hline OR 59371 & $6 / 21 / 97$ & 8 & 533 & & KFWT97 & $6 / 25 / 98$ & S 1 & 597 & 2497 & ANG \\
\hline OR 59583 & $5 / 31 / 98$ & S 1 & 323 & 245 & EWU & $7 / 16 / 98$ & S 1 & NL & & ANG \\
\hline OR 59644 & $6 / 22 / 97$ & 8 & 527 & & KFWT97 & $6 / 6 / 98$ & S 2 & 533 & & ANG \\
\hline OR 59644 & $6 / 22 / 97$ & 8 & 527 & & KFWT97 & 4/17/98 & S 3 & 545 & 1286 & EWU \\
\hline OR 59644 & $6 / 22 / 97$ & 8 & 527 & & KFWT97 & $4 / 22 / 98$ & S 3 & 544 & 1291 & EWU \\
\hline OR 59652 & $6 / 22 / 97$ & 8 & 368 & & KFWT97 & $6 / 20 / 98$ & 8 & 406 & & KFWT98 \\
\hline OR 59653 & $6 / 22 / 97$ & 8 & 362 & & KFWT97 & Aug-97 & 7 & NL & & ANG \\
\hline OR 59656 & $6 / 22 / 97$ & 8 & 400 & & KFWT97 & $6 / 21 / 98$ & 8 & 425 & & KFWT98 \\
\hline OR 59684 & $6 / 22 / 97$ & 8 & 393 & & KFWT97 & $6 / 12 / 98$ & 8 & 419 & & ANG \\
\hline OR 59691 & $6 / 22 / 97$ & 8 & 393 & & KFWT97 & $6 / 3 / 98$ & 8 & 436 & 896 & EWU \\
\hline OR 59693 & $7 / 28 / 97$ & 5 & 220 & 88 & EWU & $6 / 5 / 98$ & 6 & NL & & ANG \\
\hline OR 59704 & 7/31/97 & S 1 & 218 & 80 & EWU & $5 / 16 / 98$ & S 3 & 274 & 173 & EWU \\
\hline OR 59704 & 7/31/97 & S 1 & 218 & 80 & EWU & $6 / 12 / 98$ & S 3 & 280 & 153 & EWU \\
\hline OR 59717 & $7 / 31 / 97$ & S 3 & 232 & 140 & EWU & $7 / 13 / 98$ & S 3 & 322 & 322 & EWU \\
\hline OR 59746 & $7 / 31 / 97$ & S 3 & 304 & 288 & EWU & $7 / 13 / 98$ & S 3 & 355 & 394 & EWU \\
\hline OR 59779 & 8/4/97 & 8 & 286 & 182 & EWU & $8 / 29 / 98$ & 8 & 403 & 568 & ANG \\
\hline OR 59795 & $8 / 4 / 97$ & 8 & 406 & 514 & EWU & $6 / 20 / 98$ & 8 & 432 & & KFWT98 \\
\hline OR 59843 & $8 / 5 / 97$ & 5 & 296 & & EWU & $6 / 28 / 98$ & 8 & 330 & & ANG \\
\hline OR 59857 & 9/11/97 & SP & 287 & 213 & EWU & $5 / 2 / 98$ & S 2 & NL & & SRAD2 \\
\hline OR 59879 & $9 / 12 / 97$ & 2 & 395 & 491 & EWU & $6 / 6 / 98$ & Spokane Arm & 356 & & ANG \\
\hline OR 59891 & $9 / 18 / 97$ & S 3 & 369 & 477 & EWU & $6 / 12 / 98$ & S 3 & 410 & 511 & EWU \\
\hline OR 59894 & $9 / 18 / 97$ & S 3 & 281 & 193 & EWU & $6 / 6 / 98$ & Spokane Arm & 304 & & ANG \\
\hline OR 59912 & 7/8/97 & 4 & 206 & 40 & EWU & $7 / 16 / 98$ & S 1 & NL & & ANG \\
\hline
\end{tabular}




\section{Appendix B.}

Table B1. Raw numbers used for calculation of entire reservoir walleye abundance estimates without the recruitment adjustment.

\begin{tabular}{cccccccc}
\hline Pass & Number & Number & \multicolumn{4}{c}{ Recaptures Marked in Pass... } & Total \\
\hline $\mathbf{1}$ & 2,153 & Marked & $\mathbf{1}$ & $\mathbf{2}$ & $\mathbf{3}$ & $\mathbf{4}$ & Recaptures \\
$\mathbf{2}$ & 1,944 & 1,027 & - & - & - & - & - \\
$\mathbf{3}$ & 998 & 943 & 15 & - & - & - & 15 \\
$\mathbf{4}$ & 230 & 229 & 1 & 15 & - & - & 22 \\
$\mathbf{5}$ & 77 & 77 & 0 & 2 & 4 & - & 7 \\
Total & 5,402 & 5,080 & 23 & 1 & 0 & 0 & 1 \\
\hline
\end{tabular}

Table B2. Raw numbers used for calculation of entire reservoir walleye abundance estimates with the recruitment adjustment.

\begin{tabular}{cccccccc}
\hline & Number & Number & \multicolumn{4}{c}{ Recaptures Marked in Pass... } & Total \\
Pass & Captured & Marked & $\mathbf{1}$ & $\mathbf{2}$ & $\mathbf{3}$ & $\mathbf{4}$ & Recaptures \\
\hline $\mathbf{1}$ & 2,150 & 2,027 & - & - & - & - & - \\
$\mathbf{2}$ & 1,902 & 1,769 & 15 & - & - & - & 15 \\
$\mathbf{3}$ & 977 & 930 & 7 & 15 & - & - & 22 \\
$\mathbf{4}$ & 225 & 224 & 1 & 2 & 4 & - & 7 \\
$\mathbf{5}$ & 63 & 63 & 0 & 1 & 0 & 0 & 1 \\
Total & 5,317 & 5,013 & 23 & 18 & 4 & 0 & 45 \\
\hline
\end{tabular}

Table B3. Raw numbers used for calculation of the size of the walleye spawning run in the Spokane River Arm.

\begin{tabular}{ccccccccc}
\hline & Number & Number & \multicolumn{3}{c}{ Recaptures Marked in Pass... } & Total \\
Pass & Captured & Marked & $\mathbf{1}$ & $\mathbf{2}$ & $\mathbf{3}$ & $\mathbf{4}$ & $\mathbf{5}$ & Recaptures \\
\hline $\mathbf{1}$ & 29 & 29 & - & - & - & - & - & - \\
$\mathbf{2}$ & 215 & 215 & 0 & - & - & - & - & 0 \\
$\mathbf{3}$ & 536 & 536 & 1 & 11 & - & - & - & 12 \\
$\mathbf{4}$ & 263 & 263 & 0 & 3 & 9 & - & - & 12 \\
$\mathbf{5}$ & 296 & 296 & 1 & 4 & 13 & 1 & - & 19 \\
$\mathbf{6}$ & 196 & 179 & 1 & 4 & 5 & 2 & 4 & 16 \\
Total & 1,535 & 1,518 & 3 & 22 & 27 & 3 & 4 & 59 \\
\hline
\end{tabular}




\section{Appendix C.}

Table C1. Age-length key for walleye collected from Lake Roosevelt by EWU during 1998.

\begin{tabular}{|c|c|c|c|c|c|c|c|c|c|c|c|c|c|c|c|}
\hline \multirow{2}{*}{$\begin{array}{c}\text { Length } \\
\text { Group (cm) }\end{array}$} & \multirow[b]{2}{*}{$\mathbf{n}$} & \multicolumn{14}{|c|}{ Number of Walleye of Age... } \\
\hline & & $\mathbf{0}$ & 1 & 2 & 3 & 4 & 5 & 6 & 7 & 8 & 9 & 10 & 11 & 12 & 13 \\
\hline 1 & 0 & & & & & & & & & & & & & & \\
\hline 2 & 0 & & & & & & & & & & & & & & \\
\hline 3 & 0 & & & & & & & & & & & & & & \\
\hline 4 & 0 & & & & & & & & & & & & & & \\
\hline 5 & 1 & 1 & & & & & & & & & & & & & \\
\hline 6 & 0 & & & & & & & & & & & & & & \\
\hline 7 & 0 & & & & & & & & & & & & & & \\
\hline 8 & 2 & 2 & & & & & & & & & & & & & \\
\hline 9 & 1 & 1 & & & & & & & & & & & & & \\
\hline 10 & 6 & 5 & 1 & & & & & & & & & & & & \\
\hline 11 & 19 & 11 & 8 & & & & & & & & & & & & \\
\hline 12 & 28 & & 28 & & & & & & & & & & & & \\
\hline 13 & 33 & 13 & 20 & & & & & & & & & & & & \\
\hline 14 & 37 & 7 & 30 & & & & & & & & & & & & \\
\hline 15 & 30 & 12 & 18 & & & & & & & & & & & & \\
\hline 16 & 51 & 31 & 20 & & & & & & & & & & & & \\
\hline 17 & 83 & & 83 & & & & & & & & & & & & \\
\hline 18 & 119 & & 119 & & & & & & & & & & & & \\
\hline 19 & 187 & & 187 & & & & & & & & & & & & \\
\hline 20 & 207 & & 166 & 41 & & & & & & & & & & & \\
\hline 21 & 207 & & 207 & & & & & & & & & & & & \\
\hline 22 & 189 & & 189 & & & & & & & & & & & & \\
\hline 23 & 169 & & 101 & 68 & & & & & & & & & & & \\
\hline 24 & 134 & & 134 & & & & & & & & & & & & \\
\hline 25 & 190 & & 114 & 76 & & & & & & & & & & & \\
\hline 26 & 79 & & 47 & 32 & & & & & & & & & & & \\
\hline 27 & 62 & & 62 & & & & & & & & & & & & \\
\hline 28 & 66 & & 13 & 53 & & & & & & & & & & & \\
\hline 29 & 100 & & 40 & 40 & 20 & & & & & & & & & & \\
\hline 30 & 112 & & & 45 & 67 & & & & & & & & & & \\
\hline 31 & 138 & & & 55 & 55 & 28 & & & & & & & & & \\
\hline 32 & 116 & & & 70 & 46 & & & & & & & & & & \\
\hline 33 & 111 & & & 67 & 44 & & & & & & & & & & \\
\hline 34 & 115 & & & 46 & 69 & & & & & & & & & & \\
\hline 35 & 125 & & & 50 & 75 & & & & & & & & & & \\
\hline 36 & 163 & & & 33 & 130 & & & & & & & & & & \\
\hline 37 & 145 & & & 58 & 58 & & 29 & & & & & & & & \\
\hline 38 & 134 & & & 27 & 27 & 54 & 27 & & & & & & & & \\
\hline 39 & 160 & & & & 160 & & & & & & & & & & \\
\hline 40 & 179 & & & & & 107 & 72 & & & & & & & & \\
\hline 41 & 127 & & & & 51 & 76 & & & & & & & & & \\
\hline 42 & 129 & & & & 52 & 52 & & 26 & & & & & & & \\
\hline 43 & 110 & & & & 44 & 44 & 22 & & & & & & & & \\
\hline 44 & 103 & & & & 21 & 82 & & & & & & & & & \\
\hline 45 & 109 & & & & & 65 & 44 & & & & & & & & \\
\hline 46 & 111 & & & & & 44 & 67 & & & & & & & & \\
\hline 47 & 136 & & & & & 27 & 54 & 54 & & & & & & & \\
\hline 48 & 104 & & & & & 42 & 42 & 21 & & & & & & & \\
\hline 49 & 117 & & & & & & 70 & 47 & & & & & & & \\
\hline
\end{tabular}




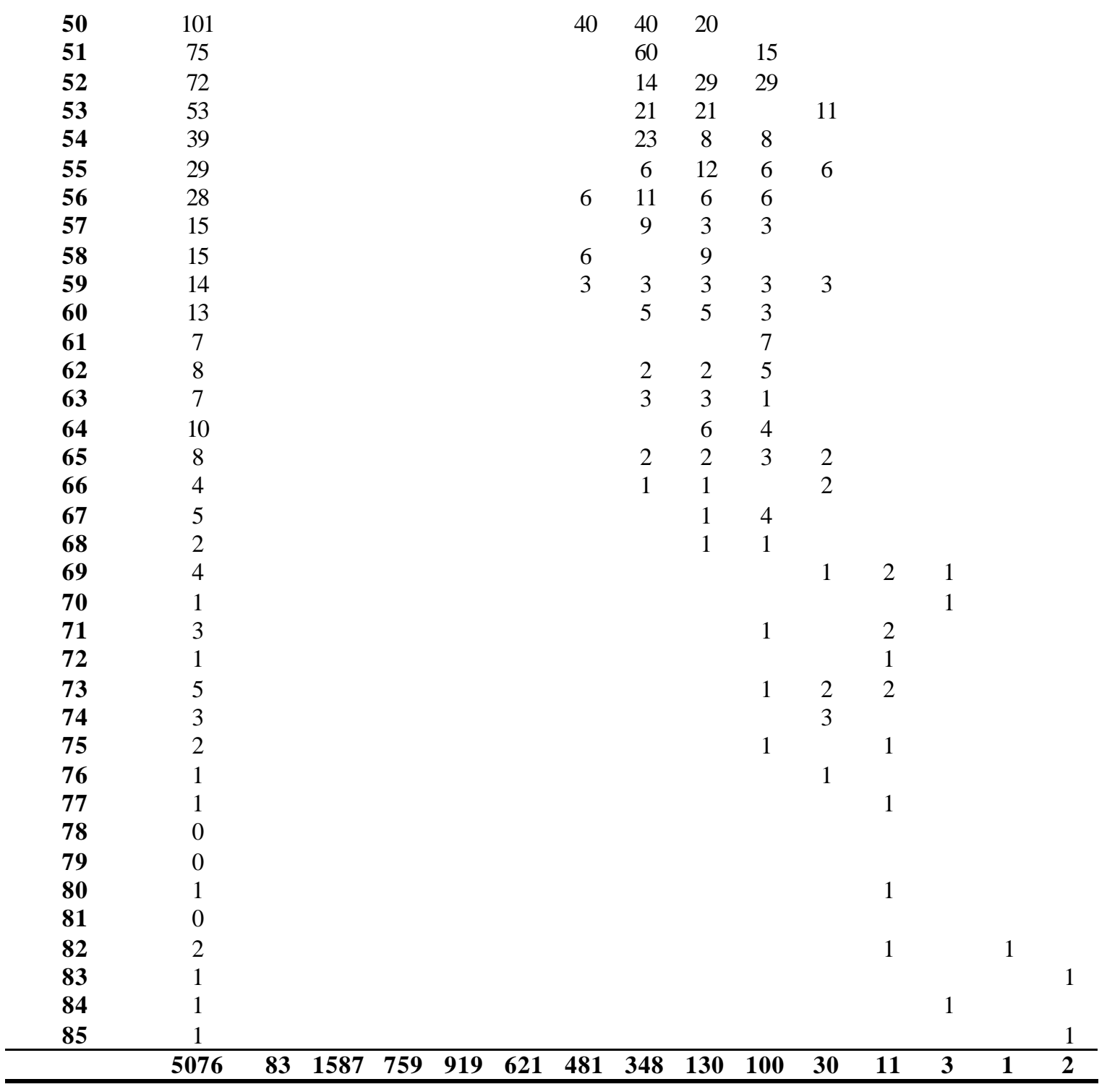




\section{Appendix D.}

Table D1. Relative abundance (R.A.; \%) and catch-per-unit-effort (CPUE; fish/hr) of fish collected via boat electrofishing from Lake Roosevelt between April $1^{\text {st }}$ and December $10^{\text {th }}, 1998$. Total effort was 313.66 hours.

\begin{tabular}{|c|c|c|c|c|c|}
\hline Family & Species & $\mathbf{n}$ & R.A. (\%) & $\begin{array}{c}\text { CPUE } \\
\text { (fish/hr) }\end{array}$ & Size Range (mm) \\
\hline \multirow[t]{8}{*}{ Salmonidae } & Chinook & 14 & 0.1 & $<0.1$ & $69-522$ \\
\hline & Kokanee & 3,551 & 23.9 & 11.3 & $75-569$ \\
\hline & Rainbow Trout & 677 & 4.6 & 2.2 & $52-560$ \\
\hline & Cutthroat Trout & 1 & $<0.1$ & $<0.1$ & 321 \\
\hline & Brown Trout & 98 & 0.7 & 0.3 & $149-698$ \\
\hline & Brook Trout & 123 & 0.8 & 0.4 & $85-422$ \\
\hline & Mountain Whitefish & 68 & 0.5 & 0.2 & $59-545$ \\
\hline & Lake Whitefish & 30 & 0.2 & 0.1 & $362-595$ \\
\hline \multirow[t]{6}{*}{ Cyprinidae } & Northern Pikeminnow & 202 & 1.4 & 0.6 & $17-590$ \\
\hline & Peamouth & 25 & 0.2 & 0.1 & $72-232$ \\
\hline & Redside Shiner & 4 & $<0.1$ & $<0.1$ & $69-120$ \\
\hline & Longnose Dace & 12 & 0.1 & $<0.1$ & $60-80$ \\
\hline & Carp & 299 & 2.0 & 1.0 & $45-848$ \\
\hline & Tench & 27 & 0.2 & 0.1 & $125-541$ \\
\hline \multirow[t]{4}{*}{ Catostomidae } & Largescale Sucker & 3,267 & 22.0 & 10.4 & $56-654$ \\
\hline & Bridgelip Sucker & 35 & 0.2 & 0.1 & $130-436$ \\
\hline & Longnose Sucker & 215 & 1.4 & 0.7 & $45-515$ \\
\hline & Hybrid Sucker & 10 & 0.1 & $<0.1$ & $467-594$ \\
\hline \multirow[t]{2}{*}{ Ictaluridae } & Brown Bullhead & 5 & $<0.1$ & $<0.1$ & $36-215$ \\
\hline & Yellow Bullhead & 1 & $<0.1$ & $<0.1$ & 172 \\
\hline Gadidae & Burbot & 132 & 0.9 & 0.4 & $381-716$ \\
\hline \multirow[t]{4}{*}{ Centrarchidae } & Largemouth Bass & 173 & 1.2 & 0.6 & $41-463$ \\
\hline & Smallmouth Bass & 1,172 & 7.9 & 3.7 & $47-450$ \\
\hline & Pumpkinseed & 12 & 0.1 & $<0.1$ & $75-115$ \\
\hline & Black Crappie & 50 & 0.3 & 0.2 & $30-367$ \\
\hline \multirow[t]{2}{*}{ Percidae } & Yellow Perch & 433 & 2.9 & 1.4 & $42-266$ \\
\hline & Walleye & 4,169 & 28.1 & 13.3 & $46-851$ \\
\hline \multirow[t]{3}{*}{ Cottidae } & Piute Sculpin & 44 & 0.3 & 0.1 & $46-142$ \\
\hline & Torrent Sculpin & 6 & $<0.1$ & $<0.1$ & $52-110$ \\
\hline & Mottled Sculpin & 2 & $<0.1$ & $<0.1$ & $85-92$ \\
\hline Total & & 14,857 & & 47.37 & \\
\hline
\end{tabular}

